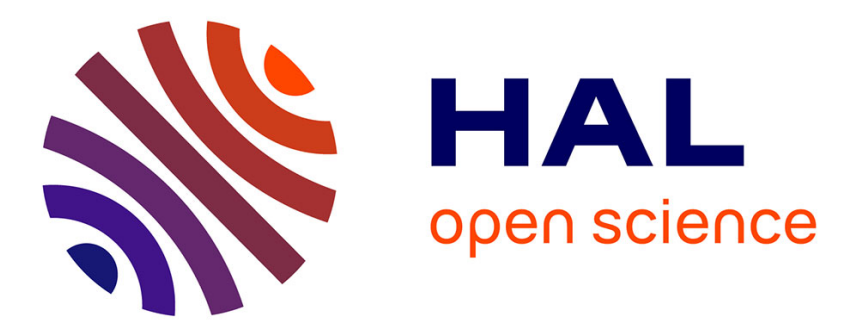

\title{
Benchmarking impact hydrocodes in the strength regime: Implications for modeling deflection by a kinetic impactor
}

Angela Stickle, Megan Bruck Syal, Andy F. Cheng, Gareth S. Collins,

Thomas Davison, Galen Gisler, Nicole Güldemeister, Tamra Heberling, Robert Luther, Patrick Michel, et al.

\section{To cite this version:}

Angela Stickle, Megan Bruck Syal, Andy F. Cheng, Gareth S. Collins, Thomas Davison, et al.. Benchmarking impact hydrocodes in the strength regime: Implications for modeling deflection by a kinetic impactor. Icarus, 2020, 338, pp.113446. 10.1016/j.icarus.2019.113446 . hal-03084619

\section{HAL Id: hal-03084619 \\ https://hal.science/hal-03084619}

Submitted on 21 Dec 2020

HAL is a multi-disciplinary open access archive for the deposit and dissemination of scientific research documents, whether they are published or not. The documents may come from teaching and research institutions in France or abroad, or from public or private research centers.
L'archive ouverte pluridisciplinaire HAL, est destinée au dépôt et à la diffusion de documents scientifiques de niveau recherche, publiés ou non, émanant des établissements d'enseignement et de recherche français ou étrangers, des laboratoires publics ou privés. 
Benchmarking impact hydrocodes in the strength regime: implications for modeling deflection by a kinetic impactor

Angela M. Stickle ${ }^{1}$, Megan Bruck Syal ${ }^{2}$, Andy F. Cheng ${ }^{1}$, Gareth S. Collins ${ }^{3}$, Thomas M. Davison $^{3}$, Galen Gisler ${ }^{4}$, Nicole Güldemeister ${ }^{5}$, Tamra Heberling ${ }^{4}$, Robert Luther ${ }^{5,7}$, Patrick Michel $^{6}$, Paul Miller ${ }^{2}$, J. Michael Owen ${ }^{2}$, Emma S.G. Rainey ${ }^{1}$, Andrew S. Rivkin ${ }^{1}$, Thomas Rosch $^{1}$, Kai Wünnemann ${ }^{5,7}$

${ }^{1}$ Johns Hopkins University Applied Physics Laboratory, Laurel MD, 20723, USA

${ }^{2}$ Lawrence Livermore National Laboratory, Lawrence Livermore, CA

${ }^{3}$ Impacts and Astromaterials Research Centre, Department of Earth Science and Engineering, Imperial College London, London, United Kingdom

${ }^{4}$ Los Alamos National Laboratory, Los Alamos

5 Museum für Naturkunde, Berlin Germany, Leibniz Institute for Evolution and Biodiversity Science, Berlin, Germany

${ }^{6}$ Université Côte d'Azur, Observatoire de la Côte d'Azur, CNRS, Laboratoire Lagrance, Nice, France

${ }^{7}$ Institute of Geological Sciences, Planetary Sciences and Remote Sensing, Freie Universität Berlin, Berlin, Germany

Corresponding Author: Angela M. Stickle

11100 Johns Hopkins Rd. M/S 200-W230

Laurel, MD 20723, USA

+1 (240) 228-3822

Angela.Stickle@jhuapl.edu

Keywords: Asteroids, Cratering, Impact processes 


\section{Abstract}

The Double Asteroid Redirection Test (DART) is a NASA-sponsored mission that will be the first direct test of the kinetic impactor technique for planetary defense. The DART spacecraft will impact into Didymos-B, the moon of the binary system 65803 Didymos and the resulting period change will be measured from Earth. Impact simulations will be used to predict the crater size and momentum enhancement expected from the DART impact. Because the specific material properties (strength, porosity, internal structure) of the Didymos-B target are unknown, a wide variety of numerical simulations must be performed to better understand possible impact outcomes. This simulation campaign will involve a large parameter space being simulated using multiple different shock physics hydrocodes. In order to understand better the behaviors and properties of numerical simulation codes applicable to the DART impact, a benchmarking and validation program using different numerical codes to solve a set of standard problems was designed and implemented. The problems were designed to test the effects of material strength, porosity, damage models, and target geometry on the ejecta following an impact and thus the momentum transfer efficiency. Several important results were identified from comparing simulations across codes, including the effects of model resolution and porosity and strength model choice: 1) Momentum transfer predictions almost uniformly exhibit a larger variation than predictions of crater size; 2) The choice of strength model, and the values used for material strength, are significantly more important in the prediction of crater size and momentum enhancement than variation between codes; 3) Predictions for crater size and momentum enhancement tend to be similar (within 15-20\%) when similar strength models are used in different codes. These results will be used to better design a modeling plan for the DART mission as well as to better understand the potential results that may be expected due to unknown target properties. The DART impact simulation team will determine a specific desired material parameter set appropriate for the Didymos system that will be standardized (to the extent possible) across the different codes when making predictions for the DART mission. Some variation in predictions will still be expected, but that variation can be bracketed by the results shown in this study.

\section{Introduction}

The Double Asteroid Redirection Test (DART) is a NASA-sponsored mission, currently in Phase C development (as of January, 2019). DART is the first direct test of kinetic impactor technology for planetary defense, and involves the impact of a spacecraft into the moon of a binary system in order to monitor momentum transfer to the target. High-fidelity impact simulations are one tool used to better predict the results of this impact. Because the target of the DART impact is a binary system that has not previously been visited by spacecraft, many of the target properties are unknown and the potential modeling parameter space is large. To deal with this, several different hydrocodes are employed by the team to examine possible effects. This variety of hydrocodes comes with some uncertainty, however, as different codes utilize different numerical techniques and material model implementations. In order to understand better the behaviors and properties of numerical simulation codes applicable to the DART impact, a benchmarking and validation program using different numerical codes to solve a set of standard problems was designed and implemented. The problems are designed to test the effects of material strength, porosity, damage models, and target geometry on the ejecta following an impact and thus the momentum transfer efficiency. Here, we briefly introduce the DART mission concept, kinetic impactors for planetary defense, the hydrocode benchmarking campaign performed by the DART team and collaborators, 
and the codes used in this study. This is followed by the results of five different benchmarking

\subsection{The Double Asteroid Redirection Test}

Approaches to asteroid impact mitigation fall into four broad categories [Board et al., 2010]: civil defense, slow-push/pull methods, kinetic impact, and nuclear detonation. These approaches are differently suited to various impact scenarios, and they are roughly listed in order of increasing impactor size and decreasing warning time. Deflection by nuclear device has been shown by extensive numerical simulation to be effective against NEOs as large as $1 \mathrm{~km}$ in diameter. Testing this method on an asteroid is not necessary, due to its effectiveness and the availability of extensive test history data. The next-most potent mitigation technique, the kinetic impactor, is untested in the regimes where it would be of most use: objects of $\sim 100-300 \mathrm{~m}$ diameter. Kinetic impactors are conceptually simple: a mass is thrown at a threatening object and the added momentum of the mass changes the threat's orbit such that impact with Earth is avoided. Given decadal-scale warning times, imposed speed changes of $\mathrm{mm} / \mathrm{s}$ to $\mathrm{cm} / \mathrm{s}$ scales are sufficient for a successful mitigation.

To understand the effectiveness of a kinetic impactor, we are reliant upon impact and shock physics codes that are calibrated to laboratory experiments many orders of magnitude smaller in size than a real-world application. Some of the most important questions about the technique, including how much momentum is carried away from the impact by ejecta, and how much the target's orbit is affected, remain unanswered.

NASA's Double Asteroid Redirection Test (DART) [Cheng et al., 2018] is a planetary defense demonstration mission intended to carry out a kinetic impactor test against a representative target (e.g., one similar to many Potentially Hazardous Asteroids (PHAs)). DART is planned to visit (65083) Didymos, a binary asteroid system with components $\sim 780 \mathrm{~m}$ and $\sim 150 \mathrm{~m}$ in diameter (informally called "Didymos A" and "Didymos B") [Naidu et al., 2016]. DART will impact Didymos $\mathrm{B}$ at $\sim 6 \mathrm{~km} / \mathrm{s}$, changing its orbit period, currently 11.9 hours, by up to several minutes. This period change will manifest in a change in the lightcurve of the Didymos system, in particular a shift in the timing of eclipses and occultations of Didymos A by Didymos B and vice versa. Because the period change is observable in the lightcurve, the required post-impact observations can be made with ground-based telescopes, and the amount of period change can be used to measure the change in speed of Didymos B caused by the DART impact. The spectral characteristics of Didymos A classify the asteroid as an S-type, a type associated with ordinary chondrite meteorites [Dunn et al., 2013], the most common meteorite type seen to fall to Earth, and Didymos B is believed to be composed of similar material (if it co-accreted or formed after rotational disruption of the primary [Walsh et al., 2012]. Didymos is both representative of the population of the most likely impactors and also allows modeling efforts to use a very well-known and common material as the target.

\subsection{Momentum Enhancement by Kinetic Impactor}

The efficiency of deflection from a kinetic impactor is often measured using the momentum enhancement factor, $\beta$, which defines the momentum imparted to the asteroid by impact in terms of the momentum of the impactor. $\beta$ is defined as:

$$
\beta=\frac{p_{\text {target } \text { post deflection }}}{p_{\text {impactor }}}
$$

where the momentum of the target (here, Didymos-B) post-impact is $p_{\text {target,post deflection }}=$ mass $_{\text {target,post }}$ deflection $* \Delta v_{\text {target}}$, with masstarget,post deflection $=$ masstarget, initial + massimpactor and the incoming momentum of the impactor ( $p_{\text {impactor}}$ ) is equal to the DART spacecraft momentum. Here, the mass 
of Didymos-B is estimated from the observed size of Didymos-B and assumed material properties, and $\Delta \mathrm{v}_{\text {target }}$ is the determined from the measured period change. For a general impact simulation, the initial projectile momentum and the mass of the target are inputs to the model and $\Delta \mathrm{v}_{\text {target }}$ is calculated from the simulation results. Determining $\beta$ from the DART impact is one the mission's top level requirements.

\subsection{Impact Simulation and Modeling Working Group}

The Asteroid Impact and Deflection Assessment (AIDA) concept is an international collaboration framework between NASA and ESA. AIDA was originally composed of the AIM ESA mission [Michel et al., 2016], which is currently re-designed as the Hera mission [Michel et al. 2018] which will be proposed to ESA member states for funding at the ESA Council of November 2019, and the DART mission. As part of the collaboration, an international working group was formed to better understand the range of possible outcomes of the DART impact. DART will join Deep Impact [A'Hearn et al., 2005] and LCROSS [Colaprete et al., 2010; Schultz et al., 2010] as one of three full-scale planetary impact experiments, and is the only one in which the deflection of the target will be measured. The goals of this working group are to 1) better understand the magnitude of this deflection by determining the sensitivity of impact models to impact conditions, 2) determine the momentum transfer efficiency, $\beta$, from the deflection magnitude, and its sensitivity to target properties, and 3) predict the ejecta mass and putative crater size following the DART impact. All three goals require numerous impact simulations, and will be accomplished using a variety of numerical approaches.

\subsection{Overview of Numerical Shock Physics Codes}

Simulations of dynamic processes require solving the equations of motion (conservation of mass, momentum and energy) for a given material. The set of equations is closed using a constitutive model. All shock physics codes, which are used to simulate impact processes, solve similar forms of the conservation equations. Constitutive models, however, can vary widely. Typically, a constitutive model is separated into two parts: the volumetric response of the material summarized by a material's Equation of State (EOS), and the response to deviatoric strains summarized by a strength model. The accuracy of the model predictions depends on how accurately the material models (EOS + strength) replicate material behavior, and how well known the properties included in those models are. Though the conservation equations are consistent across numerical implementations, how they are solved can vary. There are two main methods for solving the equations of motion: an Eulerian solution and a Lagrangian solution. Both methods have historically been used to produce reliable and robust shock codes.

The Eulerian solution treats continuum variables (i.e., density, temperature) from a fixed frame of reference. Equations of motion and conservation are solved using a mesh fixed in space so that material moves relative to the mesh. One benefit of the Eulerian method is that it does not suffer from mesh entanglement or oddly-shaped elements. However, Eulerian meshes have historically had difficulty tracking material interfaces, and in a given simulation many cells may include multiple materials; these are called "mixed cells". Mixed cells require averaging of material properties and state variables within the cell, which can lessen the accuracy of the model's prediction. Many techniques have been developed to try to deal with this. One such method is adaptive mesh refinement (AMR), which allows areas of high-resolution to be strategically generated within the model that allow better tracking of the shock front and of material interfaces. These regions, and the criteria for increased mesh resolution, are usually pre-defined by the user, 
and defining appropriate metrics is not always straightforward. These criteria must be carefully chosen in order to avoid introducing other systematic errors into the calculation.

In contrast, the Lagrangian method treats continuum variables from a frame of reference fixed with respect to the material. Equations of motion and conservation are solved using a mesh fixed with respect to the material so that the mesh moves through space and deforms along with the material. In general, this can be computationally more efficient than Eulerian solutions. However, care must be taken that the mesh does not distort to the extent that numerical approximations are significantly affected. A variety of approaches has also been developed to deal with strongly distorted meshes. A hybrid approach, which is popular, is referred to as Arbitrary Lagrangian Eulerian (ALE), which allows the computation to remain Lagrangian until some specified condition is met. When that happens, the mesh is allowed to relax according to specified rules as material advects through it. Here, the term "Eulerian" is used to describe this advection process, not necessarily a static grid. Other approaches involve converting strongly distorted elements into Smooth Particle Hydrodynamic (SPH) particles and allowing them to move freely within the mesh.

Meshless Lagrangian methods, such as Smooth Particle Hydrodynamics (SPH) and its adaptive versions (e.g., Spheral) use interpolation nodes (particles) to calculate values for parameters of interest. These particles interact through a "kernel function" that has a characteristic radius known as the "smoothing length". The physical quantity of any given particle is obtained by summing the relevant properties of all the particles that lie within the range of the kernel. Because there is no mesh, SPH methods are well-suited to simulate problems with large amounts of deformation, complex boundary dynamics, or for problems where material expands into large volumes. SPH codes can be quite computationally expensive, however, and treating boundary conditions is not always as straightforward as in a gridded code.

\subsection{Sources of Code Variability}

Variability in code results may arise from the way in which the flow equations are discretized and solved, which differs between codes. Pierazzo et al (2008) performed a study validating 8 numerical approaches against each other by looking at impacts into strengthless targets. This initial benchmarking campaign showed some variability in code results stemming from solution algorithms, stability parameters within the codes, and resolutions. For instance, predictions of peak pressures, crater depth, and diameter varied by $10-20 \%$ between codes. Additional complicating factors beyond those examined in detail during this initial study, like the effect of material models and how solids behave when they have some strength, are also likely to be important and lead to variation in simulation results.

Strength models are used to simulate departures of material response from strictly hydrodynamic behavior. Specific material properties will govern how a material behaves in response to stress, which ultimately leads to differing behaviors of different materials for the same impact conditions. The accuracy of the EOS is especially important early in an impact calculation, when the peak pressures are high and material strength becomes less important near the impact point. As the impact progresses, however, and deformation occurs farther from the point of first contact, material strength (described by the constitutive equation, or, colloquially, material model), becomes important for the cratering process and crater formation. High-fidelity models of material behavior can include things such as, e.g., strain hardening behaviors, rate effects, temperature effects (e.g., thermal softening), porosity, etc. In mechanical testing, geologic materials, including meteoritic material, exhibit all of the above effects, including rate- and temperature-dependent plasticity, and porosity effects [e.g., Kimberley and Ramesh, 2011; Buhl et al., 2013; Zwiessler et 
al., 2017; Winkler et al., 2018]. How (and if) these effects are accounted for in the numerical codes will affect the predicted impact response of a material. The challenge is to pick appropriate material models that include relevant physics and deformation mechanisms for the materials and problem of interest.

In addition to these physical factors, results can also be affected by strictly computational factors. The grid resolution of a given simulation will affect the calculated magnitude of energy deposited into the target during an impact and how that energy propagates through the system. Parameters that are calculated during the simulation are averaged over a given cell (for grid-based solutions), thus a larger cell size (or a lower resolution) will result in increased averaging of parameters across the spatial domain. Therefore, a larger cell size provides less accurate parameters reported for a specific location in the target, and resolution should be closely tracked in simulations. For this study, convergence studies were performed for all of the codes. In impact cratering studies, spatial resolution is often reported in terms of "cells per projectile radius" (cppr), or equivalent. For codes that have adaptively refining mesh (e.g., CTH), the resolution reported is the resolution corresponding to the most highly-refined mesh. For the tests reported here, all projectiles have a diameter of $1 / 4 "(6.35-\mathrm{mm})$. Thus, a resolution of $5 \mathrm{cppr}$ corresponds to a cell size of $0.125 \mathrm{~cm}$, and a resolution of 10,20,45, $60 \mathrm{cppr}$ correspond to cell sizes of $0.0625,0.031$, 0.007 , and $0.005 \mathrm{~cm}$, respectively.

\subsection{The AIDA/DART Benchmarking and Validation Program}

In order to understand better the behaviors and properties of numerical simulation codes applicable to the DART impact, a benchmarking and validation program using different numerical codes to solve a set of standard problems was designed and implemented. The problems are designed to test the effects of material strength, porosity, damage models, and target geometry on the ejecta following an impact and thus the momentum transfer efficiency. They include simulations of a sphere impacting into a strengthless aluminum target, a strengthless basalt target, an aluminum target with a constant strength (which is easily implementable across codes) and a basalt target with strength, damage, and porosity. A more complicated model, of a basalt sphere impacting a larger basalt sphere is also simulated. All models include standardized equations of state, but, in general, strength and plasticity models are allowed to vary between codes and users.

\section{Methods}

Impact modeling by numerical simulations is a crucial approach used to interpret the results of the DART kinetic impact deflection experiment, to infer physical properties of the target asteroid, and to advance understanding of impact processes on asteroids. Several distinct types of numerical methods can be used to model the DART deflection experiment, differing in the fundamental approaches to solving flow equations as well as in the modeling of target material properties and responses to impact stresses. Because of the differences in possible code design and method, a benchmarking and validation task was undertaken by the AIDA/DART Impact Modeling and Simulation Working Group in which different numerical codes were applied to solve a set of standard problems (Table 1). The results from these codes were then analyzed and compared to better understand the variability that might be expected in simulations relevant to DART.

Table 1. Summary of the Impact Codes Used in the Study 


\begin{tabular}{|c|c|c|c|}
\hline $\begin{array}{l}\text { Code } \\
\text { name }\end{array}$ & Type of mesh & Characteristics & \begin{tabular}{|l|} 
Key Code \\
References
\end{tabular} \\
\hline CTH & $\begin{array}{l}\text { Eulerian, } \\
\text { continuum } \\
\text { representation } \\
\text { of materials, } \\
\text { Adaptive Mesh } \\
\text { Refinement }\end{array}$ & $\begin{array}{l}\text { 2D and 3D geometry } \\
\text { 2-step Eulerian finite difference code } \\
\text { Allows multiple materials and } \\
\text { rheologies } \\
\text { Strength/damage model usually } \\
\text { employed: pressure-dependent yield } \\
\text { with Johnson-Cook fracture model to } \\
\text { track damage based on plastic strain } \\
\text { (scalar damage model) } \\
\text { Porosity: p-alpha porosity model }\end{array}$ & $\begin{array}{l}\text { McGlaun et al. } \\
\text { 1990; Crawford } \\
\text { et al. } 1999\end{array}$ \\
\hline $\begin{array}{l}\text { ASPH } \\
\text { (Spheral) }\end{array}$ & $\begin{array}{l}\text { Smooth Particle } \\
\text { Hydrodynamics } \\
\text { (meshless) }\end{array}$ & $\begin{array}{l}\text { 2D and 3D geometry } \\
\text { Adaptive SPH - smoothing scale varies } \\
\text { with direction } \\
\text { Exactly energy conserving } \\
\text { Strength model generally employed: } \\
\text { Tensor form of the Benz and Asphaug } \\
\text { damage model } \\
\text { Porosity: Strain-alpha porosity model }\end{array}$ & $\begin{array}{l}\text { Owen, et al. } \\
1998 ; \text { Owen } \\
2014\end{array}$ \\
\hline iSALE-2D & $\begin{array}{l}\text { Explicit } \\
\text { Arbitrary } \\
\text { Lagrangian } \\
\text { Eulerian, } \\
\text { continuum } \\
\text { representation } \\
\text { of materials }\end{array}$ & $\begin{array}{l}\text { 2D geometry; finite difference solutions } \\
\text { Allows multiple materials and } \\
\text { rheologies } \\
\text { Strength/Damage model generally } \\
\text { employed: Pressure-dependent yield } \\
\text { based on Collins et al. (2004), which } \\
\text { tracks damage based on deviatoric strain } \\
\text { Porosity: Epsilon-alpha porosity model } \\
\text { (Wünnemann et al. 2006; Collins et al. } \\
\text { 2011) }\end{array}$ & $\begin{array}{l}\text { Amsden et al. } \\
1980 \\
\text { Wünnemann et } \\
\text { al. } 2006\end{array}$ \\
\hline RAGE & $\begin{array}{l}\text { Adaptive } \\
\text { Eulerian Grid, } \\
\text { Continuous } \\
\text { Adaptive Mesh } \\
\text { Refinement, } \\
\text { continuum } \\
\text { representation } \\
\text { of materials }\end{array}$ & $\begin{array}{l}\text { 1-3D Geometry; Multidimensional } \\
\text { simulations } \\
\text { Radiation Adaptive Grid Eulerian } \\
\text { Adaptive mesh and time steps } \\
\text { Inlcudes: Radiative transfer, heat } \\
\text { conduction } \\
\text { SESAME and analytical EOS available } \\
\text { Multiple strength models available }\end{array}$ & $\begin{array}{l}\text { Gittings et al. } \\
2008\end{array}$ \\
\hline
\end{tabular}




\begin{tabular}{|c|c|c|c|}
\hline & & Porosity: p-alpha porosity model & \\
\hline PAGOSA & $\begin{array}{l}\text { Eulerian, } \\
\text { Continuum }\end{array}$ & $\begin{array}{l}\text { 3D, fixed grid, Eulerian Hydrocode } \\
\text { 2nd order accurate in time, 3rd order } \\
\text { accurate } \quad \text { in } \\
\text { Adaptive } \\
\text { Allows multiple materials per cell } \\
\text { Variety of strength models } \\
\text { available, Johnson-Cook damage model } \\
\text { usually employed } \\
\text { SESAME and analytical EOS availabel } \\
\text { Porosity: p-alpha porosity model }\end{array}$ & $\begin{array}{l}\text { Weseloh, } \\
\text { Clancy, and } \\
\text { Painter, } 2010\end{array}$ \\
\hline
\end{tabular}

Though relevant to modeling for the DART mission, the aim of the presented study is to evaluate the results of several numerical codes against one another in a standard set of cases rather than for the actual DART impact. Basalt and aluminum were chosen as projectile and target materials for many of the cases because of the availability of extensive experimental databases and because these materials are already implemented or can be implemented readily for impact simulations. The EOS was standardized between models so as to remove that as a variable (Table 2, Table 3). Where appropriate, strength parameters for aluminum and basalt were also proscribed (Table 4). The four standard cases (summarized in Figure 1 and Table 5) were intended to isolate the effects of: 1) impact flow field modeling, 2) brittle failure and fracture effects, 3) target porosity effects, and 4) finite size target effects. These were investigated by examining specific variables of interest to the DART project, including: the momentum enhancement factor, $\beta$, the ejected mass, the crater size (width and depth), and the peak pressures beneath the impact point. Note that strength changes as a function of porosity were neglected in these cases. This limits the number of parameter changes between models and allows for better understanding of controlling parameters.

Table 2. Summary of parameters in the Mie-Grüneisen EOS for aluminum 6061

\begin{tabular}{|c|c|c|c|c|c|c|}
\hline Material & $\begin{array}{c}\text { R0 (initial } \\
\text { density for } \\
\text { Hugoniot) }\end{array}$ & $\begin{array}{c}\text { T0 (initial } \\
\text { temp) }\end{array}$ & $\begin{array}{c}\text { Sound } \\
\text { speed (Cs) }\end{array}$ & S1 & $\begin{array}{c}\text { Grüneisen } \\
\text { parameter }\end{array}$ & $\begin{array}{c}\text { Specific heat } \\
\text { (cal/g*degC) }\end{array}$ \\
\hline Al-6061 & 2.703 & $2.59 \mathrm{E}-2 \mathrm{eV}$ & $5.22 \mathrm{~km} / \mathrm{s}$ & 1.37 & 1.97 & $1.07 \mathrm{E}+11$ \\
\hline
\end{tabular}

Table 3. Summary of parameters for the Tillotson EOS [Benz and Asphaug, 1999; Tillotson, 1962] 


\begin{tabular}{|c|c|c|c|c|c|c|c|c|c|c|}
\hline Material & $\begin{array}{c}\mathbf{r h o 0} \\
\left(\mathbf{k g} / \mathbf{m}^{\mathbf{3}}\right)\end{array}$ & $\mathbf{A ~ ( J / \mathbf { m } ^ { \mathbf { 3 } } )}$ & $\mathbf{B}\left(\mathbf{J} / \mathbf{m}^{\mathbf{3}}\right)$ & $\mathbf{E 0}(\mathbf{J} / \mathbf{g})$ & Eiv $(\mathbf{J} / \mathbf{g})$ & $\begin{array}{c}\text { Eev } \\
(\mathbf{J} / \mathbf{g})\end{array}$ & $\mathbf{a}$ & B & alpha & $\boldsymbol{\beta}$ \\
\hline Basalt & 2700 & $2.60 \mathrm{E}+10$ & $2.67 \mathrm{E}+10$ & $4.87 \mathrm{E}+5$ & $4.72 \mathrm{E}+3$ & $1.82 \mathrm{E}+4$ & 0.50 & 1.50 & 5.00 & $5.0^{\mathrm{a}}$ \\
\hline Aluminum & 2700 & $7.52 \mathrm{E}+10$ & $6.50 \mathrm{E}+10$ & $5.00 \mathrm{E}+3$ & $3.00 \mathrm{E}+3$ & $1.50 \mathrm{E}+4$ & 0.5 & 1.63 & 5 & 5 \\
\hline
\end{tabular}

a. Tillotson parameter for lunar gabbroic anorthosite [O'Keefe and Ahrens, 1982], substituting the basalt reference density and bulk modulus as reported by Nakamura and Fujiwara (1991)

Table 4. Summary of parameters prescribed for basalt and Al-6061

\begin{tabular}{|c|c|c|c|c|}
\hline Basalt & $\begin{array}{l}\text { Fully } \\
\text { dense }\end{array}$ & $\begin{array}{c}20 \% \\
\text { porosity }\end{array}$ & $\begin{array}{c}45 \% \\
\text { porosity }\end{array}$ & $\begin{array}{c}60 \% \\
\text { porosity }\end{array}$ \\
\hline Density $\left[\mathrm{kg} / \mathrm{m}^{3}\right]$ & 2800 & 2600 & 1500 & 1200 \\
\hline $\begin{array}{l}\text { Quasistatic Compressive strength } \\
{[\mathrm{MPa}]}\end{array}$ & 400 & 400 & 400 & 400 \\
\hline $\begin{array}{l}\text { Dynamic Compressive Strength } \\
{[\mathrm{MPa}]}\end{array}$ & 600 & 600 & 600 & 600 \\
\hline QS Tensile strength [MPa] & 30 & 30 & 30 & 30 \\
\hline Dynamic Tensile Strength [MPa] & 80 & 80 & 80 & 80 \\
\hline Toughness Mpa $\sqrt{ }(\mathrm{m})$ & 1.6 & 1.6 & 1.6 & 1.6 \\
\hline Youngs Modulus [GPa] & 70 & 70 & 70 & 70 \\
\hline Shear Modulus [GPa] & 29 & 29 & 29 & 29 \\
\hline Bulk Modulus [GPa] & 49 & 49 & 49 & 49 \\
\hline Coefficient of Friction & 0.6 & 0.6 & 0.6 & 0.6 \\
\hline Poisson's ratio & 0.25 & 0.25 & 0.25 & 0.25 \\
\hline \multicolumn{5}{|l|}{ Aluminum } \\
\hline $\begin{array}{l}\text { Al-6061, constant strength } \\
\text { Yield Strength }\end{array}$ & $275 \mathrm{MPa}$ & -- & -- & -- \\
\hline Poisson's ratio & 0.33 & -- & -- & -- \\
\hline Porosity & $0 \%$ & -- & -- & -- \\
\hline
\end{tabular}




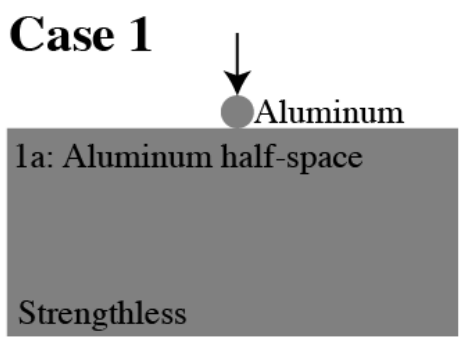

Case 2

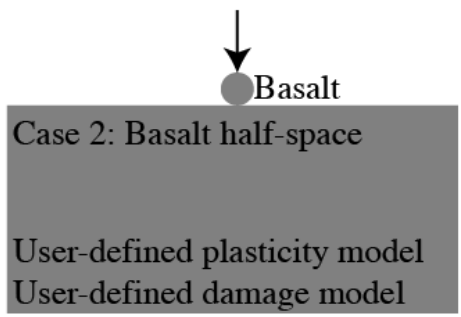

\section{Case 3}

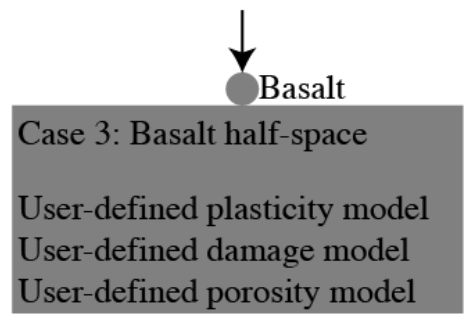

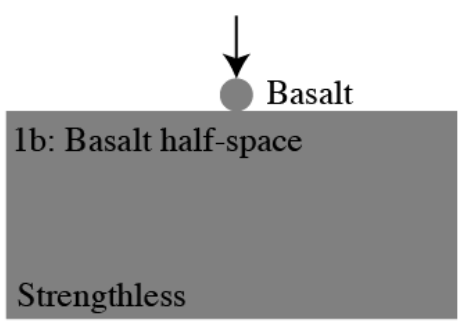

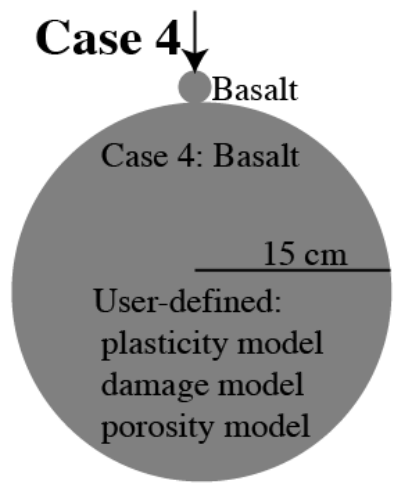

Figure 1. Schematic of standard benchmarking cases sent to each team. Cases were designed as laboratory-scale simulations and to isolate specific effects. Standard materials and models were assumed across the codes.

Table 5. Summary of the initial 4 cases compared across codes and their purpose

\begin{tabular}{|c|c|c|c|c|c|c|c|c|c|c|c|c|c|c|}
\hline & Projectile & Target & Velocity & $\begin{array}{c}\text { Impact } \\
\text { Angle (deg) }\end{array}$ & $\begin{array}{l}\text { Projectile } \\
\text { EOS }\end{array}$ & $\begin{array}{l}\text { Target } \\
\text { EOS }\end{array}$ & Projectile Plasticity Model & $\begin{array}{l}\text { Target Plasticity } \\
\text { Model }\end{array}$ & Damage model & Porosity Model & $\begin{array}{c}\text { Porosity } \\
\text { value }\end{array}$ & $\begin{array}{l}\text { Intended to } \\
\text { study }\end{array}$ & $\begin{array}{l}\text { Resolution (cppr or } \\
\text { equivalent) }\end{array}$ & Geometry \\
\hline Case la & $\begin{array}{c}0.635-\mathrm{cm} \mathrm{Al} \\
\text { sphere }\end{array} \mid$ & Al halfspace & $5 \mathrm{~km} / \mathrm{s}$ & 90 & \begin{tabular}{|c|} 
Mie- \\
Grüneisen Al \\
6061 \\
\end{tabular} & $\begin{array}{c}\text { Mie- } \\
\text { Grüneisen } \\
\text { Al } 6061 \\
\end{array}$ & none & none & none & none & 0 & $\begin{array}{c}\text { Impact flow field } \\
\text { modeling }\end{array}$ & $\begin{array}{c}3,5,7 \text { (LLNL, 3D) } \\
5,10,20,40 \text { (LLNL, } \\
2 \mathrm{D})\end{array}$ & 2D, 3D \\
\hline Case $1 \mathrm{~b}$ & $\begin{array}{c}0.635-\mathrm{cm} \\
\text { basalt } \\
\text { sphere }\end{array}$ & $\begin{array}{c}\text { basalt } \\
\text { halfspace }\end{array}$ & $5 \mathrm{~km} / \mathrm{s}$ & 90 & Tillotson & Tillotson & none & none & none & none & 0 & $\begin{array}{c}\text { Impact flow field } \\
\text { modeling }\end{array}$ & & $2 \mathrm{D}, 3 \mathrm{D}$ \\
\hline Case 2 & $\begin{array}{c}0.635-\mathrm{cm} \\
\text { basalt } \\
\text { sphere }\end{array}$ & $\begin{array}{c}\text { basalt } \\
\text { halfspace }\end{array}$ & $5 \mathrm{~km} / \mathrm{s}$ & 90 & Tillotson & Tillotson & $\begin{array}{l}\text { user specified/code } \\
\text { dependent }\end{array}$ & $\begin{array}{l}\text { user specified/code } \\
\text { dependent }\end{array}$ & $\begin{array}{c}\text { user } \\
\text { specified/code } \\
\text { dependent }\end{array}$ & none & 0 & $\begin{array}{c}\text { Brittle failure and } \\
\text { fracture effects }\end{array}$ & $5,10,20$ & $2 \mathrm{D}, 3 \mathrm{D}$ \\
\hline Case 3 & \begin{tabular}{c|}
$0.635-\mathrm{cm}$ \\
basalt \\
sphere \\
\end{tabular} & $\begin{array}{c}\text { basalt } \\
\text { halfspace }\end{array}$ & $5 \mathrm{~km} / \mathrm{s}$ & 90 & Tillotson & Tillotson & $\begin{array}{l}\text { user specified/code } \\
\text { dependent }\end{array}$ & $\begin{array}{l}\text { user specified/code } \\
\text { dependent }\end{array}$ & \begin{tabular}{|c|} 
user \\
specified/code \\
dependent
\end{tabular} & \begin{tabular}{|c|} 
user \\
specified/code \\
dependent
\end{tabular} & $20,45,60 \%$ & \begin{tabular}{|c|} 
Target Porosity \\
effects
\end{tabular} & & $2 \mathrm{D}, 3 \mathrm{D}$ \\
\hline Case 4 & \begin{tabular}{c|}
$0.635-\mathrm{cm}$ \\
basalt \\
sphere \\
\end{tabular} & $\begin{array}{c}30-\mathrm{cm} \text { basalt } \\
\text { sphere }\end{array}$ & $5 \mathrm{~km} / \mathrm{s}$ & 90 & Tillotson & Tillotson & $\begin{array}{l}\text { user specified/code } \\
\text { dependent }\end{array}$ & $\begin{array}{l}\text { user specified/code } \\
\text { dependent }\end{array}$ & $\begin{array}{c}\text { user } \\
\text { specified/code } \\
\text { dependent }\end{array}$ & \begin{tabular}{|c|} 
user \\
specified/code \\
dependent
\end{tabular} & & $\begin{array}{c}\text { Finite target size } \\
\text { effects }\end{array}$ & & 2D, 3D \\
\hline $\begin{array}{l}\text { Constant } \\
\text { Strength }\end{array}$ & \begin{tabular}{|l|}
$0.625-\mathrm{cm} \mathrm{Al}$ \\
6061 sphere
\end{tabular} & $\begin{array}{r}\text { Al } 6061 \\
\text { halfspace }\end{array}$ & $5 \mathrm{~km} / \mathrm{s}$ & 90 & \begin{tabular}{|c|} 
Mie- \\
Grüneisen Al \\
6061 \\
\end{tabular} & \begin{tabular}{|l} 
Mie- \\
Grüneisen \\
Al 6061
\end{tabular} & von Mises & von Mises & none & none & none & $\begin{array}{c}\text { Impact flow field } \\
\text { with simple } \\
\text { strength model }\end{array}$ & & $2 \mathrm{D}, 3 \mathrm{D}$ \\
\hline
\end{tabular}

A fifth case was designed to validate the numerical simulations against a hypervelocity impact experiment performed at the NASA Ames Vertical Gun Range (AVGR). This case was not simulated using every code. The experiment was a $90^{\circ}$ impact, at $2.1 \mathrm{~km} / \mathrm{s}$, into a $10 \mathrm{~cm} \times 10 \mathrm{~cm}$ x $10 \mathrm{~cm}$ block. The block was made of two parts: $110 \mathrm{~cm}$ x $10 \mathrm{~cm}$ x $5 \mathrm{~cm}$ basalt block affixed to a $10 \mathrm{~cm} \times 10 \mathrm{~cm} \times 10 \mathrm{~cm}$ polymethylmethacrylate (PMMA) block. The PMMA was chosen to match impedance with the basalt and was used as a window to examine crater growth as a function of time following impact (Figure 2A,B). Because the purpose of this case was specifically to 
compare and validate numerical simulations against experimental results (e.g., Figure 18), the impact geometry and velocity are not required to match the other 4 Cases. Rather, this experiment
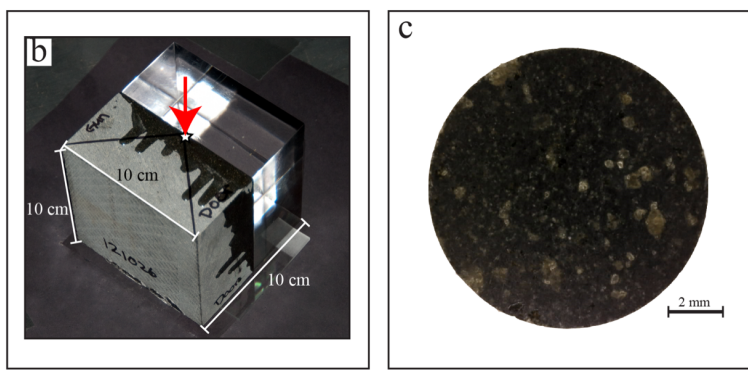

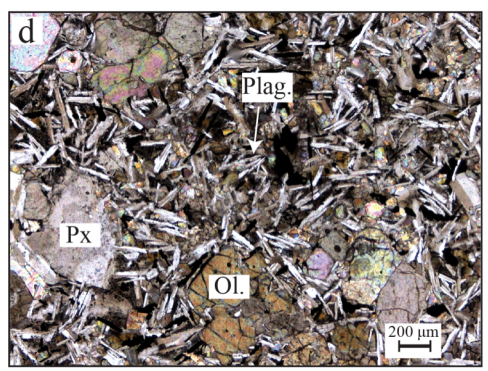

Figure 2. Setup for the experiment for comparisons in Case 5. a) Schematic of impact geomery; b) setup of the actual impact experiment, showing the basalt block with PMMA window. Impacts were from the top at the center of the block, and the block was set atop two glass slides to minimize interactions with the floor of the vacuum chamber following impact; c) small cutout showing texture of the basalt with visible olivine phenocrysts; d) thin section of the basalt used. The basalt was a fine-grained Columbia River flood basalt.

\subsection{Codes Used in This Study}

\subsubsection{CTH Simulations}

CTH is an Eulerian shock-physics code developed at Sandia National Laboratories [McGlaun et al., 1990] that has been applied to a wide variety of high speed large deformation problems, e.g. planetary impact cratering. It has the ability to perform multi-dimensional, multi-material calculations for a wide range of material models and EOS. For all benchmark cases both 2D and 3D CTH simulations were performed to examine its effect on $\beta$ as well as the crater dimensions. All simulations were run using CTH version 12.0.

The amount of momentum transfer from the impact as a function of time, $\beta(t)$, was calculated for each simulation. All mass in the simulation moving upward (positive y direction in $2 \mathrm{D}$, positive $\mathrm{z}$ direction in 3D) in the plane above the initial impact plane was assigned as "ejecta mass". The ejecta momentum was then calculated as, $p_{i}=m_{i} v_{i}$, where $p_{i}$ is the momentum of the $i$ th piece of ejecta, $m_{i}$ is its mass, and $v_{i}$ is the ejecta velocity. The $90 \%$ percentile velocity for ejecta at a given time step was calculated and used. To limit computational requirements, the mesh extent was limited. All mass crossing the mesh boundary (and thus leaving the simulation) was tracked. This lost momentum was defined as the lost mass times the $90^{\text {th }}$ percentile of the ejecta velocities at a given time step. The momentum multiplication factor, $\beta$, is calculated as the sum of the ejecta momentum and lost momentum divided by the projectile momentum for all pieces of ejecta mass. 
Impact crater dimensions were calculated using two different algorithms, "simple" and "robust". For nonporous simulations, the depth and width of the crater were calculated with a "simple" method: The cells of the target material along the projectile velocity vector were tracked, and the minimum absolute value of the height location of any of these cells was assigned as the crater depth. Crater diameter (width) was calculated by tracking the cells along the impact plane. The minimum absolute value of the non-depth dimensions ( $\mathrm{y}$ in $2 \mathrm{D}, \mathrm{x}$ and $\mathrm{y}$ in $3 \mathrm{D}$ ) corresponds to this crater profile on the plane where the projectile first contacted the target.

Simulations of impacts into porous targets generated numerical artifacts that disrupted the "simple" algorithm described above, and a more robust algorithm was needed. For example, in 2D simulations a small upward moving jet along the centerline was seen, which resulted in an artificially shallow crater being identified using the simple algorithm described above. The "robust" algorithm is defined here: to calculate crater depth, the algorithm was modified and a scan along the dimensions of interest was performed, i.e., along the x-direction in a 2D simulation or along the $\mathrm{x}$ and $\mathrm{y}$-direction in a 3D simulation. The minimum absolute value of the height location was recorded for each cell column in these dimensions. The global minimum of these values thus defines the crater depth. Care was taken to ensure that if small vacancies exist in the impacted material, these vacancies were not mistaken for the crater floor. Calculating crater width required a similar scan to be performed in the appropriate dimensions along the impact plane $(\mathrm{y}=0$ for $2 \mathrm{D}, \mathrm{z}=0$ for $3 \mathrm{D})$. The width was defined as the maximum value of the vector length connecting impacted material.

Adaptive Mesh Refinement (AMR) [Crawford, 1999] was utilized in all simulations for computational efficiency, with refinement occurring for all projectile material and at moving interfaces. For 2D simulations, the resolution ranged from 5-20 cppr while for 3D simulations the resolution ranged from 2.5-5.5 cppr. Convergence tests were performed for Case 1a and Case 2 (in 2D) and Case 1a (in 3D) to examine the effect of resolution on crater dimensions and momentum transfer. The effect of grid size on the calculation of $\beta$ was also examined. Resolution studies determined that the calculated $\beta$ was not dependent on the extent of the mesh so long as the ejecta mass was accurately tracked.

\subsubsection{CTH Parameters}

Two separate strength and damage models were used within CTH for these benchmarking cases: the "geo" model and the "BDL" model. The "geo" yield surface is a pressure-dependent yield surface incorporating thermal softening and density degradation. This yield behavior was coupled to a Johnson-Cook fracture (JCF) model to track damage within the material. The JCF model is a scalar damage model used to predict failure of materials [Johnson and Cook, 1985]. A damage parameter, $\mathrm{D}$, ranges from 0 (pristine, undamaged material) to 1 (failed material), where $\mathrm{D}$ is a function of equivalent plastic strain rate, local value of plastic strain to fracture, pressure, local yield stress, temperature and loading path. Here, D is assumed to be a function of the local value of plastic strain to fracture and material heterogeneity (in the form of Weibull distributed flaws) only. Damage by extensional failure (spallation) occurs when the material undergoes stresses higher than the maximum tensile stress.

The second strength and damage model used in CTH benchmarking simulations was the Brittle Damage with Localized Thermal Softening (BDL) model [Crawford et al., 2013; Schultz and Crawford, 2016]. This model includes a pressure-dependent yield and brittle damage model similar to that of Collins et al. [2004], in which the plastic strain at failure increases across the 
brittle and ductile regimes and the yield strength of fully damaged material follows a Coulomb friction law. The BDL model also incorporates a pressure-dependent melt curve [Senft and Stewart, 2009] to compute thermal softening and a statistical crack model [Schultz and Crawford, 2016]. The crack spacing follows a power law in strain rate, and within cracks localized temperature changes are induced by frictional shear heating and heat loss due to thermal conduction.

For Case 5, which differs slightly from the prescribed Cases 1-4, CTH simulations were run with the Tilltoson equation of state and the BDL model with stipulated strength parameters for basalt. The Pyrex projectile was simulated using a Mie-Gruneisen equation of state and a pressuredependent yield surfaces with parameters from Stickle and Schultz [2014] and Marsh [1980]. The parameters for the Pyrex were set to mimic the breakup behavior seen in experiments. A JohnsonCook continuum damage model ("Johnson-Cook Fracture, [Johson and Cook, 1985]) was added with a strain-to-failure of $5 \%$, a melting temperature of $2900 \mathrm{~K}$, a tensile strength of $1.8 \mathrm{GPa}$ and a Weibull modulus of 10.

\subsubsection{Adaptive Smooth Particle Hydrodynamics}

Spheral is an open-source Adaptive Smoothed Particle Hydrodynamics (ASPH) code [Owen et al., 1998; Owen, 2010], which has been used extensively for small-body cratering studies [Owen et al., 2014; Owen et al., 2015; Bruck Syal et al., 2016a; Bruck Syal et al., 2016b]. Meshless hydrodynamics methods such as ASPH allow for the momentum carried in crater ejecta to be calculated in a relatively straightforward manner as the ejecta particles are automatically tracked as they move. Spheral differs from most standard implementations of SPH in that the smoothing scale between particles can vary with direction, which allows for more realistic treatment of strongly anisotropic strain fields; it is also exactly energy conserving [Owen et al., 2014].

For this study, most Spheral simulations were carried out in a fully 3D geometry, so that damage propagation in the basalt targets could be more accurately tracked. Some axisymmetric (2D) simulation for Case 1 (aluminum target, without damage) were carried out to assess differences between 2D and 3D geometries. Convergence tests were performed for both crater size and momentum transfer in 2D and 3D simulations. Note that Spheral resolution is described by "nrI," the number of ASPH particles per impactor radius (similar to the cells-per-projectile-radius or "cppr" metric used by meshed codes).

Half-space targets (Cases 1, 2, and 3) were modeled using high resolution in the area of crater formation (5-7 particles-per-projectile-radius, out to a radius of $3 \mathrm{~cm}$ ), with resolution gradually becoming coarser towards the edge of the domain (at a radius of $12 \mathrm{~cm}$ ). These limits were chosen through an iterative process to determine when simulation results were not affected by interactions at the edge of the target, and through comparisons with constant-resolution targets. Similarly, high resolution (5 particles-per-projectile-radius) was used near the crater in Case 4 (30-cm spherical target), with resolution gradually coarsening beyond $5 \mathrm{~cm}$ in radius from the impact point. Uniform resolution (5 particles-per-projectile-radius) was used in Case 5 (10-cm cube target).

Tillotson EOS parameters were used for all aluminum and basalt materials (Table 3). For all cases, summaries of parameters used can be seen in Appendix A. For the Pyrex impactor in Case 5, Mie-Gruneisen coefficients from Stickle \& Schultz (2012) were chosen to represent the Pyrex. Aluminum strength, when used, was represented using the von Mises criterion, using a constant yield strength of $\mathrm{Y0}=275 \mathrm{MPa}$ and a shear modulus of $\mathrm{G}=26.5 \mathrm{GPa}$. Basalt targets also used von Mises strength, with $\mathrm{Y} 0=1 \mathrm{GPa}$ and $\mathrm{G}=29 \mathrm{GPa}$. This strength model was coupled to a tensor generalization of the Benz-Asphaug implementation of Grady-Kipp damage for SPH codes [Benz 
and Asphaug, 1994]. The damage model used a version that is compatible with particles of varying resolution and applied the "pseudo-plastic" strain algorithm, with $\mathrm{k}=5 \mathrm{e} 24 \mathrm{~cm}^{-3}$ and $\mathrm{m}=9.0$ for the Weibull constants. Porosity was modeled using the $\varepsilon$ - $\alpha$ strain-based model [Collins et al., 2011], with values of $\varepsilon \mathrm{e}=0.0, \varepsilon \chi=-0.4$, and $\kappa=0.8$. Case 3 (half-space target) used porosities of $\phi=0.2$ and 0.4 and Case 4 (sphere target) used $\phi=0.2$. For Case 5 , which aimed to simulate a real basalt target used in an impact experiment, we assumed that some natural porosity would have been present in the sample $(\sim 7 \%)$, and used a reference density of $3.01 \mathrm{~g} / \mathrm{cc}$ so that the bulk density

\subsection{4 iSALE simulations}

The iSALE-2D shock physics code [Wünnemann et al., 2006] is based on the SALE hydrocode solution algorithm [Amsden et al., 1980]. SALE was modified to include an elasto-plastic constitutive model, fragmentation models, various EOS, and multiple materials in order to simulate hypervelocity impact processes in solid materials Melosh et al., 1992; Ivanov et al., 1997]. More recent improvements include a modified strength model [Collins et al. 2004] and a porosity compaction model [Wünnemann et al., 2006; Collins et al., 2011].

iSALE was used to simulate Cases 1-4. The Tillotson EOS was used in all cases, the "ROCK" strength model [Collins et al., 2004] was used for basalt in all cases requiring strength, while the Johnson-cook strength model [Johnson and Cook, 1983] was used for aluminum. The "Collins" damage model [Collins et al., 2004] was used where a damage model was present, and has shown accurate results for comparisons with laboratory experiments on competent rocks in previous studies [Güldemeister et al. 2015, 2017, Winkler et al. 2018]. For cases requiring porosity, the $\varepsilon$ $\alpha$ [Wünnemann et al., 2006; Collins et al., 2011] was used. A convergence study was performed for Cases $1 a^{\prime}$ and 2, with resolutions ranging from 5-60 cppr.

The mass and velocity of ejected material is analysed with the help of Lagrangian tracer particles that are initially distributed uniformly across the computational domain, in the centre of each computational cell. These tracers follow the velocity field of the material flow in the Eulerian grid. Upon ejection, which is defined as the moment when the tracer reaches an altitude of one projectile radius, the speed and angle of ejection and the radial launch position is recorded. The upward directed momentum represented by each ejected tracer particle is summed and normalised by the impactor momentum to derive a $\beta$ value for the simulation. A significant benefit of this approach is that once the tracer particle has crossed the ejection altitude the material that it represents no-longer needs to be tracked. This ensures accurate recording of even the fastest ejecta and negates the need to record momentum lost from the computational domain. Studies of the effects of target properties on ejecta characteristics that include a more detailed description and a validation of this approach were recently published [Luther et al. 2018, Raducan et al., submitted]. This approach has successfully reproduced the morphometry of ejecta deposits formed in laboratory experiments [Wünnemann et al. 2016] and surrounding lunar craters [Zhu et al., 2015], and was used to quantify momentum enhancement for strength-dominated target materials in lowgravity environments applicable to the DART mission scenario [Raducan et al., submitted]. In Case 1a', $\beta$ was calculated from the cell momenta (a similar method to that employed in $\mathrm{CTH}$ ) instead of the tracer method to reduce intercode variability.

\subsubsection{Radiation Adaptive Grid Eulerian (RAGE)}

RAGE is a multi-dimensional, multi-material Eulerian shock physics code developed by Los Alamos National Laboratories (LANL) [Byrne et al., 1992; Gittings et al., 2008]. The code 
includes adaptive time steps, adaptive mesh refinement, a p- $\alpha$ porosity model, a variety of strength models, and both SESAME [Lyon and Johnson, 1992] and analytical EOS capabilities. RAGE was used to simulate Case 1a (strengthless models) for impacts in both aluminum and basalt, and Case $1 \mathrm{~b}$ for impacts into aluminum with a Steinburg-Guinan plasticity model [Steinberg et al., 1980]. A resolution test was performed for each case, with the finest resolution of $0.031 \mathrm{~cm}(20 \mathrm{cppr})$. Since RAGE is an AMR code, the resolution refers to the finest allowed resolution. The code automatically refines or coarsens cells according to the gradients of the state variables in neighboring cells, so that the mesh is refined to a high resolution in the presence of shocks and coarsened in areas where there is little motion.

The simulations were carried out on a 2-D cylindrical axi-symmetric grid, with the impact on the axis of symmetry. Eulerian codes cannot support empty mesh cells, therefore a background atmosphere is included in all cases. A 1 bar SESAME air EOS is used as a background material for models of laboratory experiments in air, and a 100 microbar monatomic ideal gas is used for models of impacts in vacuum.

\subsubsection{PAGOSA}

PAGOSA [Weseloh et al., 2010] is a massively parallel hydrocode developed by LANL to simulate multi-dimensional dynamic behavior of solid materials subjected to high-strain rates, like those produced by hypervelocity impacts. PAGOSA is an Eulerian finite-difference code, has adaptive time steps, a p-alpha porosity model, multiple strength models, and both SESAME and analytical EOS capabilities. It uses an up-stream weighted, monotonicity-preserving advection scheme that conserves momentum and internal energy. PAGOSA uses a fixed grid mesh throughout the entire simulation. Cell size may be varied spatially so that some regions of the mesh have a higher resolution than others, but the mesh cannot change over the course of the calculation. Homogeneous-sized meshes are used throughout this work, with all cells in the mesh at the reported resolution of the specified model. A resolution test was performed for each case, with the finest resolution of $0.031 \mathrm{~cm}(20 \mathrm{cppr})$. PAGOSA was used to simulate Case 1a strengthless models and Case $1 \mathrm{~b}$ impacts into aluminum with a Steinburg-Guinan plasticity model [Steinberg et al., 1980]. The models were run as 2D axisymmetric models for efficiency.

For both RAGE and PAGOSA simulation, the momentum of all material moving in the positive y-direction (up in the images, opposite the impact velocity direction) above the original target surface was tracked and added to the original projectile momentum. This quantity was then divided by the original projectile momentum to determine the momentum enhancement factor, $\beta$.

\section{Benchmarking Results}

Benchmarking impact codes requires identification of standard cases that are repeatable across different codes that allow a comparison of the performance in accuracy, speed, and reliability. This testing requires detailed comparison of simulation results and characteristic quantities across the codes. Here, we compare crater growth and dimensions, peak pressures in the target following impact, and the momentum enhancement factor, $\beta$. We present results from the time of impact until the crater size and $\beta$ have stabilized. Not every case includes results from each numerical method.

\subsection{Case 1-1/4" sphere into half-space (strengthless)}

The first benchmarking case was designed to identify how codes behave with respect to one another using the simplest model: a strengthless target. This setup requires no additional material 
constitutive behavior outside the equation of state. This case was initially broken into two parts: Case 1a, an aluminum sphere impacting into an aluminum target, and Case 1b, a basalt sphere impacting into a basalt target. All material in Case $1 \mathrm{a}$ and $1 \mathrm{~b}$ was simulated using only an EOS with no additional plasticity model. This separation was intended to provide a better understanding of the effects of differing EOS on the $\beta$ calculation. Following initial simulation tests, a third variant was added to Case 1, called Case 1a' here. This variant included simulations using constant strength (represented using a von Mises plasticity model) for the aluminum block. This simple strength approximation is available in most widely used codes and thus represented an initial baseline to better understanding the natural variability found between codes when strength is included. Because it is implemented widely, this provided a more direct comparison between codes than later cases which include significantly more variation in plasticity and damage model implementation and choices between codes. These results are summarized below.

Figure 3 shows the results from Case $1 \mathrm{a}$ and $1 \mathrm{~b}$ using 5 different numerical codes. Spheral, RAGE and PAGOSA performed a convergence test for this case. More detail regarding the results of the RAGE and PAGOSA convergence study are summarized in Heberling et al. [2017]. For both Spheral and PAGOSA simulations, predicted $\beta$ decreases with increasing resolution. This trend is opposite for RAGE simulations, where $\beta$ increases as resolution increases.

Crater size shows the least variation between codes. Note that because the simulations do not include material strength, there is nothing to stop the crater growth, and the values for depth and diameter do not asymptote. This is expected, so a common stop time was prescribed for these simulations. Here, we chose $400 \mu \mathrm{sec}$, as this time would be well beyond the transient crater formation time for a typical laboratory experiment. There is a larger variation in the reported values for momentum enhancement factor, $\beta$, thus it is shown until $100 \mu \mathrm{sec}$ for clarity. A more complete summary of values from each code is shown in Appendix B, however a few noted results are summarized here in Table 6. At $100 \mu$ sec following impact, there is a 3-4\% difference in crater depth and diameter between codes, while the percent difference between the minimum and maximum $\beta$ is $37 \%$ for comparable resolution. At $400 \mu \mathrm{sec}$ this difference is $3.5 \%, 6 \%$ and $15 \%$ difference in depth, diameter, and $\beta$ predictions. For comparable resolutions, 2D CTH simulations predict the largest crater and $\beta$ values at $400 \mu \mathrm{sec}$. The large scatter between the $\mathrm{CTH}$ and PAGOSA simulations for impacts into a strengthless basalt target is likely due to the fact that the CTH simulations modeled a target with $0 \%$ porosity while the PAGOSA and RAGE simulations modeled a basalt target with $50 \%$ porosity. Higher porosity will result in deeper, narrower craters, and lower $\beta$. This is generally what is seen in all but the lowest resolution PAGOSA models. However, $2.5 \mathrm{cppr}$ is such a coarse resolution that the results are not likely to be accurate. From the CTH simulations, we see that there is not a large difference between predicted crater depth, diameter and $\beta$ values due to the EOS differences between aluminum and basalt.

Table 6. Summary of crater size and $\beta$ for strengthless aluminum targets (Case 1a) at 100 and 400 $\mu \mathrm{sec}$ following impact for simulations with comparable resolution. When a given result was not supplied by specific modelers, it is marked as "not provided" in the table. Gridded codes resolution is reported in "cells per projectile radius" (cppr), while the resolution for the ASPH code is reported in "nrl", which refers to the number of ASPH particles per impactor (projectile) radius. A full summary at all resolutions can be seen in Appendix B.

\begin{tabular}{|c|c|c|c|c|c|c|}
\hline Model & Resolution & Case & $\begin{array}{c}\text { Time } \\
{[\mathbf{u s}]}\end{array}$ & $\begin{array}{c}\text { Crater } \\
\text { Depth } \\
{[\mathrm{cm}]}\end{array}$ & $\begin{array}{c}\text { Crater } \\
\text { Diameter } \\
{[\mathrm{cm}]}\end{array}$ & $\boldsymbol{\beta}$ \\
\hline
\end{tabular}




\begin{tabular}{|c|c|c|c|c|c|c|} 
iSALE & $40 \mathrm{cppr}$ & $1 \mathrm{a}$ & 100 & 3.05 & 5.37 & 4.02 \\
\hline CTH (2D) & $20 \mathrm{cppr}$ & $1 \mathrm{a}$ & 100 & 3.20 & 5.54 & 4.54 \\
\hline RAGE & $20 \mathrm{cppr}$ & $1 \mathrm{a}$ & 100 & $\begin{array}{c}\text { not } \\
\text { provided }\end{array}$ & $\begin{array}{c}\text { not } \\
\text { provided }\end{array}$ & 5.40 \\
\hline PAGOSA & $20 \mathrm{cppr}$ & $1 \mathrm{a}$ & 100 & 3.17 & 5.47 & 6.45 \\
\hline $\begin{array}{c}\text { Spheral } \\
(2 \mathrm{D})\end{array}$ & $\mathrm{nrI}=20$ & $1 \mathrm{a}$ & 100 & $\begin{array}{c}\text { not } \\
\text { provided }\end{array}$ & $\begin{array}{c}\text { not } \\
\text { provided }\end{array}$ & 5.92 \\
\hline iSALE & $40 \mathrm{cppr}$ & $1 \mathrm{a}$ & 400 & 4.87 & 8.87 & 8.68 \\
\hline CTH (2D) & $20 \mathrm{cppr}$ & $1 \mathrm{a}$ & 400 & 5.18 & 9.19 & 10.22 \\
\hline PAGOSA & $20 \mathrm{cppr}$ & $1 \mathrm{a}$ & 400 & 5.10 & 9.12 & 10.16 \\
\hline RAGE & $20 \mathrm{cppr}$ & $1 \mathrm{a}$ & 400 & 5.2 & 8.4 & 9.14 \\
\hline
\end{tabular}
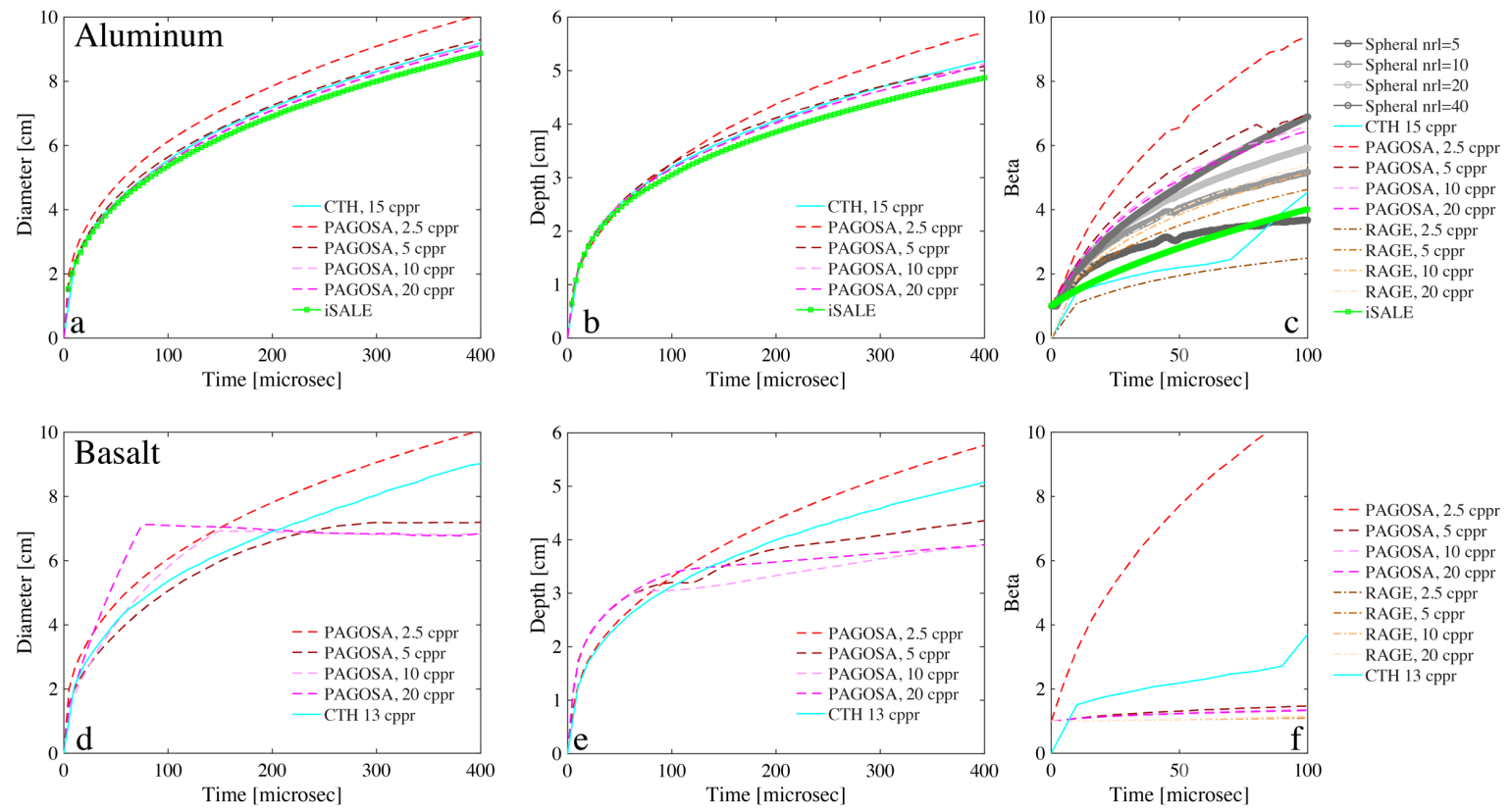

Figure 3. Summary of impacts into strengthless aluminum (a-c) and basalt (d-f) targets. All impacts are in $2 \mathrm{D}$ geometry for a $90^{\circ}$ impact at $5 \mathrm{~km} / \mathrm{s}$. Model parameters are summarized in Tables in Appendix A. Note that because the simulations do not include material strength, the crater sizes and $\beta$ continue to grow. a) crater diameter, in centimeters, as a function of time for $1 / 4$ " strengthless aluminum sphere impacting into a strengthless aluminum half-space; b) crater depth, in centimeters, as a function of time for $1 / 4$ " strengthless aluminum sphere impacting into a strengthless aluminum half-space; d) $\beta$ as a function of time for $1 / 4$ " strengthless aluminum sphere impacting into a strengthless aluminum half-space; d) crater diameter as a function of time for $1 / 4$ " strengthless basalt sphere impacting into a strengthless basalt half-space; e) crater depth as a function of time for $1 / 4$ " strengthless basalt sphere impacting into a strengthless basalt half-space; f) $\beta$ as a function of time for $1 / 4$ " strengthless basalt sphere impacting into a strengthless basalt halfspace. 

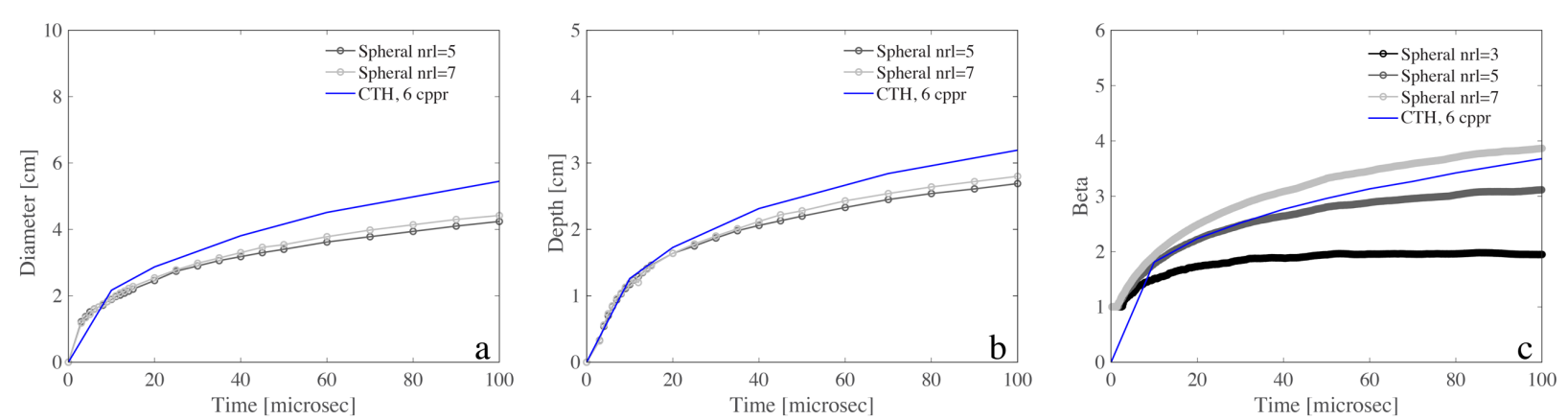

Figure 4. Comparison of 3D Spheral and CTH simulations of impacts into strengthless aluminum targets. All impacts are at $90^{\circ}$ at $5 \mathrm{~km} / \mathrm{s}$. Model parameters are summarized in Appendix A. Note that because the simulations do not include material strength, the crater sizes and $\beta$ continue to grow. a) crater diameter, b) crater depth, c) $\beta$.

Table 7. Summary of crater size and $\beta$ at 100 and $400 \mu \mathrm{sec}$ following impact for simulations with comparable resolution. When a given result was not supplied by specific modelers, it is marked as "not provided" in the table. A full summary at all resolutions can be seen in Appendix B.

\begin{tabular}{|c|c|c|c|c|c|c|}
\hline Model & Resolution & Case & $\begin{array}{c}\text { Time } \\
\text { [us] }\end{array}$ & $\begin{array}{c}\text { Crater } \\
\text { Depth } \\
\text { [cm] }\end{array}$ & $\begin{array}{c}\text { Crater } \\
\text { Diameter } \\
\text { [cm] }\end{array}$ & $\boldsymbol{\beta}$ \\
\hline CTH (3D) & $6 \mathrm{cppr}$ & $1 \mathrm{a}$ & 100 & 3.19 & 5.45 & 3.68 \\
\hline $\begin{array}{c}\text { Spheral } \\
\text { (3D) }\end{array}$ & $\mathrm{nrI}=3$ & $1 \mathrm{a}$ & 100 & $\begin{array}{c}\text { not } \\
\text { provided }\end{array}$ & $\begin{array}{c}\text { not } \\
\text { provided }\end{array}$ & 1.95 \\
\hline $\begin{array}{c}\text { Spheral } \\
\text { (3D) }\end{array}$ & $\mathrm{nrI}=5$ & $1 \mathrm{a}$ & 100 & 2.69 & 4.24 & 3.12 \\
\hline $\begin{array}{c}\text { Spheral } \\
\text { (3D) }\end{array}$ & $\mathrm{nrI}=7$ & $1 \mathrm{a}$ & 100 & 2.80 & 4.42 & 3.87 \\
\hline
\end{tabular}

Three-dimensional calculations of Case 1a were also run using CTH and Spheral, and the results are shown in Figure 4 and summarized in Table 7 and in Appendix B. An additional convergence study was performed using the Spheral code in $3 \mathrm{D}$. $\beta$ values converge at slightly finer resolution (20 particles-per-projectile-radius) but converge similarly for 2D and 3D. Crater depths and diameters did not significantly differ between $2 \mathrm{D}$ and 3D for the aluminum targets, when run with or without von Mises (constant) strength; values for both were found to be converged at a resolution near 5 particles-per-projectile-radius. For simulations in 3D and at comparable resolution ( 5 cppr for $\mathrm{CTH}$ and $\mathrm{nrI}=5$ for Spheral), $\mathrm{CTH}$ consistently predicted larger craters, with a $3 \%$ difference in crater diameter and $15 \%$ difference in crater depth at $100 \mu$ sec following impact. There is a $15 \%$ difference in prediction of $\beta$ as well.

Another parameter that is commonly analyzed following impact is the peak pressures within the target. Here, peak pressure along a line vertically below the target as well as at depth along a $45^{\circ}$ slope was documented for each simulation (Figure 5). This case is similar to what was modeled in the initial benchmarking study by Pierazzo et al. [2008] (an impact into a strengthless aluminum target, though here the impactor is much smaller). For a $5 \mathrm{~km} / \mathrm{s}$ impact, Pierazzo et al. [2008] 
reported a $15 \%$ difference in slope between codes for the pressure decay region. Here, the difference in slope of the pressure-decay region is dependent on where the peak pressures were measured. For a line at a $45^{\circ}$ angle radially from the impact point, the two codes predict peak pressures within $5 \%$ of one another (Table 8,9$)$. However, when the peak pressure is measured directly below the impact point, which is the generally reported direction for pressure decay estimates in vertical impact simulations, there is a much greater difference in slopes ( $40 \%)$. These differences may be due to a number of things, including internal numerics of the codes themselves, noise from boundary effects along the center-line of 2D simulations, as well as input parameters chosen for each simulation. Though both codes show convergence, one obvious choice may be the resolution of the simulations: the iSALE simulation was run at $40 \mathrm{cppr}$ while CTH was run at 20 cppr. Another may be the choice of EOS parameters. Here, iSALE used the EOS for Al-1100, while the CTH simulations used the parameters proscribed in Table 3, which may differ slightly

2D Strengthless Al
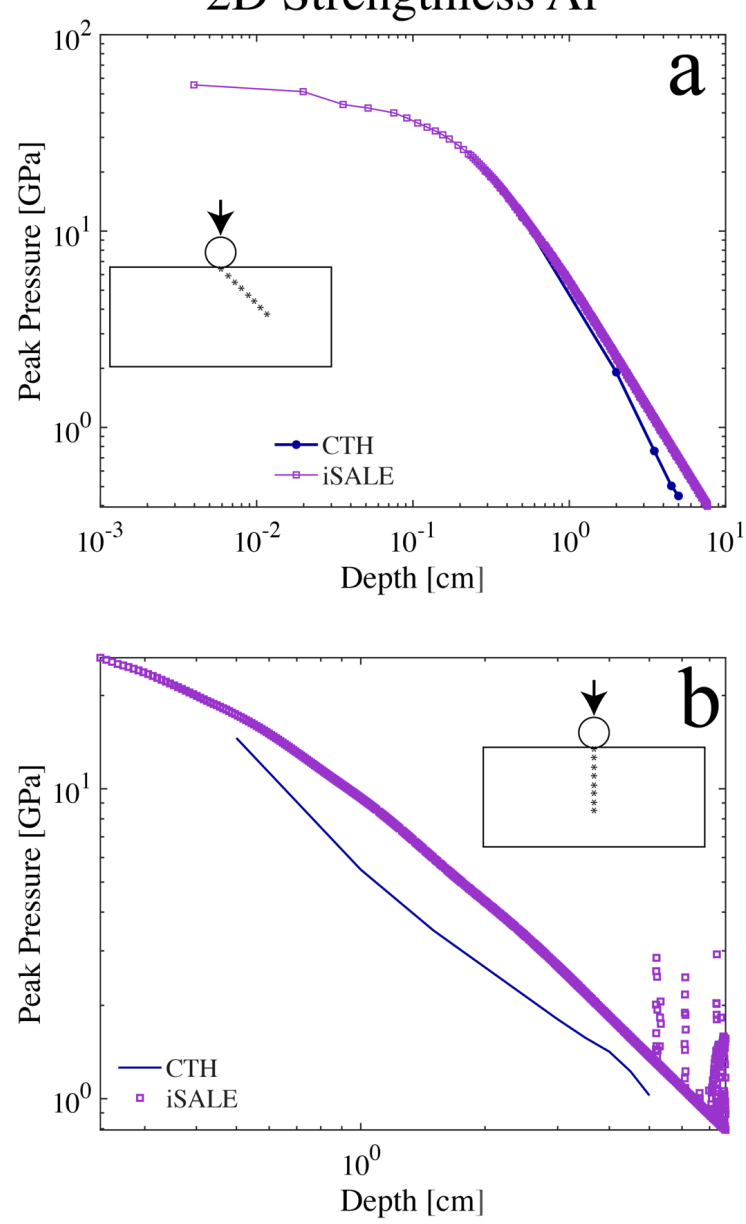

$2 \mathrm{D}$ von $\mathrm{Mises} \mathrm{Al}$
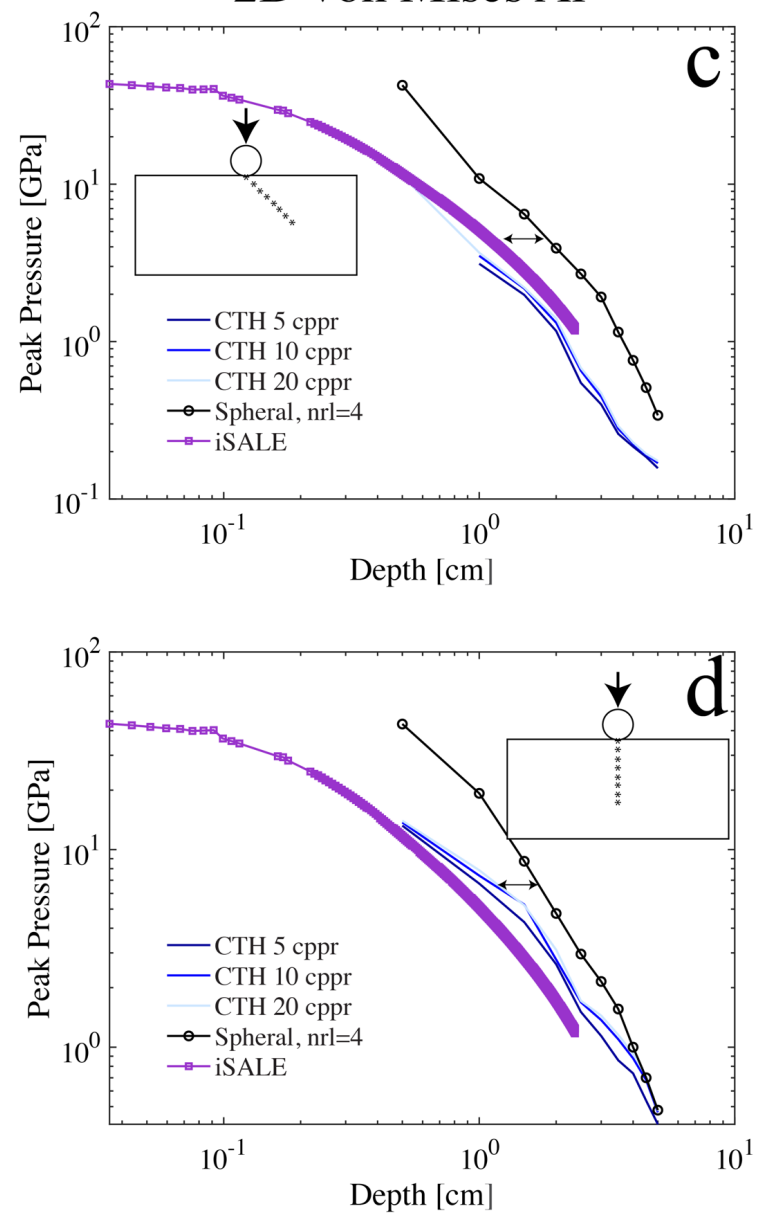

595

596

597

598

599

600

Figure 5. Pressure as a function of depth for impacts into strengthless aluminum (left) and aluminum with a constant strength (right) for simulations using CTH, iSALE, and Spheral. The offset in the Spheral simulation is likely due to difficulty of defining stationary Eulerian tracer points in a meshless code, which is a relatively new capability in Spheral. 
602 Table 8. Summary of peak pressure with depth for CTH, Spheral, and iSALE models of impacts 603 into a strengthless aluminum block. "diagonal" refers to tracers along a 45-deg diagonal from the 604 impact point, while "vertical" refers to a vertical line directly below the impact point

605

\begin{tabular}{|c|c|c|c|}
\hline $\begin{array}{l}\text { Case 1a } \\
\text { Strengthless }\end{array}$ & & \multicolumn{2}{|c|}{ Peak Pressure [GPa] } \\
\hline diagonal & $\begin{array}{c}\text { Depth } \\
{[\mathrm{cm}]}\end{array}$ & $\mathrm{CTH}$ & $i S A L E$ \\
\hline & 0.5 & 11.80 & 11.87 \\
\hline & 2 & 1.91 & 2.23 \\
\hline & 3.5 & 0.76 & 1.10 \\
\hline & 4.5 & 0.50 & 0.80 \\
\hline & 5 & 0.45 & 0.69 \\
\hline & & \multicolumn{2}{|c|}{ Peak Pressure [GPa] } \\
\hline vertical & $\begin{array}{l}\text { depth } \\
{[\mathrm{cm}]}\end{array}$ & $\mathrm{CTH}$ & $i S A L E$ \\
\hline & 0.5 & 14.58 & 17.22 \\
\hline & 1 & 5.49 & 9.32 \\
\hline & 1.5 & 3.49 & 5.96 \\
\hline & 3 & 1.80 & 2.68 \\
\hline & 3.5 & 1.57 & 2.19 \\
\hline & 4 & 1.42 & 1.84 \\
\hline & 4.5 & 1.23 & 1.58 \\
\hline & 5 & 1.02 & 1.37 \\
\hline
\end{tabular}

606

607

608

609

610

Table 9. Slope of the pressure decay region for simulations of strengthless material

\begin{tabular}{|c|c|c|c|}
\hline & Slope iSALE & $\begin{array}{c}\text { slope } \\
\text { CTH }\end{array}$ & \% difference \\
\hline diagonal & -0.52 & -0.49 & $5.34 \%$ \\
\hline vertical & -1.99 & -1.12 & $43.84 \%$ \\
\hline
\end{tabular}

\subsection{Case 1a': 1/4" Sphere into Constant Strength Aluminum half-space}



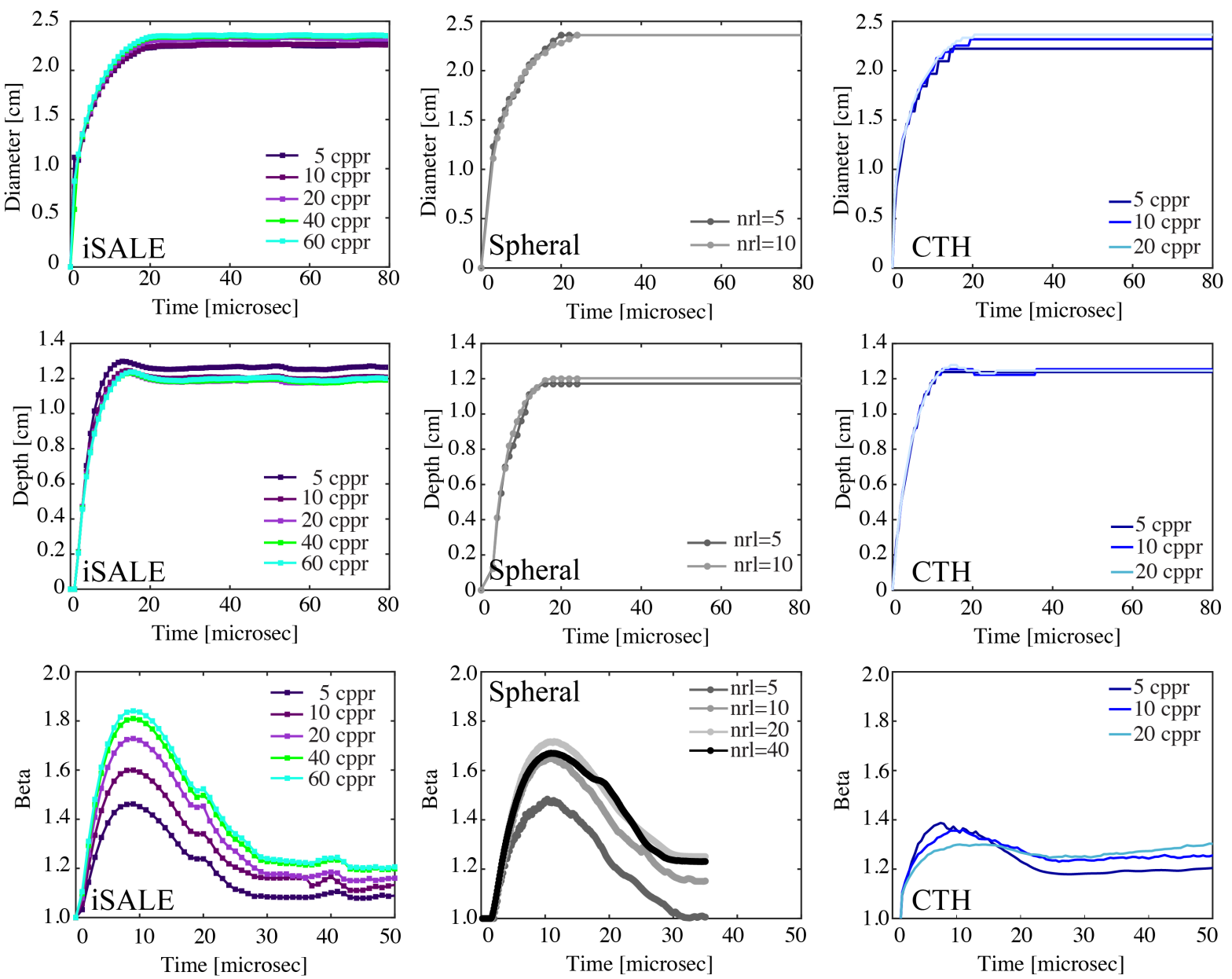

Figure 6. Summary of results of a convergence study for the iSALE-2D (left), Spheral (middle), and CTH (right) codes for an impact of a $1 / 4$ " aluminum projectile into an aluminum target that is modeled as having constant strength. Panels show crater diameter(top), crater depth (middle) and $\beta$ (bottom) for all three codes as a function of time and resolution. A comparison for the highest resolution simulations can be seen in Figure 7.

A modified Casela in which a simple constant-strength (von Mises) strength model was employed was also run using most of the models (Case $1 a^{\prime}$ ). This case was performed specifically to investigate intercode variability in strength model implementation and resolution dependence. In order to minimize intercode differences resulting from human analysis, $\beta$ as a function of time was calculated from iSALE simulation results in a similar manner to CTH results, rather than using tracer particle data. The instantaneous upward momentum of all material in the mesh above the preimpact surface was integrated and the momentum of any material leaving the mesh through the top boundary was accounted for. Crater size and momentum enhancement as a function of time were compared for each simulation. Results are shown in Figure 6, Figure 7, and in Table 11 and Table 12.

In this particular impact scenario, a significant portion of the uplifted crater rim acquires substantial upward momentum during cratering, before being decelerated to rest by the target's strength as crater growth is arrested. This acceleration and deceleration implies that the upward momentum $(\beta)$ of material above the surface first increases to a maximum, before decreasing 
632 asymptotically to the residual, ejected momentum. Figure 6 shows results of convergence studies 633 performed using the iSALE-2D code, CTH and Spheral. Note that for crater size, values converge 634 at a spatial resolution of approximately 10-20 cppr; however, convergence of the momentum 635 enhancement factor requires higher spatial resolution of around $20-40 \mathrm{cppr}$, depending on the code 636 used. This resolution sensitivity may be specific to this particular impact scenario, because the 637 strength values chosen for this set of simulations resulted in a low cratering efficiency and high638 speed ejecta, which often requires high resolution to track accurately. If the resolution of the 639 simulation is too low, the high-speed ejecta is not well resolved and hence the ejected momentum 640 is underestimated.

641 The von Mises strength model is simple and widely implemented across different codes 642 allowing for informative intermodel comparison. The values to be used in these simulations were 643 prescribed to the modelers (Table 5). Figure 7 shows results for simulations using CTH, iSALE644 2D, and Spheral. The highest resolution from Figure 6 for each code was plotted as a comparison. 645 The inter-code variability is low. Crater size predictions are within $5 \%$ of one another, with the 646 greatest difference between CTH and iSALE-2D crater depth predictions (5\%). The $\beta$ value 647 predictions vary more widely at $17 \%$ difference between the different codes (Table 10).

649 For Case 1a', three-dimensional simulations were also considered: $\mathrm{CTH}$ simulations were run at $6505 \mathrm{cppr}$ and Spheral simulations were also run at a variety of resolutions in 3D. In both cases, these 651 simulations predicted lower values for $\beta$ than the equivalent simulations in $2 \mathrm{D}$, though crater sizes 652 are similar. 

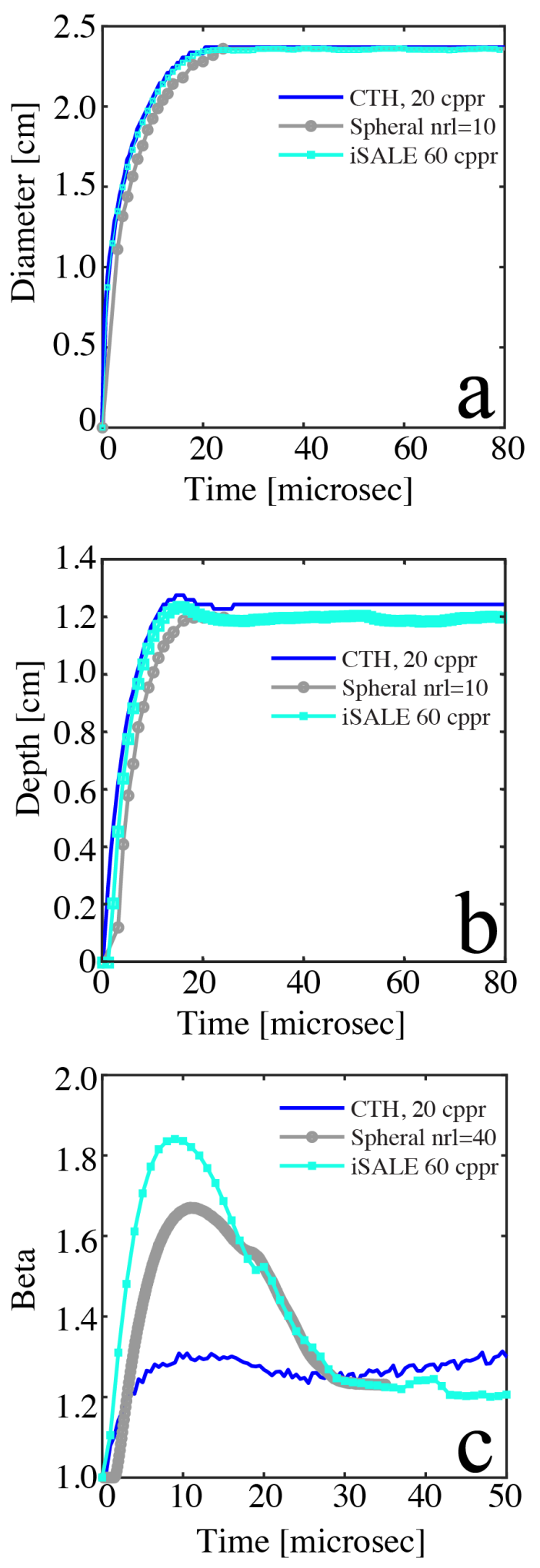

Figure 7. Comparisons of converged results between 2D simulations from CTH, iSALE-2D and 656 Spheral for Case 1a'. a) Crater diameter, b) depth, and c) $\beta$ for impacts into an aluminum block 657 with constant strength. All models are in 2D. 
Table 10. Results at end of simulation for CTH, iSALE and Spheral simulations simulating an impact into aluminum with constant strength. When a given result was not supplied by specific modelers, it is marked as "not provided" in the table.

662

663

664

665

666

\begin{tabular}{|c|c|c|c|c|c|c|c|}
\hline Model & Resolution & Case & Strength & Time [us] & $\begin{array}{c}\text { Crater } \\
\text { Depth } \\
{[\mathbf{c m}]}\end{array}$ & $\begin{array}{c}\text { Crater } \\
\text { Diameter } \\
{[\mathbf{c m}]}\end{array}$ & $\boldsymbol{\beta}$ \\
\hline CTH (2D) & $20 \mathrm{cppr}$ & $1 \mathrm{a}^{\prime}$ & von Mises & 100 & 1.25 & 2.37 & 1.49 \\
\hline $\begin{array}{c}\text { iSALE } \\
\text { (cell) }\end{array}$ & $60 \mathrm{cppr}$ & $1 \mathrm{a}^{\prime}$ & von Mises & 80 & 1.19 & 2.36 & 1.41 \\
\hline $\begin{array}{c}\text { Spheral } \\
(2 \mathrm{D})\end{array}$ & $\mathrm{nrI}=10$ & $1 \mathrm{a}^{\prime}$ & Von Mises & 35 & 1.2 & 2.36 & Not provided \\
\hline $\begin{array}{c}\text { Spheral } \\
(2 \mathrm{D})\end{array}$ & $\mathrm{nrI}=20$ & $1 \mathrm{a}^{\prime}$ & von Mises & 35 & $\begin{array}{c}\text { not } \\
\text { provided }\end{array}$ & $\begin{array}{c}\text { not } \\
\text { provided }\end{array}$ & 1.25 \\
\hline $\begin{array}{c}\text { Spheral } \\
(2 \mathrm{D})\end{array}$ & $\mathrm{nrI}=40$ & $1 \mathrm{a}^{\prime}$ & von Mises & 35 & $\begin{array}{c}\text { not } \\
\text { provided }\end{array}$ & $\begin{array}{c}\text { not } \\
\text { provided }\end{array}$ & 1.23 \\
\hline
\end{tabular}

Table 11. Summary of peak pressure with depth for CTH, Spheral, and iSALE models of impacts into a constant strength aluminum block. "diagonal" refers to tracers along a 45-deg diagonal from the impact point, while "vertical" refers to a vertical line directly below the impact point.

\begin{tabular}{|l|c|c|c|c|c|c|}
\hline $\begin{array}{l}\text { Case 1a von } \\
\text { Mises }\end{array}$ & & \multicolumn{6}{|c|}{ Peak Pressure [Gpa] } \\
\hline diagonal & depth $[\mathrm{cm}]$ & $\begin{array}{c}\text { CTH 5 } \\
\text { cppr }\end{array}$ & $\begin{array}{c}\text { CTH 10 } \\
\text { cppr }\end{array}$ & $\begin{array}{c}\text { CTH 20 } \\
\text { cppr }\end{array}$ & $\begin{array}{c}\text { Spheral } \\
n r I=4\end{array}$ & iSALE \\
\hline & 0.50 & 9.18 & 11.30 & 11.27 & 42.49 & 11.67 \\
\hline & 1.00 & 3.12 & 3.50 & 3.67 & 10.86 & 5.02 \\
\hline & 1.50 & 1.98 & 2.17 & 2.20 & 6.45 & 2.81 \\
\hline & 2.00 & 1.17 & 1.32 & 1.40 & 3.92 & 1.69 \\
\hline & 2.50 & 0.55 & 0.65 & 0.68 & 2.69 & 1.70 \\
\hline & 3.00 & 0.40 & 0.45 & 0.47 & 1.92 & 1.37 \\
\hline & 3.50 & 0.26 & 0.28 & 0.29 & 1.15 & 1.10 \\
\hline & 4.00 & 0.22 & 0.22 & 0.23 & 0.76 & 0.93 \\
\hline & 4.50 & 0.19 & 0.19 & 0.19 & 0.51 & 0.80 \\
\hline & 5.00 & 0.16 & 0.17 & 0.17 & 0.34 & 0.69 \\
\hline & & & \multicolumn{7}{|c|}{ Peak Pressure [Gpa] } & \\
\hline & & $C T H ~ 5$ & $C T H 10$ & $C T H 20$ & Spheral & \\
\hline & vertical & cppr & cppr & $n r I=4$ & $i S A L E$ \\
\hline & 0.00 & 0.00 & 0.00 & 26.50 & & \\
\hline & 0.50 & 13.22 & 13.71 & 14.00 & 43.19 & 16.84 \\
\hline & 1.00 & 6.73 & 7.38 & 7.86 & 19.26 & 9.07 \\
\hline & 1.50 & 4.29 & 5.27 & 5.23 & 8.73 & 5.68 \\
\hline
\end{tabular}




\begin{tabular}{|c|c|c|c|c|c|c|} 
& 2.00 & 2.63 & 2.77 & 3.11 & 4.75 & 4.00 \\
\hline & 2.50 & 1.51 & 1.69 & 1.72 & 2.96 & $\begin{array}{c}1.81(\text { at } \\
2.4)\end{array}$ \\
\hline & 3.00 & 1.14 & 1.37 & 1.45 & 2.15 & -- \\
\hline & 3.50 & 0.86 & 1.10 & 1.15 & 1.56 & -- \\
\hline & 4.00 & 0.74 & 0.88 & 0.93 & 1.00 & -- \\
\hline & 4.50 & 0.54 & 0.68 & 0.71 & 0.70 & -- \\
\hline & 5.00 & 0.41 & 0.47 & 0.48 & 0.48 & -- \\
\hline
\end{tabular}

667

668

669

670
671

672

673

674

675

676

677

678

679

680

681

682

683

684

685

686

687

688

689

690

691

692

693

694

695

Table 12. Slope of the pressure decay region for impacts into a constant strength aluminum block

\begin{tabular}{|c|c|c|c|c|c|}
\hline & $\begin{array}{c}\text { Slope } \\
\text { iSALE }\end{array}$ & $\begin{array}{c}\text { Slope } \\
\text { CTH 5 } \\
\text { cppr }\end{array}$ & $\begin{array}{c}\text { Slope } \\
\text { CTH 10 } \\
\text { cppr }\end{array}$ & $\begin{array}{c}\text { Slope } \\
\text { CTH 20 } \\
\text { cppr }\end{array}$ & Slope Spheral \\
\hline diagonal & -1.08 & -2.00 & -2.47 & -2.46 & -9.37 \\
\hline vertical & -7.91 & -2.85 & -2.94 & -3.01 & -9.49 \\
\hline
\end{tabular}

Peak pressure values were also calculated at depth below the impact point for simulations of impact into constant strength aluminum using results from CTH, iSALE, and Spheral (Figure 5, Table 11, Table 12). Pressures were calculated directly beneath the impact point and along a radial at $45^{\circ}$ below the impact point. The overall difference between the pressure values is not high, though the slope of the pressure-decay region in Spheral is significantly higher than in the other two codes. Both iSALE and Spheral predict high-slope pressure decay regions for a vertical line directly beneath the impact point. The pressure-decay slope increases slightly with resolution for CTH simulations.

\subsection{Case 1a modified - other strength models}

Additional simulations for impacts into an aluminum block with other strength models were also performed by most of the codes. These results are shown in Figure 8. Note here that iSALE used a Johnson-Cook [Johnson and Cook, 1983] plasticity model while PAGOSA and RAGE used a Steinberg-Guinan plasticity model [Steinburg et al., 1980] and CTH a von Mises model. At the pressures generated in a $5 \mathrm{~km} / \mathrm{s}$ impact, these material behaviors are similar, though not identical. CTH, RAGE, and PAGOSA also simulated this case at multiple resolutions. Here, all parameters of interest appear to converge around $20 \mathrm{cppr}$ resolution. There is significant variation in both crater size and predicted $\beta$ between the codes, with a total variation of $40 \%, 57 \%$ and $65 \%$ for crater depth, diameter, and $\beta$, respectively. The large range in $\beta$ is driven by the large values predicted by the RAGE code (Table 13 and Figure 8). Note that CTH and iSALE predict the closest values to one another (within 8\%); iSALE consistently predicts a larger crater. Interestingly, though the predicted crater size is different between CTH and PAGOSA (Figure 8 a,b), the predicted $\beta$ values are much more similar (30\% difference). 

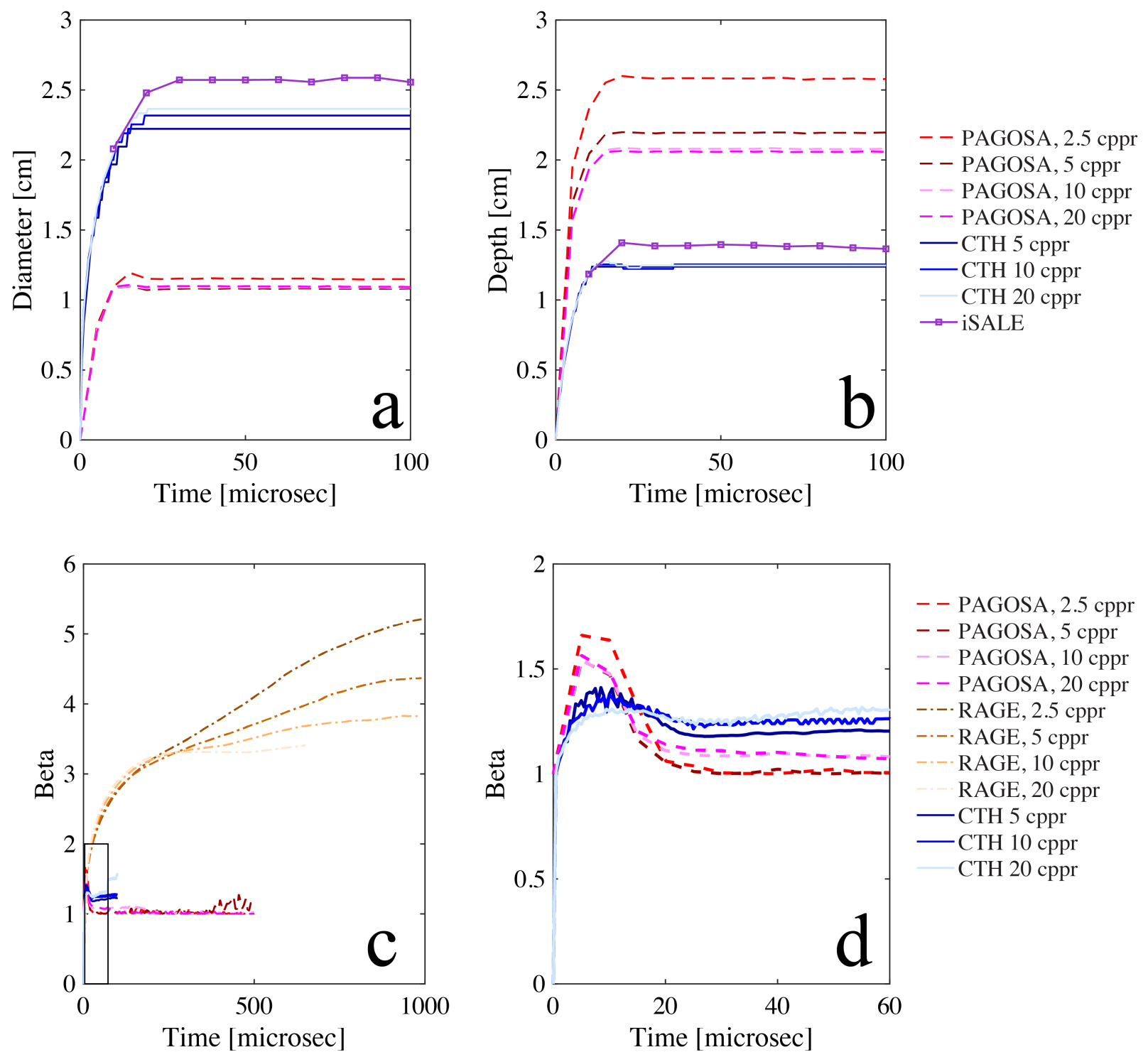

696

697

698

699

700

701

702

Figure 8. Impacts of a $1 / 4$ " aluminum projectile into an aluminum block at $5 \mathrm{~km} / \mathrm{s}$. a) crater diameter as a function of time, b) crater depth as a function of time, c) $\beta$ as a function of time, d) zoom of early-times of c. Region shown in (d) is denoted by a black box in panel c.

Table 13. Summary of crater size and predicted $\beta$ at 100 usec after impact. When a given result was not supplied by specific modelers, it is marked as "not provided" in the table.

\begin{tabular}{|c|c|c|c|c|c|c|c|}
\hline Model & Resolution & Case & Strength & $\begin{array}{c}\text { Time } \\
{[\mathbf{u s}]}\end{array}$ & $\begin{array}{c}\text { Crater } \\
\text { Depth } \\
{[\mathbf{c m}]}\end{array}$ & $\begin{array}{c}\text { Crater } \\
\text { Diameter } \\
{[\mathbf{c m}]}\end{array}$ & $\boldsymbol{\beta}$ \\
\hline iSALE & $40 \mathrm{cppr}$ & $1 \mathrm{a}$ & Johnson-Cook & 100 & 1.37 & 2.56 & $\begin{array}{c}\text { not } \\
\text { provided }\end{array}$ \\
\hline PAGOSA & $20 \mathrm{cppr}$ & $1 \mathrm{a}$ & $\begin{array}{c}\text { Steinburg- } \\
\text { Guinan }\end{array}$ & 100 & 2.06 & 1.09 & 1.03 \\
\hline
\end{tabular}




\begin{tabular}{|c|c|c|c|c|c|c|c|} 
RAGE & $20 \mathrm{cppr}$ & $1 \mathrm{a}$ & $\begin{array}{c}\text { Steinburg- } \\
\text { Guinan }\end{array}$ & 100 & $\begin{array}{c}\text { not } \\
\text { provided }\end{array}$ & $\begin{array}{c}\text { not } \\
\text { provided }\end{array}$ & 2.90 \\
\hline CTH (2D) & $20 \mathrm{cppr}$ & $1 \mathrm{a}^{\prime}$ & von Mises & 100 & 1.25 & 2.37 & 1.49 \\
\hline
\end{tabular}

\subsection{Case 2 -1/4” Sphere Impact into Basalt Block with Strength}

The second case was designed to test the effect of strength on the crater size and momentum enhancement for brittle materials. Previous benchmarking examined the effect of strength in metals [Pierazzo et al., 2008], but asteroids are not likely to be made solely of aluminum alloys. Further, the study of the strength of metals has been studied more extensively than brittle materials, and thus the number and sophistication of material models for ductile material within shock hydrocodes is greater than that for geologic materials, though most modern shock codes do include material models for a variety of geologic materials [e.g., Johnson et al., 1990; Walker and Anderson, 1992; Collins et al. 2004, 2011, 2014, Wünnemann et al. 2006 ; Ivanov et al. 1997 ; Melosh et al. 1992 ; Schultz and Crawford, 2016]. These models have a range of fidelity, and require differing amounts of a priori knowledge about the simulated material, however. Because the DART impact is small enough to be in the strength regime on a rocky asteroid, understanding the effect of brittle material models on crater size and $\beta$ prediction is important to be able to better interpret the results from the DART impact. Here, most of the codes examined impacts of $1 / 4$ " basalt projectile into a fully-dense basalt half-space with material strength. The results are shown in Figure 9 and Figure 10. Resolution studies were performed using iSALE and CTH in 2D, and Spheral in 3D. CTH simulations were also performed in 3D, but only at a resolution of $\sim 6 \mathrm{cppr}$ (using AMR). CTH simulations were performed using both the "geo" and the "BDL" strength models. Here, it appears that both crater size and $\beta$ converge at around $20 \mathrm{cppr}$ for most models.

General summaries of the results of these comparisons are seen in Table 14 and Table 15. Full comparisons are shown in Appendix B.

Table 14. Summary of results for CTH, iSALE and Spheral models in both 2D and 3D for Case 2.

\begin{tabular}{|c|c|c|c|c|c|c|c|}
\hline Model & Resolution & Case & Strength & Time [us] & $\begin{array}{c}\text { Crater } \\
\text { Depth } \\
{[\mathbf{c m}]}\end{array}$ & $\begin{array}{c}\text { Crater } \\
\text { Diameter } \\
{[\mathbf{c m}]}\end{array}$ & $\boldsymbol{\beta}$ \\
\hline CTH (2D) & $20 \mathrm{cppr}$ & 2 & geo & 100 & 2.06 & 5.03 & 3.48 \\
\hline CTH (2D) & $20 \mathrm{cppr}$ & 2 & geo & 400 & 1.90 & 7.41 & 6.54 \\
\hline CTH (2D) & $20 \mathrm{cppr}$ & 2 & BDL & 100 & 0.85 & 1.86 & 1.67 \\
\hline CTH (2D) & $20 \mathrm{cppr}$ & 2 & BDL & 300 & 1.04 & 2.56 & 1.56 \\
\hline $\begin{array}{c}\text { iSALE } \\
\text { (2D) }\end{array}$ & $40 \mathrm{cppr}$ & 2 & ROCK & 100 & 1.28 & 3.56 & 1.8 \\
\hline $\begin{array}{c}\text { iSALE } \\
\text { (2D) }\end{array}$ & $40 \mathrm{cppr}$ & 2 & ROCK & 308 & 1.21 & 4.61 & 2.25 \\
\hline & & & & & & & \\
\hline CTH (3D) & $6 \mathrm{cppr}$ & 2 & geo & 100 & 2.19 & 4.36 & 3.83 \\
\hline CTH (3D) & $6 \mathrm{cppr}$ & 2 & BDL & 100 & 0.86 & 1.78 & 1.60 \\
\hline
\end{tabular}




\begin{tabular}{|c|c|c|c|c|c|c|c|}
$\begin{array}{c}\text { Spheral } \\
\text { (3D) }\end{array}$ & $\operatorname{nrI}=7$ & 2 & von Mises & 100 & 3.24 & 7.03 & 5.87 \\
\hline CTH (3D) & $6 \mathrm{cppr}$ & 2 & geo & 500 & 2.06 & 6.00 & 5.49 \\
\hline CTH (3D) & $6 \mathrm{cppr}$ & 2 & BDL & 500 & 0.92 & 2.19 & 1.44 \\
\hline $\begin{array}{c}\text { Spheral } \\
\text { (3D) }\end{array}$ & $\mathrm{nrI}=7$ & 2 & von Mises & 400 & 3.24 & 7.03 & 11.06 \\
\hline
\end{tabular}

730

731

732

733

734

735

736

737

738

739

740

741

742

743

744

745

746

747

748

749

750

751

752

753

754

Results for iSALE simulations and the CTH BDL simulations (both at a resolution of $20 \mathrm{cppr}$ ) predict similar crater depths (14\% difference), though crater diameter exhibits a greater range (44\% difference). When the "geo" model is used, this difference between iSALE and CTH shifts to $95 \%$ and $42 \%$ for depth and diameter, respectively. This is likely because the BDL strength model in CTH is much more similar to the "ROCK" strength model in iSALE than the "geo" material model, while the "geo" model (as used here) is a more simplified plasticity model. Similarly to what was seen in Case 1, choice of strength model also affects predictions within one code. When comparing similar models in CTH using the "geo" and "BDL" strength models, values for crater depth, diameter, and $\beta$ range within a factor of 2-5 (120-280\%). This again illustrates the importance of choosing an appropriate, or consistent, plasticity model when calculating momentum transfer and crater size in the strength regime (Figure 10).

It is well documented that if a simulation is underresolved that the results are not necessarily accurate [e.g., Pierazzo, 2006]. This is consistent with what is seen when examining crater size and $\beta$ as a function of resolution (Table 15). In general, crater depth ranges from $\sim 1 \%-10 \%$ (except for one set of 2D CTH models), crater diameter predictions are within $\sim 5 \%$ of one another (again, except for one set of 2D CTH simulations), and $\beta$ predictions are generally within 2-13\% of one another as a function of resolution. Both $\mathrm{CTH}$ and Spheral have a set of simulations with a higher variation in $\beta$ than is seen in the other simulation sets.

Table 15. Summary of differences predicted by CTH, iSALE, and Spheral as a function of model resolution at various times in the calculation for Case 2. The range and percent difference in predicted values across all resolutions is summarized.

\begin{tabular}{|c|c|c|c|c|c|c|c|c|}
\hline Model & Strength & $\begin{array}{c}\text { Time } \\
{[\mathbf{u s}]}\end{array}$ & $\begin{array}{c}\text { Crater } \\
\text { Depth } \\
\text { Range } \\
\text { [cm] }\end{array}$ & $\begin{array}{c}\text { Crater } \\
\text { Diameter } \\
\text { Range } \\
{[\mathbf{c m}]}\end{array}$ & $\begin{array}{c}\boldsymbol{\beta} \\
\text { Range }\end{array}$ & $\begin{array}{c}\text { \% } \\
\text { Difference: } \\
\text { Diameter }\end{array}$ & $\begin{array}{c}\text { \% } \\
\text { Difference: } \\
\text { Depth }\end{array}$ & $\begin{array}{c}\% \\
\text { Difference: } \\
\boldsymbol{\beta}\end{array}$ \\
\hline $\begin{array}{c}\text { CTH } \\
(2 \mathrm{D})\end{array}$ & geo & 100 & 0.14 & 0.53 & 0.2 & 10.41 & 6.16 & 5.36 \\
\hline $\begin{array}{c}\text { CTH } \\
(2 \mathrm{D})\end{array}$ & geo & 400 & 0.48 & 1.38 & 1.26 & 18.63 & 20.33 & 19.26 \\
\hline $\begin{array}{c}\text { CTH } \\
(2 \mathrm{D})\end{array}$ & geo & 800 & 0.79 & 1.38 & 1.26 & 20.9 & 35.61 & 13.75 \\
\hline $\begin{array}{c}\text { CTH } \\
(2 \mathrm{D})\end{array}$ & BDL & 100 & 0.05 & 0.06 & 0.04 & 2.61 & 6.14 & 2.19 \\
\hline $\begin{array}{c}\text { CTH } \\
(2 \mathrm{D})\end{array}$ & BDL & 300 & 0.05 & 0.06 & 0.06 & 1.86 & 5.08 & 3.51 \\
\hline
\end{tabular}




\begin{tabular}{|c|c|c|c|c|c|c|c|c|}
$\begin{array}{c}\text { CTH } \\
(2 \mathrm{D})\end{array}$ & BDL & 500 & 0.05 & 0.07 & 0.07 & 1.69 & 6.41 & 4.13 \\
\hline $\begin{array}{c}\text { iSALE } \\
(2 \mathrm{D})\end{array}$ & ROCK & 100 & 0.01 & 0.13 & -- & 3.65 & 0.78 & -- \\
\hline $\begin{array}{c}\text { iSALE } \\
(2 \mathrm{D})\end{array}$ & ROCK & $\sim 300$ & 0.16 & 0.06 & -- & 3.47 & 4.72 & -- \\
\hline $\begin{array}{c}\text { Spheral } \\
(3 \mathrm{D})\end{array}$ & $\begin{array}{c}\text { von } \\
\text { Mises }\end{array}$ & 400 & 0.04 & 0.41 & 2.02 & 5.83 & 1.23 & 16.92 \\
\hline
\end{tabular}
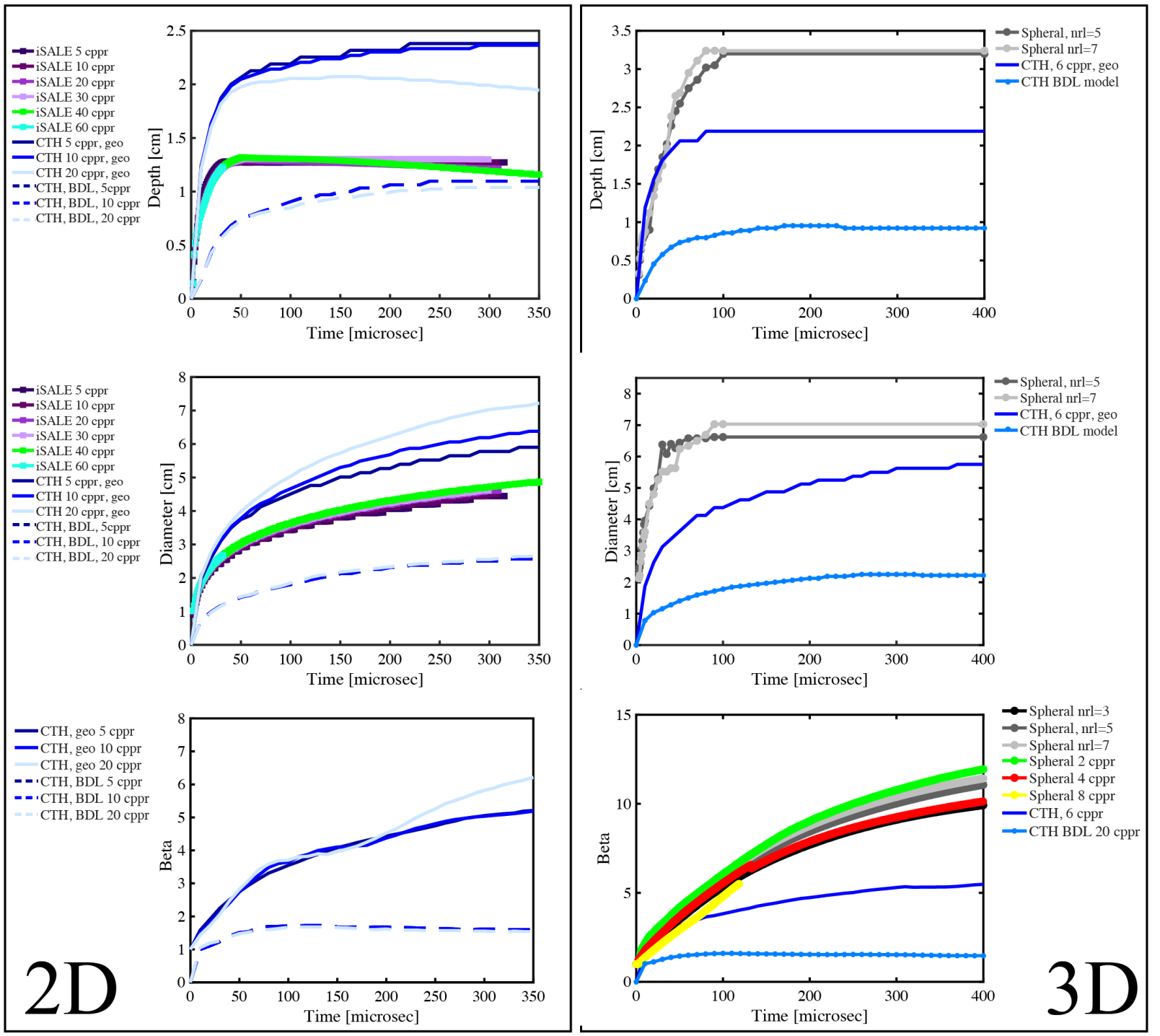

Figure 9. Results of convergence studies in 2D and 3D. Crater size and momentum enhancement predicted for impacts of $1 / 4$ " basalt projectile into a basalt half-space at $5 \mathrm{~km} / \mathrm{s}$. All simulations included material strength. (left) 2D simulation results for crater depth (top), diameter (middle) and $\beta$ (bottom) for iSALE and CTH simulations at a variety of resolutions. (right) 3D simulation 
results for crater depth (top), diameter (middle) and $\beta$ (bottom) for Spheral and CTH simulations at a variety of resolutions. Specific, high-resolution, 2D results are compared in Figure 10.
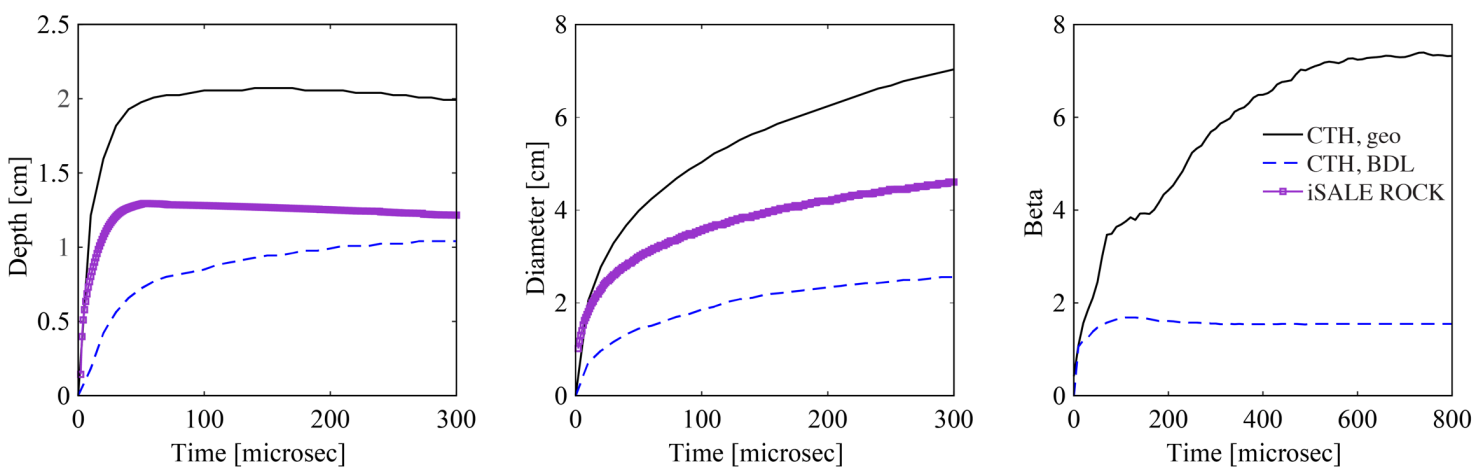

Figure 10. Crater depth (left), diameter (middle), and $\beta$ (right) for three different simulations of a $1 / 4$ " basalt impactor into a basalt half-space at $5 \mathrm{~km} / \mathrm{s}$ and $90^{\circ}$. All impact parameters are identical aside from the chosen strength model, and all simulations have similar resolution. The two models that have similar underlying physics, CTH BDL and iSALE "ROCK" result in similar craters. The generic pressure-dependent yield surface "geo" results in a substantially different crater size and much larger $\beta$.

\subsection{Case 3 - Effects of porosity}

The third benchmarking case was designed to investigate the effect of porosity models on the crater size and momentum enhancement predicted by each code. Natural geologic materials include porosity both within and between mineral grains (microporosity) and due to larger scale fractures, faults, and pore space within the material. Indeed, meteorite studies find porosities of 10-20\% [e.g., Britt et al, 2002] and many known small asteroids are estimated to have porosities greater than $20 \%$ [Britt et al., 2002]. Specific S-type asteroids are estimated to have porosities ranging from $15-25 \%$. Indeed, the target for the DART impact, 65803 Didymos is estimated to have a porosity of $\sim 18 \%-20 \%$. Therefore, it is vital to understand the ways in which porosity models affect the predicted impact effects.

Simulations at a variety of porosity values were performed using the CTH, iSALE, and Spheral codes. The results are shown in Figure 11, Figure 13, and Figure 14. Both 2-dimensional and 3dimensional simulations were performed using CTH (Figure 11, 12), while iSALE simulations are only in $2 \mathrm{D}$ and the Spheral simulations are only in $3 \mathrm{D}$. The values for $0 \%$ porosity are taken from results reported in Case 2. In general, simulations with higher porosity result in craters that are narrower and deeper that simulations with fully dense material (Figure 11). This is consistent across numerical codes. Two-dimensional models, such as those shown in Figure 11, exhibit centerline effects at the symmetry axis; here, the increased damage shown along the $\mathrm{x}=0$ line is an example. These effects can act to increase pressures and temperatures along the symmetry axis, as well as exaggerate crater rebound along the centerline. This is a result of the two-dimensional geometry, and is a well-known phenomenon. The only way to remove these sorts of effects is to perform three-dimensional simulations (e.g., Figure 12). Note that the centerline effects disappear 
in the 3D case. The crater shape is altered, and the 3D simulations predict a shallower crater than

iSALE
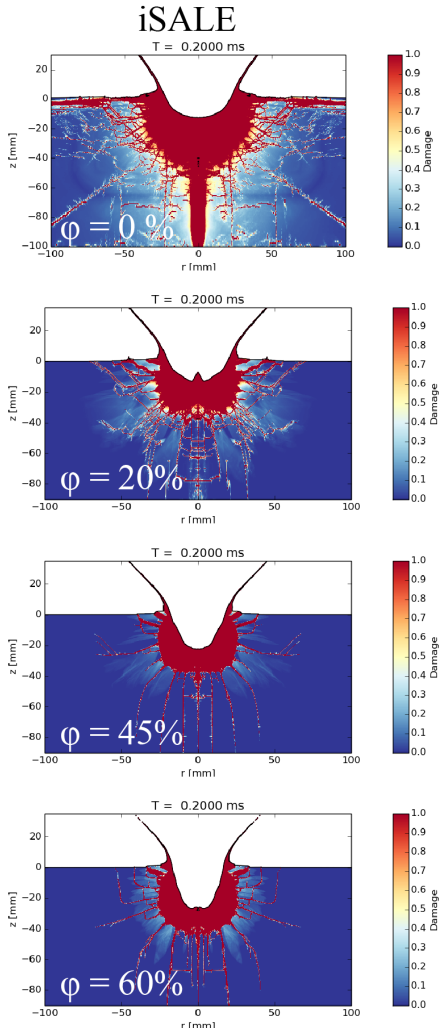
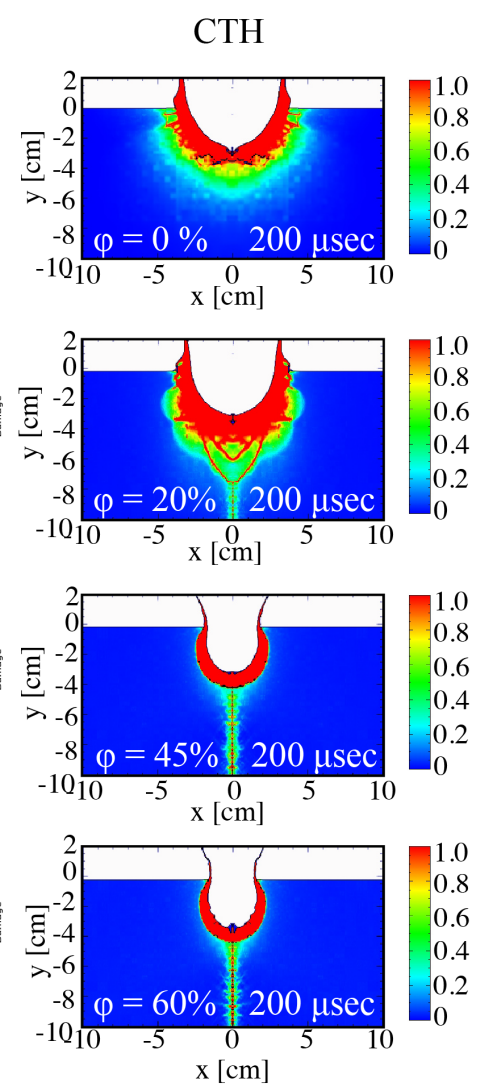
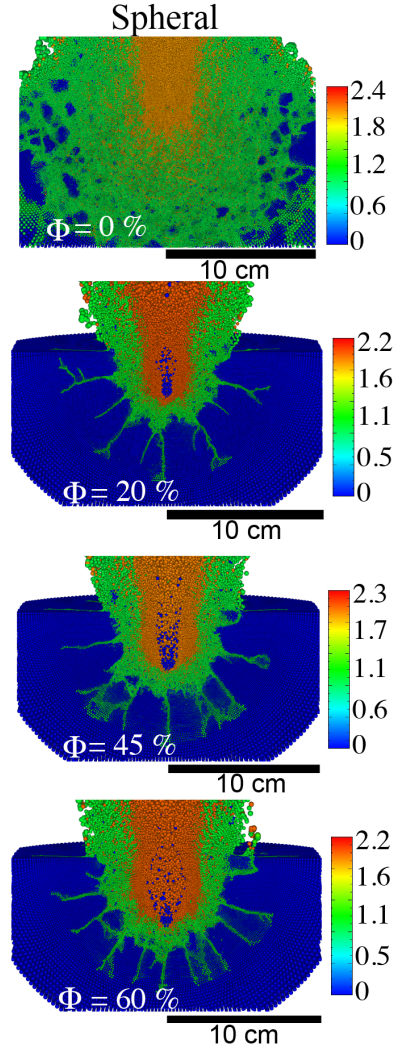

803

804

805

806

807

808

809

810

811

812

813

814

815

816

Figure 11. Crater and subsurface damage as a function of porosity. (left) 2D iSALE images, (center) 2D CTH images, (right) 3D Spheral images. All images are at 200 usec after impact. Color indicates damage, where pristine target material is represented by a value of 0.0 and fully damaged material is represented by a value of 1.0 in the scalar damage models (iSALE and CTH) and 3.0 in the tensor damage model (Spheral; trace of the damage tensor is shown). Centerline effects are seen at the symmetry axis in the 2D models. The domain size for the nonporous Spheral target extended $15 \mathrm{~cm}$ from the impact point, with an inner 9-cm region of uniformly high resolution (5 cppr), ratioing out to slightly coarser resolution near the edge of the hemispherical domain. The porous Spheral targets extended $12 \mathrm{~cm}$ from the impact point, with an inner 7-cm region of $5 \mathrm{cppr}$ resolution. Greater shock attenuation in the porous models decreases the domain size necessary for avoiding edge effects. The number of ASPH particles in each simulation ranged from 1.7 to 7.6 million. Note that the interior of the crater is filled with ejecta at this time (200 us) 


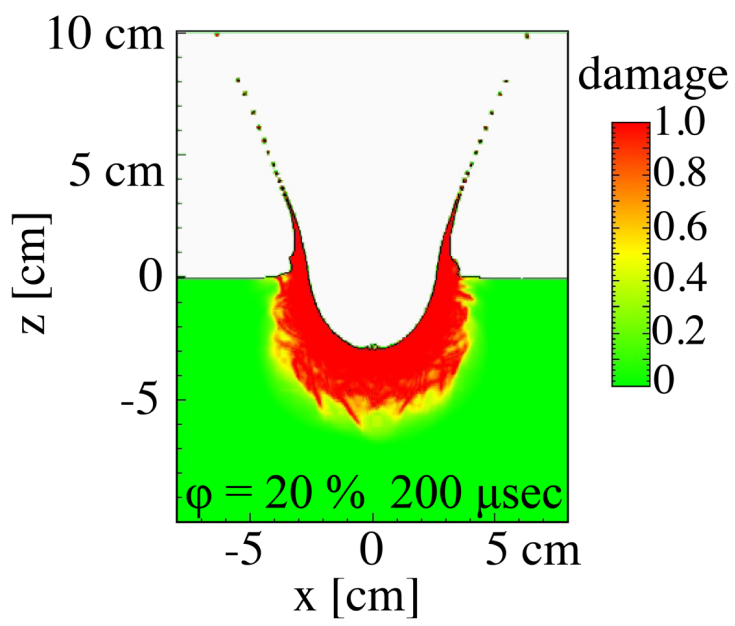

818 Figure 12. Three-dimensional CTH simulation, showing target damage at 200 usec after impact of a $1 / 4$ " projectile at $5 \mathrm{~km} / \mathrm{s}$. The target had $20 \%$ porosity. No centerline effects are apparent.

The addition of porosity models in the simulations results in increased scatter in the results from different codes (Table 16). Further, the scatter depends on the amount of porosity assumed. For a $20 \%$ porous target, at early times $(100 \mu \mathrm{sec}$ after impact $)$ the predicted crater diameter is the most consistent value across codes, with a 28\% difference among all simulations (including 2D and 3D). Crater depth and predicted momentum enhancement varied more significantly, with a $60-70 \%$ difference in prediction between codes. This is true for both 2D models compared against one another (iSALE to CTH) and for 3D models compared against one another (CTH to Spheral). In all comparisons, resolutions are similar across models with similar geometries (2D v. 3D), so the scatter is unlikely to be a resolution effect. This scatter decreases with increasing porosity. For a target with a $45 \%$ porosity, there is a $\sim 30 \%$ variation in crater depth across codes, while crater diameter and $\beta$ predictions are much more similar at $6 \%$ and $3.5 \%$ difference, respectively. When only looking at $2 \mathrm{D}$ models, crater depth varies by $\sim 25 \%$ while diameter varies by $2 \%$. At a target porosity of $60 \%$, the variability drops to $16 \%, 14 \%$, and $4 \%$ for predicted crater depth, diameter, and $\beta$, respectively.

For low values of porosity (0-20\%), CTH predicts wider craters than iSALE (Table 16, Figure 13). The difference in values narrows at higher porosities. The $\mathrm{CTH}$ simulations reported here almost uniformly predict deeper craters than similar iSALE simulations. This is likely due to strength model choice, as the "geo" and ROCK models are not identical in behavior (Figure 10).

Table 16. Summary of values for various target porosities. When a given result was not supplied by specific modelers, it is marked as "not provided" in the table. More complete summaries are shown in Appendix B.

\begin{tabular}{|c|c|c|c|c|c|c|c|c|}
\hline Model & Resolution & Case & Strength & Porosity & $\begin{array}{c}\text { Time } \\
\text { [us] }\end{array}$ & $\begin{array}{c}\text { Crater } \\
\text { Depth } \\
\text { [cm] }\end{array}$ & $\begin{array}{c}\text { Crater } \\
\text { Diameter } \\
\text { [cm] }\end{array}$ & $\boldsymbol{\beta}$ \\
\hline $\begin{array}{c}\text { Spheral } \\
\text { (3D) }\end{array}$ & $\operatorname{nrI}=5$ & 3 & $\begin{array}{c}\text { von } \\
\text { Mises }\end{array}$ & 20 & 100 & $\begin{array}{c}\text { not } \\
\text { provided }\end{array}$ & $\begin{array}{c}\text { not } \\
\text { provided }\end{array}$ & 1.31 \\
\hline
\end{tabular}




\begin{tabular}{|c|c|c|c|c|c|c|c|c|}
\hline iSALE & $40 \mathrm{cppr}$ & 3 & ROCK & 20 & 100 & 1.23 & 3.35 & 1.38 \\
\hline $\begin{array}{l}\text { CTH } \\
(2 \mathrm{D})\end{array}$ & $11 \mathrm{cppr}$ & 3 & geo & 20 & 100 & 3.29 & 4.66 & 2.68 \\
\hline $\begin{array}{l}\text { CTH } \\
(3 \mathrm{D})\end{array}$ & 5 cppr & 3 & geo & 20 & 100 & 2.84 & 4.51 & 3.05 \\
\hline iSALE & $40 \mathrm{cppr}$ & 3 & ROCK & 45 & 100 & 2.34 & 3.14 & 1.11 \\
\hline $\begin{array}{l}\text { CTH } \\
\text { (2D) }\end{array}$ & $11 \mathrm{cppr}$ & 3 & geo & 45 & 100 & 3.18 & 3.21 & 1.20 \\
\hline $\begin{array}{l}\text { CTH } \\
(3 \mathrm{D})\end{array}$ & 5 cppr & 3 & geo & 45 & 100 & 3.31 & 3.34 & 1.24 \\
\hline iSALE & $40 \mathrm{cppr}$ & 3 & ROCK & 60 & 100 & 2.89 & 2.87 & 1.05 \\
\hline $\begin{array}{l}\text { CTH } \\
\text { (2D) }\end{array}$ & $11 \mathrm{cppr}$ & 3 & geo & 60 & 100 & 3.46 & 2.74 & 1.10 \\
\hline $\begin{array}{l}\text { CTH } \\
(3 \mathrm{D})\end{array}$ & $5 \mathrm{cppr}$ & 3 & geo & 60 & 100 & 3.42 & 3.18 & 1.15 \\
\hline iSALE & $40 \mathrm{cppr}$ & 3 & ROCK & 20 & 200 & 0.71 & 3.87 & 1.51 \\
\hline $\begin{array}{l}\text { CTH } \\
(2 \mathrm{D}) \\
\end{array}$ & $11 \mathrm{cppr}$ & 3 & geo & 20 & 200 & 3.67 & 5.55 & 3.51 \\
\hline $\begin{array}{l}\text { CTH } \\
(3 \mathrm{D})\end{array}$ & 5 cppr & 3 & geo & 20 & 200 & 2.84 & 5.21 & 3.39 \\
\hline iSALE & $40 \mathrm{cppr}$ & 3 & ROCK & 45 & 200 & 2.24 & 3.54 & 1.17 \\
\hline $\begin{array}{l}\text { CTH } \\
(2 \mathrm{D})\end{array}$ & $11 \mathrm{cppr}$ & 3 & geo & 45 & 200 & 3.27 & 3.35 & 1.37 \\
\hline $\begin{array}{l}\text { CTH } \\
(3 \mathrm{D})\end{array}$ & 5 cppr & 3 & geo & 45 & 200 & 3.66 & 3.52 & 1.34 \\
\hline iSALE & $40 \mathrm{cppr}$ & 3 & ROCK & 60 & 200 & 2.80 & 3.32 & 1.08 \\
\hline $\begin{array}{l}\text { CTH } \\
(2 \mathrm{D}) \\
\end{array}$ & $11 \mathrm{cppr}$ & 3 & geo & 60 & 200 & 3.76 & 2.84 & 1.19 \\
\hline $\begin{array}{l}\text { CTH } \\
(3 \mathrm{D})\end{array}$ & $5 \mathrm{cppr}$ & 3 & geo & 60 & 200 & 3.80 & 3.33 & 1.19 \\
\hline
\end{tabular}


iSALE (2D)
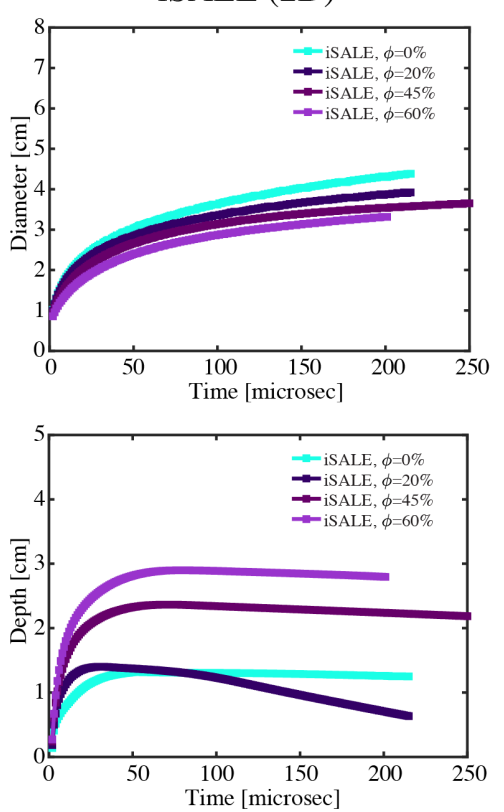

CTH (2D)
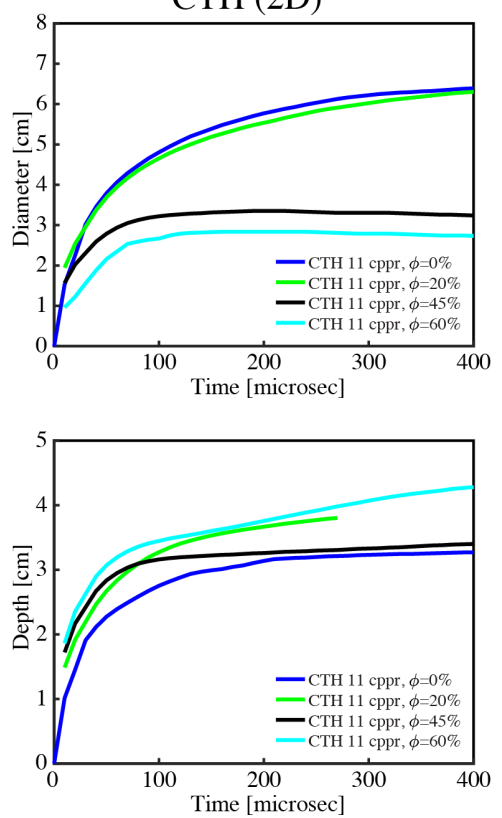

CTH (3D)
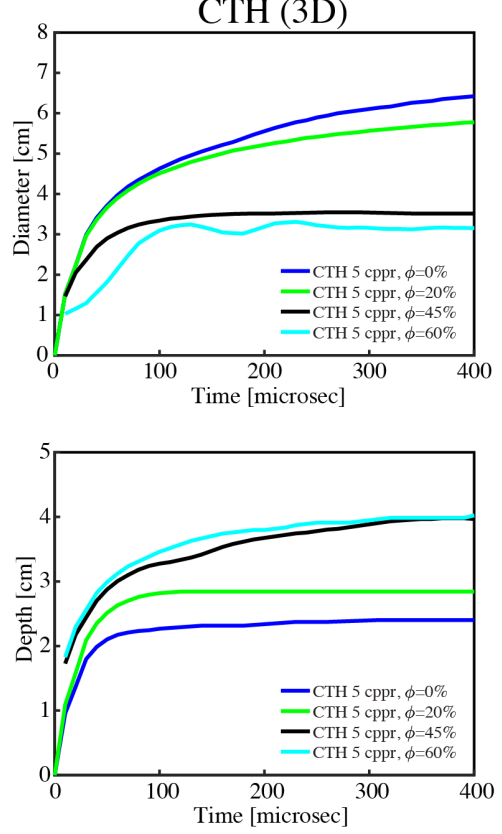

848

849

850

851

852

853

854

855

856

857

858

859

860

Figure 13. Crater diameter (top) and depth (bottom) at four different target porosities for iSALE (2D) and CTH (2D, 3D) simulations. Porosity has a large effect on crater shape and size.
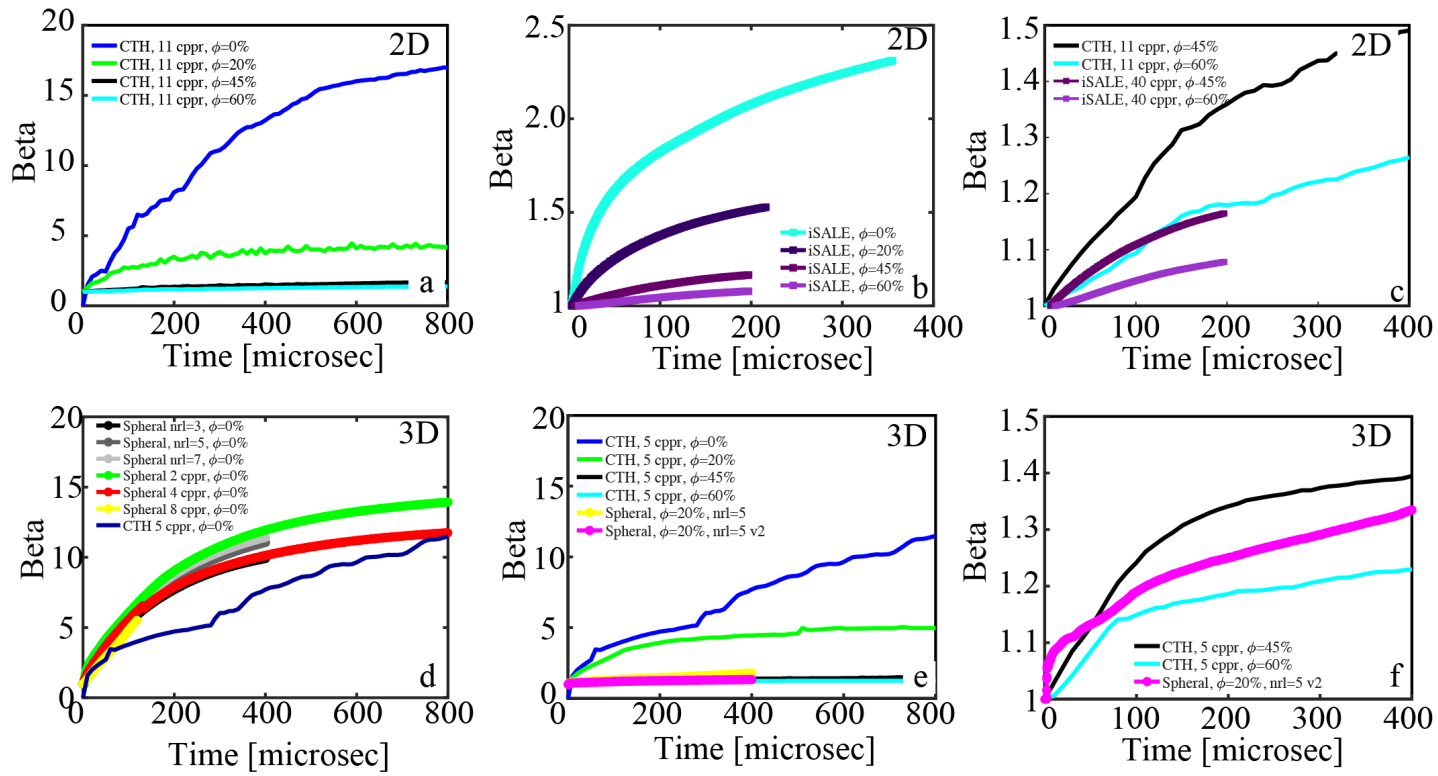

Figure 14. Comparison of $\beta$ as a function of porosity for (top) 2D simulations, (bottom) 3D and simulations. All simulations were of a vertical impact into a porous basalt block at $5 \mathrm{~km} / \mathrm{s}$. a) 2D $\mathrm{CTH}$ simulations showing momentum enhancement as a function of porosity. As porosity increases, $\beta$ decreases. b) 2D iSALE simulations as a function of porosity, showing a similar trend to CTH. Note the iSALE used the "ROCK" model here, while CTH simulations were done using the "geo" model, which can explain to lower values for $\beta$. c) Comparison of high porosities for 2D CTH and iSALE simulations. Though they give different results at low porosities, once the porosity increases enough both code give much more similar predictions. d) 3D CTH and Spheral 
simulations at zero porosity; e) 3D CTH and Spheral simulations showing $\beta$ as a function of porosity. Like in $2 \mathrm{D}, \beta$ decreases with increasing porosity. The magnitude of decrease is similar between 2D and 3D models. f) Comparison of $\beta$ predictions for high porosities from 3D CTH and Spheral simulations. The two codes use different material behavior and porosity model assumptions. Using $20 \%$ porosity in Spheral gives a result between the predictions for $45 \%$ and $60 \%$ porosity in $\mathrm{CTH}$.

The calculated momentum enhancement is also strongly dependent on the porosity of the target (Figure 14). This is expected because significant energy from the impact is expended in pore collapse and the amount of ejecta generated from an impact into a porous target is decreased compared to a more dense target. For 2D models (Figure $14 \mathrm{a}$-c), there is a significant difference $(\sim 4 \mathrm{X}$ at $200 \mu \mathrm{sec})$ between the momentum enhancement predicted by CTH and iSALE at porosities of $0-20 \%$. This is likely due to the differences in material models chosen; CTH used the "geo" model while iSALE used the "ROCK" model. This difference becomes less noticeable, however, as porosity becomes larger, though $\mathrm{CTH}$ still predicts higher momentum enhancement in this case (Figure 14c). There is also a noticeable difference (15-30\%) between the momentum enhancement predicted by 3D CTH and Spheral at the porosity most important for the DART impact ( 20\%). Some of this difference is likely due to the way that porosity is modeled in the codes: CTH used a p- $\alpha$ porosity model while Spheral used an $\varepsilon-\alpha$ approach.

\subsection{Case 4 - Impacts into basalt sphere}

Cases 1-3 involved impacts into a planar, half-space target. This is generally a reasonable assumption in situations such as the DART impact where the target size is much larger than the projectile. However, some target surface curvature may still be important during the DART impact due to the small size of Didymos-B. Case 4 was designed to better understand how target geometry may affect $\beta$, specifically for the case of a curved target versus a planar one. Simulations for Case 4 were performed using CTH, iSALE, and Spheral. A variety of strength models and porosity values were simulated (Figure 15 and Figure 16) in both 2D and 3D. As in Case 3, increased porosity results in deeper, narrower craters and lower $\beta$ values when all other parameters are kept constant (e.g., Table 17). A summary of results for CTH, iSALE, and Spheral simulations at 200 $\mu$ sec after impact is shown in Table 17; a full table is shown in Appendix B. Similarly to previous cases, when the strength model changes (e.g., using "geo" v. "BDL" in CTH, Figure 15), crater shape and size will differ much more dramatically. Momentum enhancement is still lower for increased porosity when different strength models are compared. There is not a large difference in $\beta$ values for comparable models between $2 \mathrm{D}$ and $3 \mathrm{D}$ simulations (Figure 16); this difference is more pronounced for crater size.

Table 17. Summary of values for crater depth, diameter, and $\beta$ at $200 \mu$ sec following impact for a variety of porosity values. When a given result was not supplied by specific modelers, it is marked as "not provided" in the table.

\begin{tabular}{|c|c|c|c|c|c|c|c|c|}
\hline Model & Resolution & Case & Strength & $\begin{array}{c}\text { Porosity } \\
{[\mathbf{\%}]}\end{array}$ & $\begin{array}{c}\text { Time } \\
{[\mathbf{u s}]}\end{array}$ & $\begin{array}{c}\text { Crater } \\
\text { Depth } \\
{[\mathbf{c m}]}\end{array}$ & $\begin{array}{c}\text { Crater } \\
\text { Diameter } \\
{[\mathbf{c m}]}\end{array}$ & $\boldsymbol{\beta}$ \\
\hline $\begin{array}{c}\text { CTH } \\
(2 \mathrm{D})\end{array}$ & $12 \mathrm{cppr}$ & 4 & geo & 0 & 200 & 3.09 & 7.48 & 4.43 \\
\hline
\end{tabular}




\begin{tabular}{|c|c|c|c|c|c|c|c|c|}
$\begin{array}{c}\text { CTH } \\
(2 \mathrm{D})\end{array}$ & $12 \mathrm{cppr}$ & 4 & geo & 20 & 200 & 2.74 & 5.23 & 2.44 \\
\hline $\begin{array}{c}\mathrm{CTH} \\
(2 \mathrm{D})\end{array}$ & $25 \mathrm{cppr}$ & 4 & BDL & 10 & 200 & 1.46 & 2.86 & 1.12 \\
\hline $\begin{array}{c}\mathrm{CTH} \\
(2 \mathrm{D})\end{array}$ & $25 \mathrm{cppr}$ & 4 & BDL & 20 & 200 & 1.63 & 2.74 & 1.06 \\
\hline $\begin{array}{c}\text { iSALE } \\
(2 \mathrm{D})\end{array}$ & $15 \mathrm{cppr}$ & 4 & ROCK & 20 & 200 & 1.15 & 4.19 & 1.44 \\
\hline $\begin{array}{c}\text { CTH } \\
(3 \mathrm{D})\end{array}$ & $3 \mathrm{cppr}$ & 4 & geo & 0 & 200 & 2.44 & 5.63 & 4.92 \\
\hline $\begin{array}{c}\text { CTH } \\
(3 \mathrm{D})\end{array}$ & $3 \mathrm{cppr}$ & 4 & geo & 20 & 200 & 1.31 & 2.13 & 1.13 \\
\hline $\begin{array}{c}\text { Spheral } \\
(3 \mathrm{D})\end{array}$ & $5 \mathrm{cppr}$ & 4 & $\begin{array}{c}\text { von } \\
\text { Mises }\end{array}$ & 20 & 200 & $\begin{array}{c}\text { not } \\
\text { provided }\end{array}$ & $\begin{array}{c}\text { not } \\
\text { provided }\end{array}$ & 1.51 \\
\hline
\end{tabular}

902

903
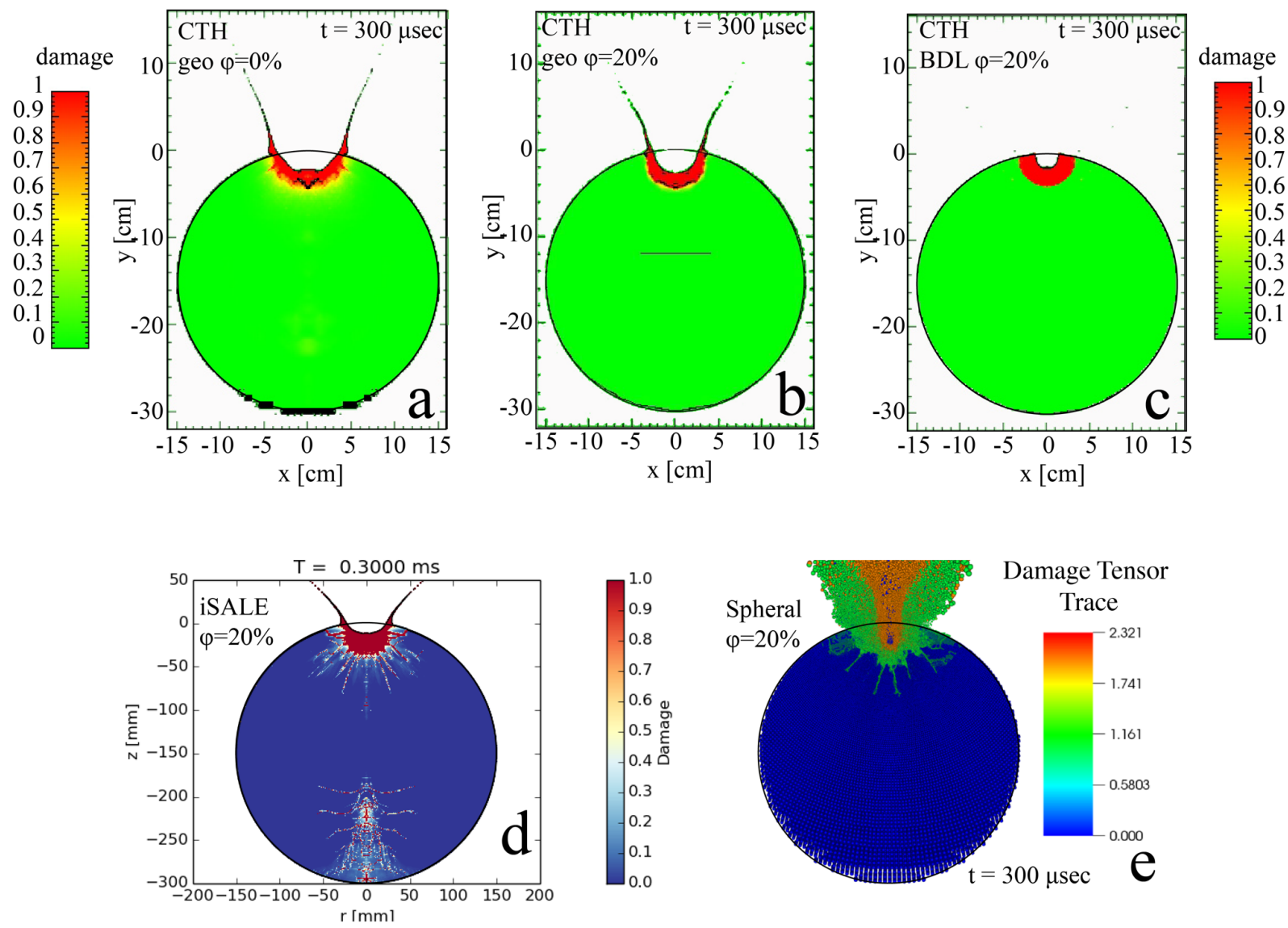

904

905

906

907

908

909

910
Figure 15. Images at $300 \mathrm{usec}$ after impact of a $1 / 4$ " projectile into a $30-\mathrm{cm}$ basalt sphere at $5 \mathrm{~km} / \mathrm{s}$ at normal incidence. CTH and iSALE simulations are 2D and Spheral simulation is 3D. a) image of damage from a CTH simulation using the "geo" strength model and assuming 0\% porosity; b) image of damage from a CTH simulation using the "geo" strength model and assuming 20\% porosity. Note that neither the "geo" model or the appended damage model are not designed to 
911 track fracture in a rigorous way so the subsurface fracturing is less apparent than in other 912 simulations; c) image of damage from a CTH simulation using the "BDL" strength model and 913 assuming 20\% porosity; d) image of damage from an iSALE simulation assuming 20\% porosity; 914 e) Spheral simulation using $20 \%$ porosity, showing the trace of the damage tensor.

915
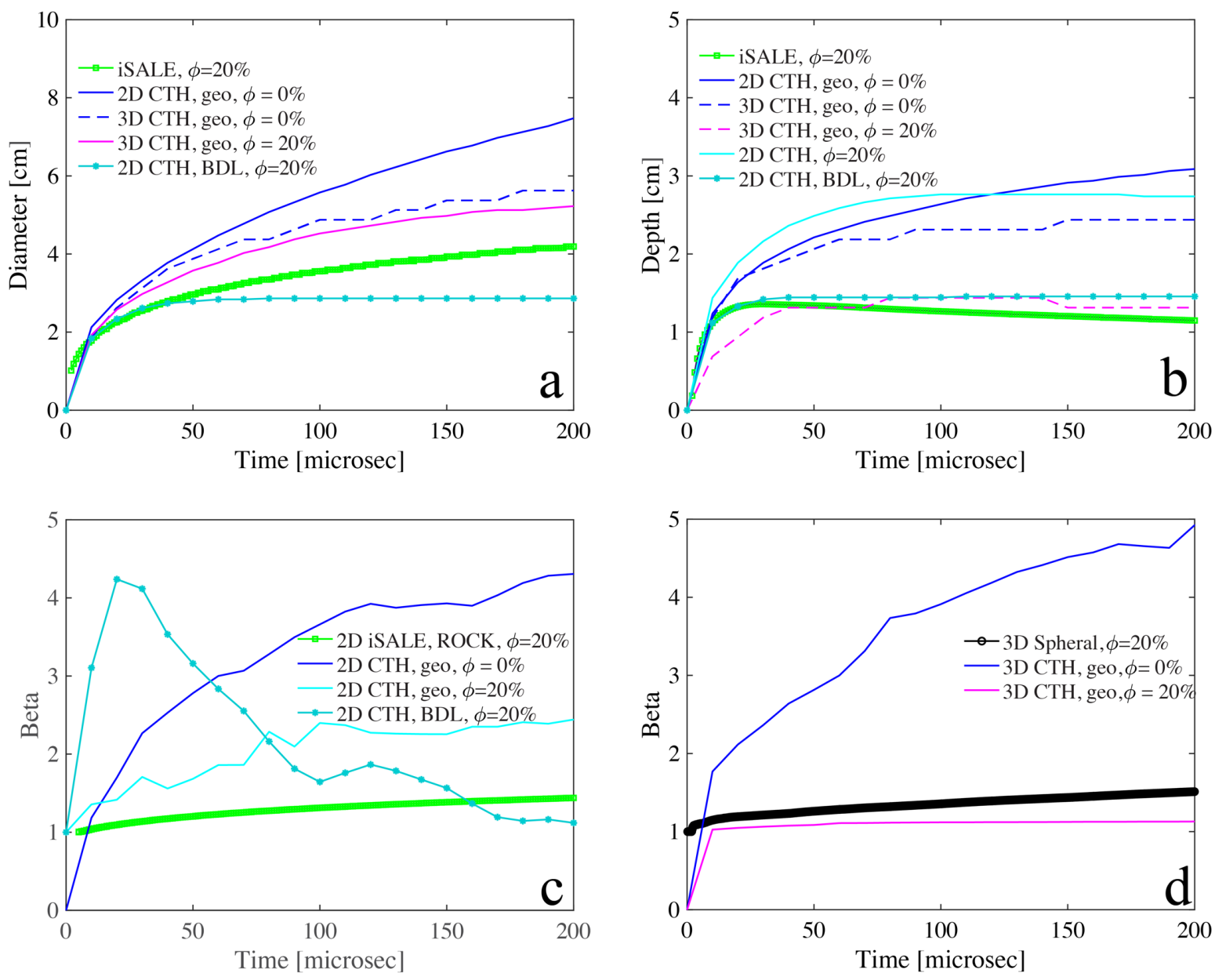

916

917

918

919

920

921

922

923

924

925

926

927

928

929

930

931

Figure 16. Graphs of a) crater diameter, b) crater depth, and c,d) momentum enhancement for a variety of simulations of an $1 / 4$ " sphere impacting into a basalt sphere at $5 \mathrm{~km} / \mathrm{s}$. c) 2D iSALE simulation for a $20 \%$ porous target compared with 3 different 2D CTH simulations using different strength models and simulating different target porosity; d) comparisons between 3D CTH and Spheral simulations.

When predicted values are compared across codes, there is some significant scatter. A lot of this is, again, due to differences in chosen strength models and porosity values (Figure $16 \mathrm{a}, \mathrm{b}$ ). When these parameters are held constant (or more similar), this scatter decreases but is still present (for example: Figure 16c, iSALE 'ROCK' compared with CTH 'BDL'). For instance, there is a $\sim 20 \%$ difference in predictions of crater diameter between 2D iSALE and CTH ("geo") simulations. Crater depth has a higher scatter, with an $\sim 140 \%$ difference in predictions. When the BDL model is used in CTH instead, this variation drops to $\sim 40 \%$ for in crater depth prediction and $\sim 35 \%$ in crater diameter prediction. As can be seen in Figure 16, the predicted $\beta$ value from CTH is highly dependent on both strength model choice and porosity. This holds true for 3D simulations as well. 
Comparisons between 3D CTH and 3D Spheral simulations show an $\sim 25 \%$ difference in predicted $\beta$ for a $20 \%$ porous target. This difference is much more pronounced when a fully dense target is assumed in CTH. These results suggest that plasticity and porosity model choices have a stronger effect on crater size and momentum enhancement predictions than target geometry (at this scale).

\section{7 Case 5 - Comparison to experiment}

Cases 1-4 were designed to benchmark various hydrocodes against one another. Case 5, however, was intended as a validation exercise. Code validation is defined as the process of testing results against known real-world situations. Often, the validity of a simulation is determined by choices in material modeling. Here, basic strength parameters and material characteristics as well as impact conditions were proscribed, but modelers were allowed to choose material models. For example, simulations using Spheral assumed that some natural porosity is been present in the sample ( $7 \%)$, and used a reference density of $3.01 \mathrm{~g} / \mathrm{cc}$ so that the bulk density of the block was $2.8 \mathrm{~g} / \mathrm{cc}$ (the measured value). Results for both CTH and Spheral are shown in Figure 18. These were compared against an experiment performed at the NASA Ames Vertical Gun Range, shown in Figure 17. Note that $\beta$ was not calculated for this experiment and so only final crater size and extent of fracturing was compared between the experiment and simulations (Table 18). Both codes performed well in this blind comparison. Simulations using CTH predicted crater width and depth between $1-11 \%$ and $35 \%$ different that the experiment, respectively. Simulations using Spheral predicted crater widths between $9-20 \%$ different than measured in the experiment and a diameter that was $43 \%$ different than the measured value. Both codes predicted damage regions roughly

954

955

956

957

958

959

960

961

962

963 consistent with those measured in the experiment.
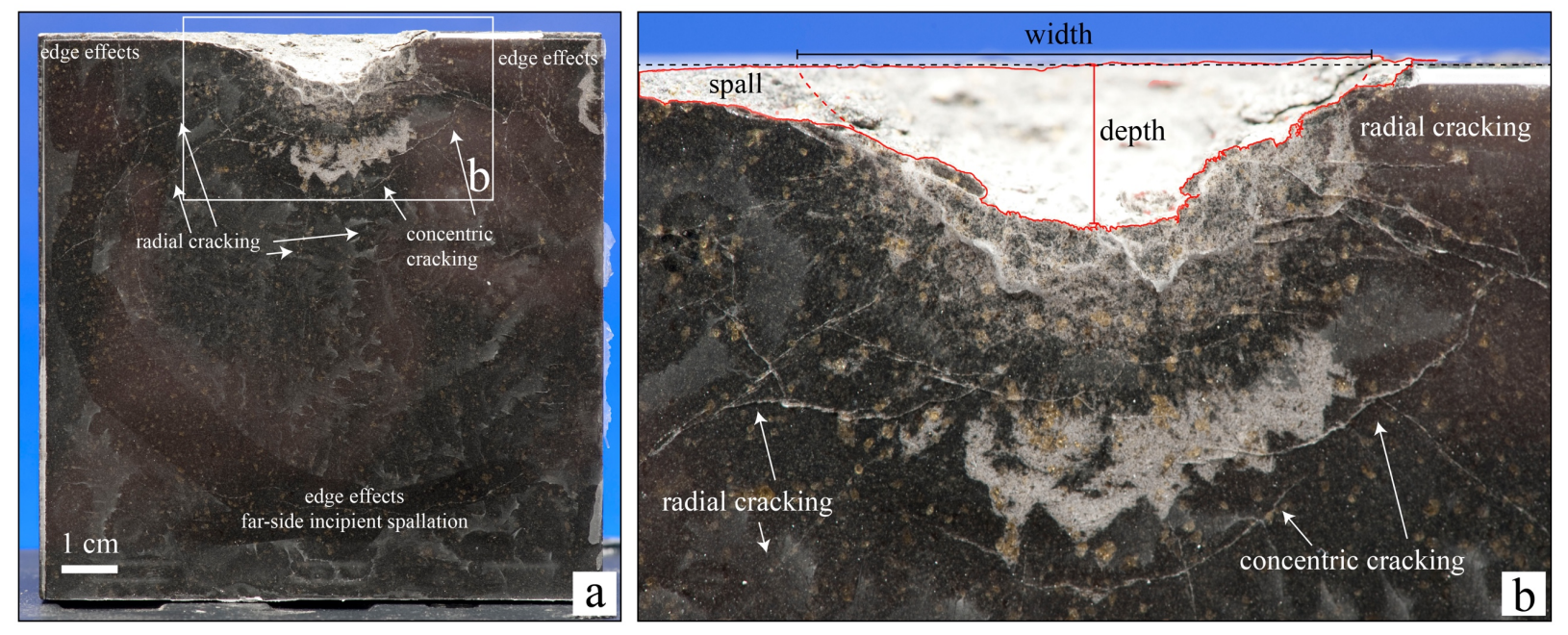

Figure 17. Middle plane of the experiment post-impact, showing crater and fracture patterns. The dirty appearance of the basalt is epoxy residue from where the PMMA window was removed. a) $10 \mathrm{~cm}$ x $10 \mathrm{~cm}$ face, along centerline of the crater. There are some edge effects seen in the upper corners as well as some incipient spallation at the farside of the block. These occurred after the crater was completely formed, and did not affect the final crater size or shape. b) close-up of the final crater, showing fracture pattern and crater size. The target was fractured in both the concentric and radial directions. The black dashed line shows the top surface of the block, the red outline denotes the final crater edges, and the dashed red line shows the approximate crater shape when 
964 the spallation is "removed". The locations where crater width and depth were measured are noted. 965 The olivine phenocrysts are clearly seen and are cut by fractures in some locations.

966
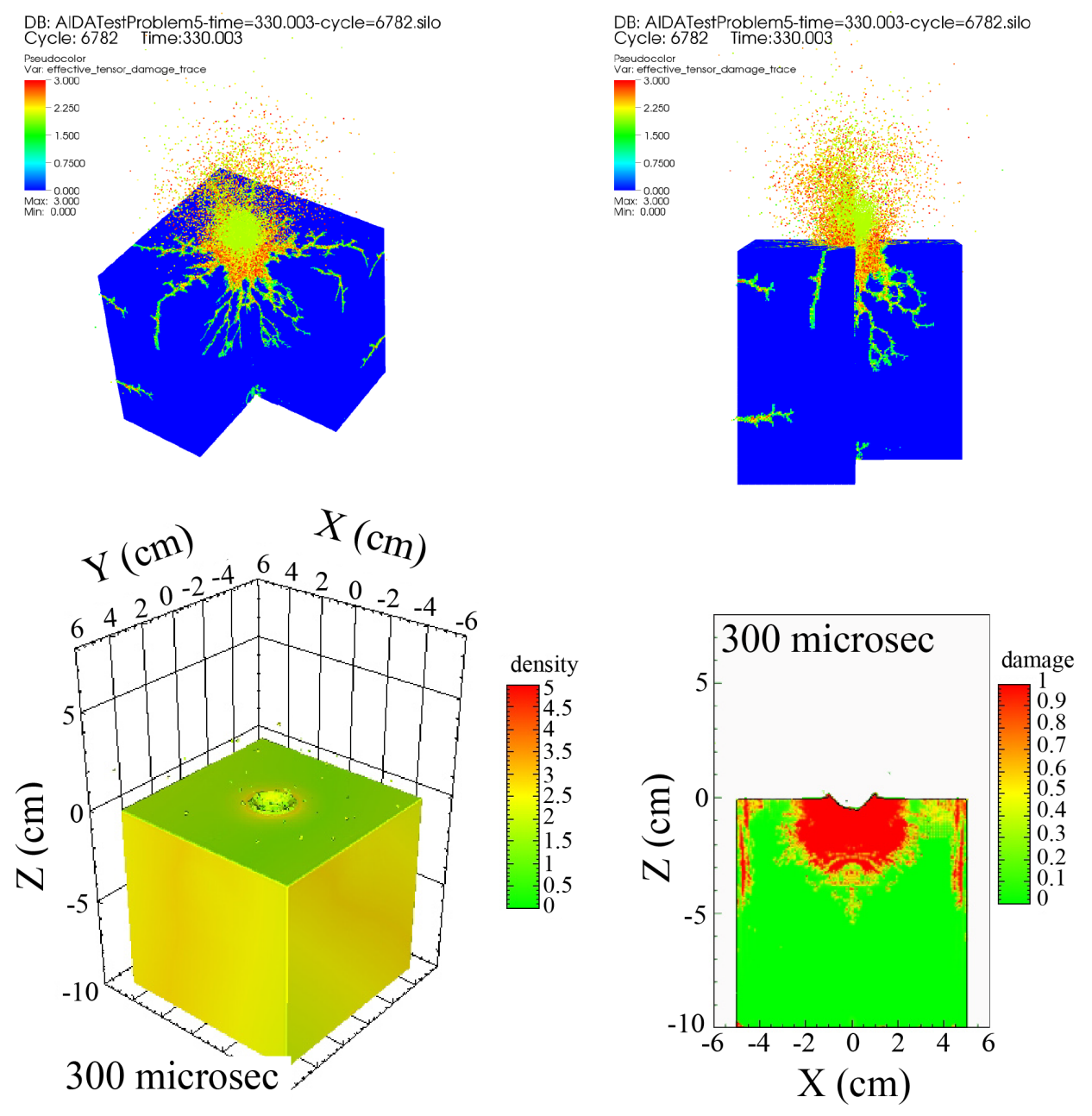

Figure 18. Results of simulations from Spheral (top) and CTH (bottom) simulations of a $1 / 4$ " Pyrex impactor into a $10-\mathrm{cm} \times 10-\mathrm{cm} \times 10-\mathrm{cm}$ basalt block at $2.1 \mathrm{~km} / \mathrm{s}$, showing crater size, density, and damage in the target at 300 microsec after impact. Both codes predict significant subsurface fracturing, which matches what was seen in the experiment.

974

Table 18. Summary results for CTH and Spheral blind comparisons to an AVGR experiment of a $2.1 \mathrm{~km} / \mathrm{s}$ impact into a basalt block

\begin{tabular}{|c|c|c|c|c|}
\hline & $\begin{array}{c}\text { Crater Width } \\
{[\mathrm{cm}]}\end{array}$ & Crater depth $[\mathrm{cm}]$ & $\begin{array}{l}\text { Concentric cracking } \\
\text { depth }[\mathrm{cm}] \\
(\text { approx })\end{array}$ & $\begin{array}{c}\text { radial } \\
\text { cracking } \\
\text { extent }[\mathrm{cm}] \\
(\text { approx })\end{array}$ \\
\hline $\begin{array}{c}\text { AVGR } \\
\text { experiment } \\
\mathbf{1 2 1 0 3 0}\end{array}$ & $\begin{array}{l}\text { 4.2, including } \\
\text { spall } \\
3.0-3.4, \\
\text { excluding spall }\end{array}$ & 0.90 & $\begin{array}{c}\sim 3 \mathrm{~cm} \text { below impact } \\
\text { point }\end{array}$ & 4.94 \\
\hline
\end{tabular}




\begin{tabular}{|c|c|c|c|c|}
$\begin{array}{c}\text { CTH Simulation } \\
\text { (330 usec) }\end{array}$ & 3.43, excl. spall & 1.4 & $3-3.5$ & 5.3 \\
\hline $\begin{array}{c}\text { Spheral } \\
\text { Simulation } \\
\text { (330 usec) }\end{array}$ & 2.72 & 1.6 & 2.5 & 5.6 \\
\hline
\end{tabular}

975

976

977

978

979

980

981

982

983

984

985

986

987

988

989

990

991

992

993

994

995

996

997

998

999

1000

1001

1002

1003

1004

1005

1006

1007

1008

1009

1010

1011

1012

1013

1014

1015

\section{Summary}

In support of the AIDA/DART mission, a benchmarking and validation exercise was completed to better understand the expected variability when calculating momentum enhancement and crater size using a variety of codes. This variability in prediction comes both from inherent differences between codes (e.g., type of mesh, types of material models) as well as variations in material models found in different codes. Though many of the codes used in this study had been previously benchmarked against one another for strengthless targets, and validated against experiments [Pierazzo et al., 2008], this was a new effort to determine how the codes compared in the strength regime of cratering.

Some key takeaway points from these comparisons are:

1. Prediction of momentum enhancement is highly resolution dependent, and may require higher resolutions to converge than crater size.

2. When similar strength models are used in different codes, predictions for crater size and momentum enhancement tend to be similar (within 15-20\%).

3. The choice of strength model, and the values used for material strength, are significantly more important in the prediction of crater size and momentum enhancement than variation between codes. Material models should be chosen appropriately for the specific applications being evaluated.

4. Material porosity can have large effects on the crater size and significantly affect $\beta$ predictions. Addition of porosity also results in increased scatter in the results from different codes. This is seen across codes.

5. There is a noticeable difference (15-30\%) between the momentum enhancement predicted by CTH and Spheral at porosities important for the DART impact ( 20\%), which is likely due to the specific porosity model implementations and how they differ in the two codes.

6. For impacts into strengthless targets, crater size shows the least variation between codes compared with momentum enhancement predictions. The variations are similar to what was seen in Pierazzo et al. [2008].

7. Hydrocode predictions of momentum enhancement almost uniformly shows a larger variation than linear predictions of crater size (depth and width). This may be due, in part, to contrasting target responses between codes.

8. Both CTH and Spheral performed well in the blind-comparison to an AVGR experiment. Predictions of crater size and extent of fracturing were between $10-40 \%$ different than the measured values.

The Impact Simulation Working Group includes members who use a variety of different codes to simulate the DART impact, including all those compared here. Initially, there was concern that the natural variability in the codes would increase the uncertainty in predicted crater size and 
momentum enhancement of Didymos-B from the DART impact. The comparisons shown here suggest that this is not the case. In fact, the variability in material model implementation and chosen strength and porosity parameters results in larger differences in predicted crater size and/or momentum enhancement than using different codes, which has a natural variability of $\sim 15 \%$ (e.g., Pierazzo et al., 2008; Case 1a, 1b). Simulation resolution also plays a large role in the consistency of prediction, especially when calculating momentum enhancement which requires a higher resolution to converge. These findings have implications for DART impact models and simulation approach. When using multiple codes, it is vital to select the appropriate (and available) material models for specific codes. One should also try to pick material models that are as consistent between different codes as possible. When different strength models are chosen in different codes, it becomes difficult to understand what causes the large variation in predictions. Alongside prescribing a specific material behavior, specific values for strength and resolution of simulations should be prescribed and an effort made to maintain them across the team. If equivalent simulations are done in CTH, iSALE, and Spheral using the "BDL", ROCK, and Collins damage models [Schultz and Crawford, 2016; Collins et al., 2004], respectively, we would expect variations consistent with what was seen in this study. If the three different codes are used to simulate impacts with varying conditions (e.g., modifying impact angle or target structure), any additional variability from that change can then be determined. The specific material model chosen must be consistent with the application being evaluated. For instance, an understanding of damage propagation may be obtained from most of the material models described above (e.g., Fig. 15), but fracture is better tracked using specific models, as seen in Figure 15d. The DART impact simulation team will determine a specific desired material parameter set appropriate for the Didymos system (including strength and porosity values) as part of the modeling effort, and this will be standardized (to the extent possible) across the different codes when making predictions for the DART mission. Some variation in predictions will still be expected, but that variation can be bracketed by the results shown here.

\section{Acknowledgements}

This study was partially funded by the NASA Double Asteroid Redirection Test. Thank you to everyone who volunteered their time to run simulations for this comparison and participate in discussions: Carolyn Ernst, Nancy Chabot, Cathy Plesko. N.G. and R.L. acknowledge the financial support by the DFG grant \#WU 355/6-2 (MEMIN FOR887). We gratefully acknowledge the developers of iSALE-2D, including Dirk Elbeshausen, Boris Ivanov, and Jay Melosh. iSALE: www.isale-code.de. P.M. acknowledges funding support by the European Space Agency (ESA). We thank the crew at the Ames Vertical Gun Range for their assistance in obtaining the experimental data, and two reviewers who provided comments and suggestions to strengthen the manuscript. Parts of this work were performed under the auspices of the U.S. Department of Energy by Lawrence Livermore National Laboratory under Contract DE-AC52- 07NA27344. LLNL-JRNL-769659-DRAFT. LA-UR-19-22134

\section{References}

A’Hearn, M.F. et al (2005) Deep Impact: Excavating Comet Tempel 1, Science, 310, 258 Amsden, A. A., Ruppel, H. M., \& Hirt, C. W. (1980). SALE: A simplified ALE computer program for fluid flow at all speeds (No. LA-8095). Los Alamos Scientific Lab., NM (USA). 
1061

1062

1063

1064

1065

1066

1067

1068

1069

1070

1071

1072

1073

1074

1075

1076

1077

1078

1079

1080

1081

1082

1083

1084

1085

1086

1087

1088

1089

1090

1091

1092

1093

1094

1095

1096

1097

1098

1099

1100

1101

1102

1103

1104

1105

1106

Benz, W., Asphaug, E. (1994), Impact Simulations with Fracture. I. Method and Tests, Icarus 107, pp. 98-116.

Benz, W., \& Asphaug, E. (1999). Catastrophic disruptions revisited. Icarus, 142(1), 5-20.

Board, S. S., \& National Research Council. (2010). Defending planet earth: Near-Earth-Object surveys and hazard mitigation strategies. National Academies Press.

Britt, D. T., Yeomans, D., Housen, K., \& Consolmagno, G. (2002). Asteroid Density, Porosity, and Structure. Asteroids III, 485-500.

Bruck Syal, M., Owen, J. M., Miller, P. L. (2016a), Deflection by kinetic impact: Sensitivity to asteroid properties, Icarus, 269, pp. 50-61. doi: 10.1016/j.icarus.2016.01.010.

Bruck Syal, M., Rovny, J., Owen, J. M., Miller, P. L. (2016b), Excavating Stickney crater at Phobos, Geophys. Res. Lett., 43, 10,595-10,601, doi: 10.1002/2016GL070749.

Buhl, E.; Poelchau, M. H.; Dresen, G.; Kenkmann, T., (2013) Deformation of dry and wet sandstone targets during hypervelocity impact experiments, as revealed from the MEMIN Program, Meteoritics \& Planetary Science 48(1), 71-86.

Byrne, R. N., T. Betlach, and M. L. Gittings. (1992) "RAGE: A 2D adaptive grid Eulerian nonequilibrium radiation code." DNA Numerical Methods Symposium (Defense Nuclear Agency, 28-30 April 1992).

Cheng, A. F., Rivkin, A. S., Michel, P., Atchison, J., Barnouin, O., Benner, L., ... \& Pravec, P. (2018). AIDA DART asteroid deflection test: Planetary defense and science objectives. Planetary and Space Science, 157, 104-115.

Colaprete A. et al (2010) Detection of water in the LCROSS ejecta plume. Science, 330, 463-468

Collins, G. S., H. J. Melosh, and B. A. Ivanov (2004), Modeling damage and deformation in impact simulations, Meteoritics and Planetary Science, 39, 2, 217-231.

Collins, G. S., Melosh, H. J., \& Wünnemann, K. (2011). Improvements to the $\varepsilon-\alpha$ porous compaction model for simulating impacts into high-porosity solar system objects.

International Journal of Impact Engineering, 38(6), 434-439.

Crawford, D. (1999). Adaptive mesh refinement in CTH (No. SAND99-1118C). Sandia National Laboratories (SNL), Albuquerque, NM, and Livermore, CA.

Crawford, D., P. Schultz, and S. Quintana (2013), A model of localized shear heating with implications for the morphology and paleomagnetism of complex craters, Large Meteorite Impacts and Planetary Evolution $V$.

Dunn, T.L., Burbine, T.H., Bottke, W., Clark, J.P., (2013) Mineralogies and source regions of near-Earth asteroids. Icarus 222, 273-282.

Gittings, M., Weaver, R., Clover, M., Betlach, T., et al.. (2008). The RAGE radiationhydrodynamic code. Computational Science \& Discovery, 1(1), 015005. doi:10.1088/17494699/1/1/015005.

Güldemeister, N., Wünnemann, K. Quantitative analysis of impact-induced seismic signals by numerical modeling (2017), Icarus 296, 15-27.

Güldemeister, N., Wünnemann, K., Poelchau, M.H. (2015) Scaling impact crater dimensions in cohesive rock by numerical modeling and laboratory experiments, Large Meteorite Impacts and Planetary Evolution V, Doi: https://doi.org/10.1130/2015.2518(02).

Heberling, T., Gisler, G., Plesko, C., and R. Weaver (2017) Calculaating the momentum enhancement factor for asteroid deflection studies, Procedia Engineering, 204, 124-129.

Ivanov, B. A., Deniem, D., \& Neukum, G. (1997). Implementation of dynamic strength models into 2D hydrocodes: Applications for atmospheric breakup and impact cratering. International Journal of Impact Engineering, 20(1-5), 411-430. 
Johnson, G.R.; Cook, W.H. (1983) A constitutive model and data for metals subjected to large strains, high strain rates and high, Proceedings of the 7th International Symposium on Ballistics, 541-547, retrieved 2009-05-13.

Johnson, G. R., \& Cook, W. H. (1985). Fracture characteristics of three metals subjected to various strains, strain rates, temperatures and pressures. Engineering fracture mechanics, 21(1), 31-48.

Johnson, G.R., Homlquist, T.J., Lankford, J., Anderson, C.E., and J. Walker (1990) A computational Constitutive Model and Test Data for Ceramics Subjected to Large Strains, High Strain Rates, and High Pressures, Honeywell, Inc., Final Technical Report, Contract DE-AC04-87AL-42550.

Kimberley, J., \& Ramesh, K. T. (2011). The dynamic strength of an ordinary chondrite. Meteoritics \& Planetary Science, 46(11), 1653-1669.

Luther, R.; Zhu, M.H.; Collins, G.S.; Wünnemann, K.; Effect of Target Properties and Impact Velocity on Ejection Dynamics and Ejecta Deposition (2018), Meteoritics \& Planetary Science 53 (8), 1705-1732.

Lyon, S. P., and Johnson, J. D. (1992) SESAME: The Los Alamos National Laboratory Equation of State Database, Los Alamos National Laboratory, Report No. LA-UR-92-3407.

McGlaun, J. M., Thompson, S. L., \& Elrick, M. G. (1990). CTH: a three-dimensional shock wave physics code. International Journal of Impact Engineering, 10(1-4), 351-360.

Melosh, H. J., Ryan, E. V., \& Asphaug, E. (1992). Dynamic fragmentation in impacts: Hydrocode simulation of laboratory impacts. Journal of Geophysical Research: Planets, 97(E9), 14735-14759.

Michel, P., Cheng, A., Küppers, M., Pravec, P., et al. (2016). Science case for the asteroid impact mission (AIM): a component of the asteroid impact \& deflection assessment (AIDA) mission. Advances in Space Research, 57(12), 2529-2547.

Michel, P., Kueppers, M., Sierks, H., Carnelli, I., et al.. (2018). European component of the AIDA mission to a binary asteroid: Characterization and interpretation of the impact of the DART mission. Advances in Space Research, 62(8), 2261-2272.

Nakamura, A., \& Fujiwara, A. (1991). Velocity distribution of fragments formed in a simulated collisional disruption. Icarus, 92(1), 132-146.

Naidu, S., Benner, L., Brozovic, M., Ostro, S.J., et al. (2016). Observations and Characterization of Binary Near-Earth Asteroid 65803 Didymos, the Target of the AIDA Mission. In $A G U$ Fall Meeting Abstracts.

O'Keefe, J. D., \& Ahrens, T. J. (1982). Cometary and meteorite swarm impact on planetary surfaces. Journal of Geophysical Research: Solid Earth, 87(B8), 6668-6680.

Owen, J. M., Villumsen, J.V., Shapiro, P.R., Martel, H. (1998) Adaptive smoothed particle hydrodynamics: Methodology. II Astrophys. J. Suppl. Ser., 116, pp. 155-209,

Owen, J. M. (2010), ASPH modeling of material damage and failure, Proceedings of the Fifth International SPHERIC Workshop, pp. 297-304.

Owen, J. M. (2014), A compatibly differenced total energy conserving form of SPH, Int. J. Numer. Methods Fluids, 75 (11), pp. 749-774.

Owen, J. M., Miller, P. L., Rovny, J., Wasem, J., Howley, K., Herbold, E. (2015), Asteroid Diversion Considerations and Comparisons of Diversion Techniques, Proc. Eng. 103, pp. 466-474. 
Pierazzo E. (2006) Numerical modeling of impact cratering. Proceedings, 1st International Conference on Impact Cratering in the Solar System. ESA Special Publication SP-612. pp. $115-122$.

Pierazzo, E., Artemieva, N., Asphaug, E., Baldwin, E. C., Cazamias, J., Coker, R., ... \& Holsapple, K. A. (2008). Validation of numerical codes for impact and explosion cratering: Impacts on strengthless and metal targets. Meteoritics \& Planetary Science, 43(12), 19171938. ) doi:10.1111/j.1945-5100.2008.tb00653.x.

Raducan, S.; Davison, T.M.; Luther, R.; Collins, G.S.; The Role of Asteroid Strength, Porosity and Internal Friction in Impact Momentum Transfer (2019), Icarus (submitted).

Schultz, P. H., Hermalyn, B., Colaprete, A., Ennico, K., Shirley, M., \& Marshall, W. S. (2010). The LCROSS cratering experiment. Science, 330(6003), 468-472.

Schultz, P. H., and D. A. Crawford (2016), Origin and implications of non-radial Imbrium Sculpture on the Moon, Nature, 535, 391-394.

Senft, L. E., and S. T. Stewart (2009), Dynamic fault weakening and the formation of large impact craters, Earth and Planetary Science Letters, 287, 471-482.

Steinberg, D. J, S. G. Cochran, and M. W. Guinan (1980) A constitutive model for metals applicable at high-strain rate, Journal of Applied Physics, 51(3).

Stickle, A. M., \& Schultz, P. H. (2013). Investigating pressure magnitudes at depth for oblique impacts into layered targets: Applications to terrestrial impacts in sedimentary targets. Meteoritics \& Planetary Science, 48(9), 1638-1650.

Sulsky, D., Chen, Z., \& Schreyer, H. L. (1994). A particle method for history-dependent materials. Computer methods in applied mechanics and engineering, 118(1-2), 179-196.

Tillotson, J. H. (1962). Metallic equations of state for hypervelocity impact (No. GA-3216). General dynamics San Diego CA General Atomic Div.

Walsh, K.J., Richardson, D.C., Michel, P., (2012) Spin-up of rubble-pile asteroids: Disruption, satellite formation, and equilibrium shapes, Icarus 220,514-529.

Walker, J.D., and C.E. Anderson (1990) Implementatino of the Johnson-Holmquist Ceramics Model into CTH, 4522/109, Southwest Research Institute, San Antonio, TX.

Weseloh, Wayne N., S. P. Clancy, and J. W. Painter, (2010) PAGOSA Physics Manual, Los Alamos National Laboratory, Report No. LAUR-14425- M .

Winkler, R.; Luther, R.; Poelchau, M. H.; Wünnemann, K.; Kenkmann, T., Subsurface deformation of experimental hypervelocity impacts in quartzite and marble targets (2018), Meteoritics \& Planetary Science 53(8), 1733-1755 doi: 10.1111/maps.13080.

Wünnemann, K., Collins, G. S., \& Melosh, H. J. (2006). A strain-based porosity model for use in hydrocode simulations of impacts and implications for transient crater growth in porous targets. Icarus, 180(2), 514-527.

Wünnemann, K.; Zhu, M.H.; Stöffler, D. (2016) Impacts into quartz sand: Crater formation, shock metamorphism, and ejecta distribution in laboratory experiments and numerical models, Meteoritics \& Planetary Science 51 (10), 1762-1794.

Zhu, M.H.; Wünnemann, K.; Potter, R.W.K. (2015)Numerical modeling of the ejecta distribution and formation of the Orientale basin on the Moon, Journal of Geophysical Research: Planets, 120, 2118-2134, doi:10.1002/2015JE004827.

Zwiessler, R.; Kenkmann, T.; Poelchau, M. H.; Nau, S.; Hess, S., (2017) On the use of a split Hopkinson pressure bar in structural geology: High strain rate deformation of Seeberger sandstone and Carrara marble under uniaxial compression, Journal of Structural Geology 97, 225-236. 


\section{Appendix A. Summary of parameters used in simulations}

Table A.1 Simulation parameters for CTH, Spheral, iSALE-2D, RAGE, and PAGOSA for Case 1a: $90^{\circ}$ impact of $0.635-\mathrm{cm}$ aluminum sphere into a strengthless aluminum half-space at $5 \mathrm{~km} / \mathrm{s}$.

\begin{tabular}{|c|c|c|c|c|c|c|c|c|}
\hline $\begin{array}{c}\text { Case 1a } \\
0.635 \text {-cm Al sphere } \\
\text { into strengthless } \mathrm{Al} \\
\text { halfspace } \\
\end{array}$ & Projectile & Target & Projectile EOS & Target EOS & $\begin{array}{c}\text { Projectile } \\
\text { Plasticity } \\
\text { Model }\end{array}$ & $\begin{array}{c}\text { Target } \\
\text { Plasticity } \\
\text { Model }\end{array}$ & $\begin{array}{l}\text { Resolution } \\
\text { (cppr or } \\
\text { equivalent) }\end{array}$ & Geometry \\
\hline CTH & $\begin{array}{l}\text { tensile strength } \\
\text { (pfrac): } 600 \mathrm{Mpa}\end{array}$ & $\begin{array}{c}\text { tensile strength (pfrac): } 600 \\
\mathrm{Mpa}\end{array}$ & Tillotson (see Table 3) & Tillotson (see Table 3) & none & none & $5,10,20$ & $2 \mathrm{DC}$ \\
\hline $\mathrm{CTH}$ & $\begin{array}{l}\text { tensile strength } \\
\text { (pfrac): } 600 \mathrm{Mpa}\end{array}$ & $\begin{array}{c}\text { tensile strength (pfrac): } 600 \\
\mathrm{Mpa}\end{array}$ & Tillotson (see Table 3) & Tillotson (see Table 3) & none & none & 3,5 & $3 \mathrm{D}$ \\
\hline Spheral & -- & -- & Tillotson (see Table 3 ) & Tillotson (see Table 3 ) & & & $5-7$ & $2 \mathrm{D}$ \\
\hline iSALE & -- & -- & Tillotson Al-1100 & Tillotson Al-1100 & none & none & 40 & $2 \mathrm{D}$ \\
\hline RAGE & -- & -- & Tillotson & Tillotson & none & none & $3,5,10,20$ & $2 \mathrm{D}$ \\
\hline PAGOSA & -- & -- & Tillotson & Tillotson & none & none & $3,5,10,20$ & $2 \mathrm{D}$ \\
\hline
\end{tabular}

Table A.2 Simulation parameters for CTH, Spheral, iSALE-2D, RAGE, and PAGOSA for Case 1a': $90^{\circ}$ impact of $0.635-\mathrm{cm}$ aluminum sphere into a constant-strength aluminum halfspace at $5 \mathrm{~km} / \mathrm{s}$.

\begin{tabular}{|c|c|c|c|c|c|c|}
\hline $\begin{array}{l}\text { Case } 1 \mathrm{a}^{\prime} \text { - constant } \\
\text { strength } \\
0.635-\mathrm{cm} \mathrm{Al} \text { sphere } \\
\text { into Al halfspace }\end{array}$ & Projectile EOS & Target EOS & Projectile Plasticity Model & $\begin{array}{c}\text { Target Plasticity } \\
\text { Model }\end{array}$ & $\begin{array}{l}\text { Resolution } \\
\text { (cppr or } \\
\text { equivalent) }\end{array}$ & Geometry \\
\hline CTH & Mie-Gruneisen Al-6061 & Mie-Gruneisen Al-6061 & $\begin{array}{c}\text { von Mises } \\
\text { Yield strength }=275 \mathrm{MPa} \\
\text { Poissons ratio }=0.33 \\
\text { Tmelt }=11604 \mathrm{~K} \\
\text { pfrac (tensile strength) }=600 \\
\mathrm{MPa}\end{array}$ & $\begin{array}{c}\text { von Mises } \\
\text { Yield strength }=275 \\
\text { MPa } \\
\text { Poissons ratio }=0.33 \\
\text { Tmelt }=11604 \mathrm{~K} \\
\text { pfrac (tensile strength) } \\
=600 \mathrm{MPa}\end{array}$ & 5,2020 & $2 \mathrm{D}$ \\
\hline $\mathrm{CTH}$ & Mie-Gruneisen Al-6061 & Mie-Gruneisen Al-6061 & $\begin{array}{c}\text { von Mises } \\
\text { Yield strength }=275 \mathrm{MPa} \\
\text { Poissons ratio }=0.33 \\
\text { Tmelt }=11604 \mathrm{~K} \\
\text { pfrac (tensile strength) }=600 \\
\mathrm{MPa}\end{array}$ & $\begin{array}{c}\text { von Mises } \\
\text { Yield strength }=275 \\
\text { MPa } \\
\text { Poissons ratio }=0.33 \\
\text { Tmelt }=11604 \mathrm{~K} \\
\text { pfrac (tensile strength) } \\
=600 \mathrm{MPa}\end{array}$ & 3,5 & 3D \\
\hline Spheral & Tillotson & Tillotson & $\begin{array}{c}\text { von Mises } \\
\text { Yield strength }=275 \mathrm{MPa} \\
\text { Poissons ratio }=0.33\end{array}$ & $\begin{array}{c}\text { von Mises } \\
\text { Yield strength }=275 \\
\text { MPa } \\
\text { Poissons ratio }=0.33\end{array}$ & 5 & 3D \\
\hline iSALE & & & $\begin{array}{c}\text { von Mises } \\
\text { equivalent stress }=275 \mathrm{MPa} \\
\text { Minimum pressure }=2.44 \mathrm{GPa}\end{array}$ & $\begin{array}{c}\text { von Mises } \\
\text { equivalent stress }=275 \\
\mathrm{MPa} \\
\text { Minimum pressure }= \\
2.44 \mathrm{GPa}\end{array}$ & $5,10,20,40,60$ & $2 \mathrm{D}$ \\
\hline RAGE & Tillotson & Tillotson & Steinburg-Guinan & Steinburg-Guinan & $3,5,10,20$ & $2 \mathrm{D}$ \\
\hline PAGOSA & Tillotson & Tillotson & Steinburg-Guinan & Steinburg-Guinan & $3,5,10,20$ & $2 \mathrm{D}$ \\
\hline
\end{tabular}


$1214 \mathbf{~ k m} / \mathbf{s}$. The Tillotson EOS with values for basalt is named "gabbroic anorthosite" in the CTH 1215 distribution, and labeled accordingly here.

\begin{tabular}{|c|c|c|c|c|c|c|}
\hline $\begin{array}{c}\text { Case } 1 \mathrm{~b} \\
0.635 \text {-cm basalt sphere } \\
\text { into strengthless basalt } \\
\text { halfspace }\end{array}$ & Projectile & Target & Projectile EOS & Target EOS & $\begin{array}{c}\text { Resolution } \\
\text { (cppr or } \\
\text { equivalent) }\end{array}$ & Geometry \\
\hline CTH & $\begin{array}{c}\text { spall strength }= \\
80 \mathrm{MPa}\end{array}$ & $\begin{array}{c}\text { spall strength }=80 \\
\mathrm{MPa}\end{array}$ & $\begin{array}{l}\text { Tillotson "Gabbroic Anorthosite" } \\
\begin{array}{c}\mathrm{R} 0=2.8 \quad * \mathrm{~g} / \mathrm{cc} \text {, fully dense basalt } \\
\mathrm{A}=2.67 \mathrm{E} 11 \quad * \mathrm{erg} / \mathrm{cc}=\text { dyne } / \mathrm{cm}^{\wedge} 2 \\
\mathrm{~B}=2.67 \mathrm{e} 11 \quad * \mathrm{erg} / \mathrm{cc}=\text { dyne } / \mathrm{cm}^{\wedge} 2 \\
\mathrm{~A} 0=0.5 \quad * \text { (default value) } \\
\mathrm{B} 0=1.50 \quad * \text { (default value) } \\
\mathrm{ALFA}=5.0 \quad * \text { (default value) } \\
\mathrm{BET}=5.0 \quad * \text { (default value) } \\
\mathrm{EIV}=4.72 \mathrm{e} 10 * \mathrm{erg} / \mathrm{g} \text { (default value) } \\
\mathrm{ECV}=1.82 \mathrm{e} 11 * \mathrm{erg} / \mathrm{g} \text { (default value) } \\
\mathrm{E} 0=4.87 \mathrm{e} 12 \quad * \mathrm{erg} / \mathrm{g} \text { (default value) }\end{array}\end{array}$ & $\begin{array}{c}\text { Tillotson "Gabbroic Anorthosite" } \\
\begin{array}{cc}\mathrm{R} 0=2.8 \quad * \mathrm{~g} / \mathrm{cc}, \text { fully dense basalt } \\
\mathrm{A}=2.67 \mathrm{E} 11 & * \mathrm{erg} / \mathrm{cc}=\text { dyne } / \mathrm{cm}^{\wedge} 2 \\
\mathrm{~B}=2.67 \mathrm{e} 11 & * \mathrm{erg} / \mathrm{cc}=\text { dyne } / \mathrm{cm}^{\wedge} 2 \\
\mathrm{~A} 0=0.5 & * \text { (default value) } \\
\mathrm{B} 0=1.50 & * \text { (default value) } \\
\mathrm{ALFA}=5.0 & * \text { (default value) } \\
\mathrm{BET}=5.0 & * \text { (default value) } \\
\mathrm{EIV}=4.72 \mathrm{e} 10 & * \mathrm{erg} / \mathrm{g} \text { (default value) } \\
\mathrm{ECV}=1.82 \mathrm{e} 11 & * \mathrm{erg} / \mathrm{g} \text { (default value) } \\
\mathrm{E} 0=4.87 \mathrm{e} 12 & * \mathrm{erg} / \mathrm{g} \text { (default value) }\end{array}\end{array}$ & 5 & $2 \mathrm{DC}$ \\
\hline $\mathrm{CTH}$ & $\begin{array}{c}\text { spall strength }= \\
80 \mathrm{MPa}\end{array}$ & $\begin{array}{c}\text { spall strength }=80 \\
\mathrm{MPa}\end{array}$ & $\begin{array}{c}\text { Tillotson "Gabbroic Anorthosite" } \\
\text { R0=2.8 } \quad * \mathrm{~g} / \mathrm{cc} \text {, fully dense basalt } \\
\mathrm{A}=2.67 \mathrm{E} 11 \quad * \mathrm{erg} / \mathrm{cc}=\text { dyne } / \mathrm{cm}^{\wedge} 2 \\
\mathrm{~B}=2.67 \mathrm{e} 11 \quad * \mathrm{erg} / \mathrm{cc}=\text { dyne } / \mathrm{cm}^{\wedge} 2 \\
\mathrm{~A} 0=0.5 \quad * \text { (default value) } \\
\mathrm{B} 0=1.50 \quad * \text { (default value) } \\
\mathrm{ALFA}=5.0 \quad * \text { (default value) } \\
\mathrm{BET}=5.0 \quad * \text { (default value) } \\
\mathrm{EIV}=4.72 \mathrm{e} 10 * \mathrm{erg} / \mathrm{g} \text { (default value) } \\
\mathrm{ECV}=1.82 \mathrm{e} 11 \quad * \mathrm{erg} / \mathrm{g} \text { (default value) } \\
\mathrm{E} 0=4.87 \mathrm{e} 12 \quad * \mathrm{erg} / \mathrm{g} \text { (default value) }\end{array}$ & 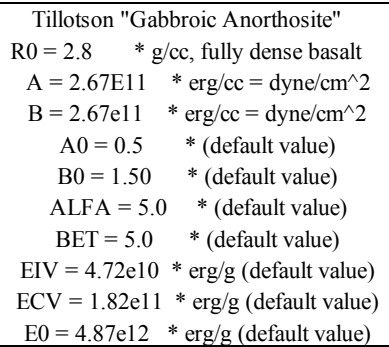 & 5 & $3 \mathrm{DR}$ \\
\hline Spheral & & & Tillotson (see Table 3) & Tillotson (see Table 3) & $5-7$ & 3DR \\
\hline RAGE & & & Tillotson & Tillotson & & \\
\hline PAGOSA & & & Tillotson & Tillotson & & \\
\hline
\end{tabular}


Table A.4 Simulation parameters for CTH, Spheral, iSALE-2D, RAGE, and PAGOSA for Case 2: $90^{\circ}$ impact of 0.635-cm basalt sphere into a basalt half-space at $5 \mathrm{~km} / \mathrm{s}$. The Tillotson EOS with values for basalt is named "gabbroic anorthosite" in the CTH distribution, and labeled accordingly here.

\begin{tabular}{|c|c|c|c|c|c|c|c|c|}
\hline $\begin{array}{c}\text { Case } 2 \\
0.635 \text {-cm basalt } \\
\text { sphere into basalt } \\
\text { halfspace }\end{array}$ & Projectile EOS & Target EOS & Projectile Plasticity Model & Target Plasticity Model & Damage model & $\begin{array}{l}\begin{array}{c}\text { Porosity } \\
\text { Model }\end{array} \\
\text {. }\end{array}$ & $\begin{array}{c}\text { Resolution } \\
\text { (cppr or } \\
\text { equivalent) }\end{array}$ & Geometry \\
\hline СТH & 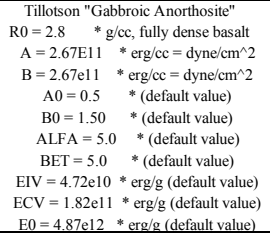 & 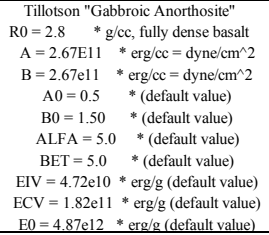 & $\begin{array}{c}\text { Pressure-dependent Yield } \\
\text { Yield }=1 \mathrm{GPa} \text {, poisson }=0.25, \text { dydp }=0.5, \\
\text { yzero }=40 \mathrm{MPa}\end{array}$ & $\begin{array}{c}\text { Pressure-dependent Yield } \\
\text { Yield }=1 \text { G PFa, poisson }=0.25 \text {, dydp }= \\
0.5 \text {, yzero }=40 \mathrm{MPa}\end{array}$ & $\begin{array}{c}\text { Johnson-Cook Fracture } \\
\text { D1 =0.05, Tmelt }=0.16 \text { e ev, } \\
\text { JFPF0 }=-80 \text { Ma, weibull } \\
\text { Modulus }=10\end{array}$ & none & $5,10,20$ & $2 \mathrm{DC}$ \\
\hline СТн & 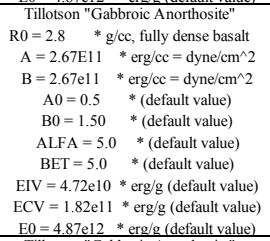 & 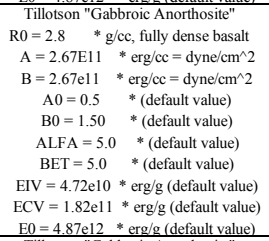 & $\begin{array}{c}\text { Pressure-dependent Yield } \\
\text { Yield }=1 \text { G PPa, poisson }=0.25, \text { dydp }=0.5, \\
\text { yzero }=40 \mathrm{Mpa} \text {, prac }=80 \mathrm{MPa}\end{array}$ & $\begin{array}{c}\text { Pressure-dependent Yield } \\
\text { Yield }=1 \text { GPa, poisson }=0.25 \text {, dydp }= \\
0.5 \text {, yzero }=40 \mathrm{MPa}\end{array}$ & $\begin{array}{c}\text { Johnson-Cook Fracture } \\
\text { D1 }=0.05 \text {, Tmelt }=0.16 \text { evv, } \\
\text { JFPF0 }=-80 \text { Mara, weibull } \\
\text { Modulus }=10\end{array}$ & none & 5 & 3D \\
\hline СтH & 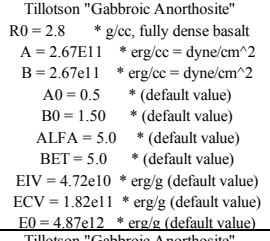 & 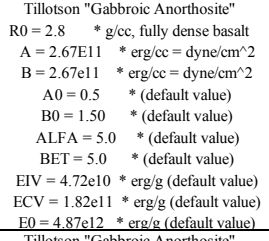 & $\begin{array}{c}\text { Brittle Damage with Localized Thermal } \\
\text { Softening (BDL) } \\
\text { pfrac }=80 \mathrm{MPa} \\
\mathrm{Y} 0=36.4 \mathrm{MPa}, \mathrm{YM}=2.4 \mathrm{GPa}, \mathrm{CFI}=1.8 .8, \\
\mathrm{CFD}=0.6, \mathrm{PBD}=4.91 \mathrm{GPa}, \mathrm{PBP} 1=9.38 \\
\text { GPa, PBP2 }=18.75 \mathrm{GPa}\end{array}$ & 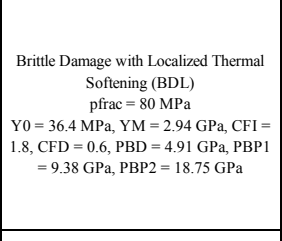 & BDL & none & $5,10,20$ & $2 \mathrm{DC}$ \\
\hline стн & 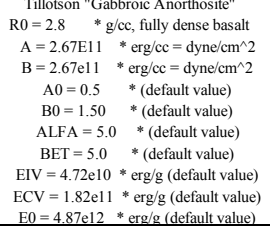 & 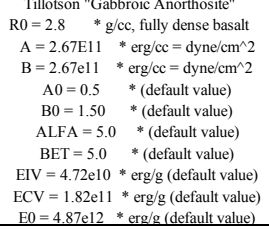 & $\begin{array}{c}\text { Brittle Damage with Localized Thermal } \\
\text { Softening (BDL) } \\
\text { pfrac }=80 \mathrm{MPa} \\
\mathrm{Y} 0=36.4 \mathrm{MPa} \text {, } \mathrm{YM}=2.94 \mathrm{GPa}, \mathrm{CFI}=1.8 .8 \\
\mathrm{CFD}=0.6, \mathrm{PBD}=4.91 \mathrm{GPa}, \mathrm{PBP} 1=9.38 \\
\mathrm{GPa}, \mathrm{PBP} 2=18.75 \mathrm{GPa}\end{array}$ & 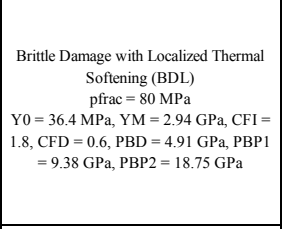 & BDL & none & 5 & 3D \\
\hline Spheral & 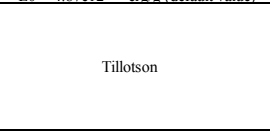 & 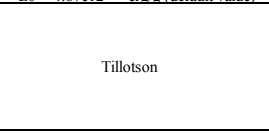 & $\begin{array}{l}\text { von Mises } \\
\mathrm{Y} 0=600 \mathrm{Mpa}, \mathrm{G}=29 \mathrm{Gpa}\end{array}$ & $\begin{array}{l}\text { von Mises } \\
\mathrm{Y} 0=600 \mathrm{Mpa}, \mathrm{G}=29 \mathrm{Gpa}\end{array}$ & \begin{tabular}{|c|} 
Tensor generalization of the \\
Benz-Asphaug implentation of \\
Grady-Kipd atamage (Benz and \\
Asphaug, 1994) \\
Weibull constants: $\mathrm{k}=5 \mathrm{~S} 24 \mathrm{~cm}-3$, \\
$\mathrm{m}=9.0$
\end{tabular} & & & \\
\hline iSALE & Tillotson & Tillotson & \begin{tabular}{|c|} 
"ROCK" Strength parameters: \\
Cohesion of intact material \\
$21.0 \mathrm{MPa}$ \\
(calculated from $\mathrm{QS}$ compressive strength) \\
Coeff. of internal friction for intact material \\
1.8 \\
Limiting strength for intact material \\
$1.7 \mathrm{GPa}$ \\
Cohesion of damaged material \\
0.0 \\
Coeff. of internal friction for damaged \\
material 0.6 \\
Limiting strength for damaged material \\
$1.7 \mathrm{GPa}$
\end{tabular} & 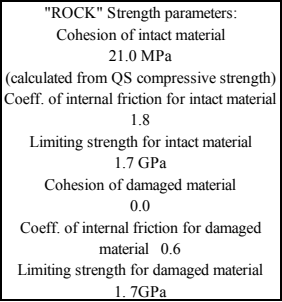 & \begin{tabular}{|c|} 
Defined in Collins et al, 2004 \\
Damage parameters listed with \\
plasticity model.
\end{tabular} & none & 40 & 2D \\
\hline
\end{tabular}


Table A.5 Simulation parameters for CTH, Spheral, iSALE-2D, RAGE, and PAGOSA for Case 3: $90^{\circ}$ impact of 0.635-cm basalt sphere into a porous basalt half-space at $5 \mathrm{~km} / \mathrm{s}$.

\begin{tabular}{|c|c|c|c|c|c|c|c|c|}
\hline $\begin{array}{c}\text { Case } 3 \\
0.635-\mathrm{cm} \text { basalt } \\
\text { sphere into basalt } \\
\text { halfspace with } \\
\text { porosity } \\
\end{array}$ & Projectile EOS & Target EOS & Projectile Plasticity Model & Target Plasticity Model & Damage model & Porosity Model & $\begin{array}{l}\text { Resolution } \\
\text { (cppr or } \\
\text { equivalent) }\end{array}$ & Geometry \\
\hline CTH & Sesame 7360 & Sesame 7360 & $\begin{array}{c}\text { Pressure-dependent Yield } \\
\text { Yield } \\
=1 \mathrm{GPa} \text {, poisson }=0.25 \text {, dydp } \\
=0.5, \text { yzero }=40 \mathrm{MPa}\end{array}$ & $\begin{array}{c}\text { Pressure-dependent } \text { Yield } \\
\text { Yield }=1 \mathrm{GPa} \text {, poisson }=0.25, \\
\text { dydp }=0.5, \text { yzero }=40 \mathrm{MPa}\end{array}$ & $\begin{array}{c}\text { Johnson-Cook Fracture } \\
\mathrm{D} 1=0.05, \text { Tmelt }=0.16 \mathrm{eV}, \mathrm{JFPF} 0= \\
80 \mathrm{MPa}, \text { Weibull Modulus }=10\end{array}$ & p-alpha model & $5,10,20$ & $2 \mathrm{DC}$ \\
\hline CTH & Sesame 7360 & Sesame 7360 & $\begin{array}{c}\text { Pressure-dependent } Y \text { ield } \\
\text { Yield }=1 \mathrm{GPa} \text {, poisson }=0.25 \text {, dydp } \\
=0.5, \text { yzero }=40 \mathrm{Mpa} \text {, prac }=80 \\
\mathrm{MPa}\end{array}$ & $\begin{array}{l}\text { Pressure-dependent } Y \text { ield } \\
\text { Yield }=1 \mathrm{GPa} \text {, poisson }=0.25, \\
\text { dydp }=0.5, \text { yzero }=40 \mathrm{MPa}\end{array}$ & $\begin{array}{c}\text { Johnson-Cook Fracture } \\
\text { D1 }=0.05, \text { Tmelt }=0.16 \mathrm{eV}, \mathrm{JFPF} 0= \\
80 \mathrm{MPa} \text {, Weibull Modulus }=10\end{array}$ & p-alpha model & 5 & 3D \\
\hline Spheral & Tillotson - basalt & Tillotson - basalt & $\begin{array}{c}\text { von Mises } \\
\text { Y0=600 Mpa, G=29 Gpa }\end{array}$ & $\begin{array}{c}\text { von Mises } \\
\text { Y0= } 600 \mathrm{Mpa}, \mathrm{G}=29 \mathrm{Gpa}\end{array}$ & $\begin{array}{c}\text { Tensor generalization of the Benz- } \\
\text { Asphaug implentation of Grady-Kipp } \\
\text { damage (Benz and Asphaug, 1994) } \\
\text { Weibull constants: } \mathrm{k}=5 \mathrm{e} 24 \mathrm{~cm}-3, \\
\mathrm{~m}=9.0\end{array}$ & $\begin{array}{c}\text { epsilon-alpha model } \\
\text { epsilon-e }=0.0 \text {, epsilon-chi }=-0.4, \\
\text { and kappa }=0.8\end{array}$ & 5 & \\
\hline iSALE & Tillotson - basalt & Tillotson - basalt & \begin{tabular}{|c|} 
"ROCK" Strength parameters: \\
Cohesion of intact material \\
$21.0 \mathrm{MPa}$ \\
(calculated from QS compressive \\
strength) \\
Coeff. of internal friction for intact \\
material 1.8 \\
Limiting strength for intact material \\
$1.7 \mathrm{GPa}$ \\
Cohesion of damaged material \\
0.0 \\
Coeff. of internal friction for \\
damaged material 0.6 \\
Limiting strength for damaged \\
material $1.7 \mathrm{GPa}$
\end{tabular} & \begin{tabular}{|} 
"ROCK" Strength parameters: \\
Cohesion of intact material \\
$21.0 \mathrm{MPa}$ (calculated from QS \\
compressive strength) \\
Coeff. of internal friction for intact \\
material 1.8 \\
Limiting strength for intact \\
material $\quad 1.7 \mathrm{GPa}$ \\
Cohesion of damaged material \\
0.0 \\
Coeff. of internal friction for \\
damaged material 0.6 \\
Limiting strength for damaged \\
material $1.7 \mathrm{GPa}$
\end{tabular} & $\begin{array}{l}\text { Defined in Collins et al., } 2004 \\
\text { Damage parameters listed with } \\
\text { plasticity model. }\end{array}$ & $\begin{array}{c}\text { epsilon-alpha model } \\
\text { Porosity model parameter: } \\
\text { Initial distension (porosity) } 1.25 \text {; } \\
1.82 ; 2.5(20 \%, 45 \%, 60 \%) \\
\text { Elastic threshold }-1.00 \mathrm{D}-03 \\
\text { Transition distension } 1.1 \\
\text { Exponential coeff. } 0.8 \text { for } 20 \% \\
\text { porosity, } 0.98 \text { for } 45 \text { and } 60 \% \\
\text { porosity; } \\
\text { Sound speed ratio } 1.0 \text { for } 20 \% \\
\text { porosity, } 0.5 \text { for } 45 \% \text { porosity, } \\
0.4 \text { for } 60 \% \text { porosity }\end{array}$ & 40 & $2 \mathrm{D}$ \\
\hline
\end{tabular}


Table A.6 Simulation parameters for CTH, Spheral, iSALE-2D, RAGE, and PAGOSA for Case4: $90^{\circ}$ impact of 0.635-cm basalt sphere into a porous basalt sphere at $5 \mathrm{~km} / \mathrm{s}$. The Tillotson EOS with values for basalt is named "gabbroic anorthosite" in the CTH distribution, and labeled accordingly here.

\begin{tabular}{|c|c|c|c|c|c|c|c|c|}
\hline \begin{tabular}{|c|} 
Case 4 \\
$0.635-\mathrm{cm}$ basalt \\
sphere into $30-\mathrm{cm}$ \\
basalt sphere with 0- \\
$20 \%$ porosity \\
\end{tabular} & Projectile EOS & Target EOS & Projectile Plasticity Model & Target Plasticity Model & Damage model & Porosity Model & $\begin{array}{c}\text { Resolution } \\
\text { (cppr or } \\
\text { equivalent) }\end{array}$ & Geometry \\
\hline СТH & 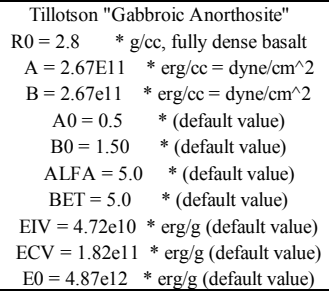 & 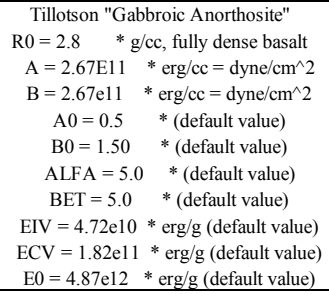 & $\begin{array}{c}\text { Pressure-dependent Yield } \\
\begin{aligned} \text { Yield } & =1 \mathrm{GPa} \text {, poisson }=0.25, \text { dydp } \\
& =0.5, \text { yzero }=40 \mathrm{MPa}\end{aligned}\end{array}$ & $\begin{array}{c}\text { Pressure-dependent } Y \text { ield } \\
\text { Yeld }=1 \text { GPa, poisson }=0.25, \\
\text { dydp }=0.5, \text { yzero }=40 \mathrm{MPa}\end{array}$ & $\begin{array}{c}\text { Johnson-Cook Fracture } \\
\text { D1 }=0.05, \text { Tmelt }=0.16 \text { eV, } \\
\text { JFPF } 0=-80 \text { MPa, weibull } \\
\text { Modulus }=10\end{array}$ & none & $5,10,20$ & $2 \mathrm{DC}$ \\
\hline СТH & 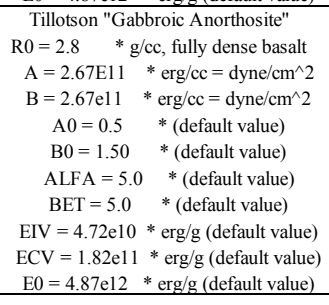 & 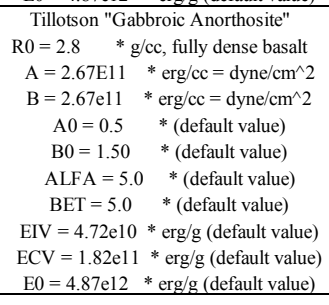 & $\begin{array}{c}\text { Pressure-dependent } \text { Yield } \\
\text { Yield }=1 \text { GPa, poisson }=0.25 \text {, dydp } \\
=0.5, \text { yzero }=40 \mathrm{Mpa} \text {, prac }=80 \\
\mathrm{MPa}\end{array}$ & $\begin{array}{c}\text { Pressure-dependent } \text { Yield } \\
\text { Yield }=1 \text { GPa, poisson }=0.25, \\
\text { dydp }=0.5, \text { yzero }=40 \mathrm{MPa}\end{array}$ & $\begin{array}{c}\text { Johnson-Cook Fracture } \\
\text { D1 }=0.05, \text { Tmelt }=0.16 \mathrm{eV}, \\
\text { JFPF } 0=-80 \mathrm{MPa}, \text { Weibull } \\
\text { Modulus }=10\end{array}$ & none & 5 & $3 \mathrm{D}$ \\
\hline iSALE & Tillotson - basalt & Tillotson - basalt & \begin{tabular}{|} 
"ROCK" Strength parameters: \\
Cohesion of intact material \\
$21.0 \mathrm{MPa}$ \\
(calculated from QS compressive \\
strength) \\
Coeff. of internal friction for intact \\
material 1.8 \\
Limiting strength for intact material \\
$1.7 \mathrm{GPa}$ \\
Cohesion of damaged material \\
0.0 \\
Coeff. of internal friction for damaged \\
material 0.6 \\
Limiting strength for damaged material \\
$1.7 \mathrm{GPa}$
\end{tabular} & $\begin{array}{l}\text { "ROCK" Strength parameters: } \\
\text { Cohesion of intact material } \\
21.0 \mathrm{MPa} \\
\text { (calculated from QS compressive } \\
\text { strength) } \\
\text { Coeff. of internal friction for intact } \\
\text { material } 1.8 \\
\text { Limiting strength for intact material } \\
1.7 \mathrm{GPa} \\
\text { Cohesion of damaged material } \\
0.0 \\
\text { Coeff. of internal friction for } \\
\text { damaged material } 0.6 \\
\text { Limiting strength for damaged } \\
\text { material } \quad 1.7 \mathrm{GPa}\end{array}$ & \begin{tabular}{|l} 
Defined in Collins et al., \\
2004 \\
Damage parameters listed \\
with plasticity model.
\end{tabular} & \begin{tabular}{|c} 
epsilon-alpha model \\
Porosity model \\
parameter: \\
Initial distension \\
(porosity) 1.25 \\
Elastic threshold - \\
$1.00 \mathrm{D}-\mathrm{D}-3$ \\
Transition distension \\
1.1 \\
Exponential coeff. 0.8 \\
Sound speed ratio 1.0 \\
for 20\% porosity
\end{tabular} & 40 & $2 \mathrm{D}$ \\
\hline
\end{tabular}


Table A.7 Simulation parameters for CTH, Spheral, iSALE-2D, RAGE, and PAGOSA for Case 5: 90 impact of 0.635-cm Pyrex sphere into a 10-cm basalt block at $2.1 \mathrm{~km} / \mathrm{s}$

\begin{tabular}{|c|c|c|c|c|c|c|c|c|c|c|}
\hline $\begin{array}{l}\text { Case } 5: 0.635 \\
\mathrm{~cm} \text { Pyrex } \\
\text { projectile into a } \\
10-\mathrm{cm} \text { basalt } \\
\text { block, } 2.1 \mathrm{~km} / \mathrm{s}\end{array}$ & Projectile & Target & Projectile EOS & Target EOS & $\begin{array}{c}\text { Projectile Plasticity } \\
\text { Model }\end{array}$ & $\begin{array}{c}\text { Target Plasticity } \\
\text { Model }\end{array}$ & Damage model & Porosity Model & $\begin{array}{c}\text { Resolution } \\
\text { (cppr or } \\
\text { equivalent) }\end{array}$ & Geometry \\
\hline $\mathrm{CTH}$ & Pyrex & Basalt & Mie-Gruneisen & 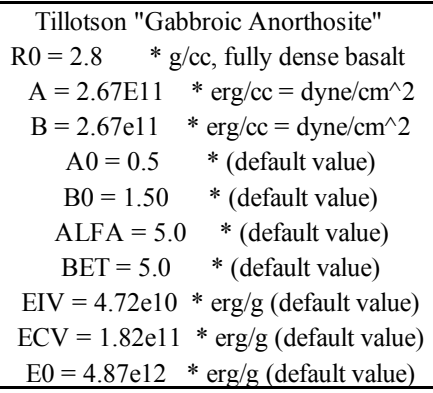 & $\begin{array}{c}\text { Pressure-dependent } \\
\text { Yield } \\
\text { Yield }=10 \mathrm{GPa}, \\
\text { poisson }=0.2, \mathrm{dydp}= \\
0.5, \text { yzero }=900 \mathrm{Mpa}, \\
\text { Tmelt }=0.25 \mathrm{eV}\end{array}$ & $\begin{array}{c}\text { Pressure-dependent } \\
\text { Yield } \\
\text { Yield }=1 \mathrm{GPa}, \\
\text { poisson }=0.25, \text { dydp } \\
=0.5, \text { yzero }=40 \mathrm{MPa}\end{array}$ & \begin{tabular}{|c|} 
Projectile: \\
Johnson-Cook Fracture \\
D1 $=0.05$, Tmelt $=0.25 \mathrm{eV}$, \\
JFPF0 $=-1.8 \mathrm{GPa}$, Weibull \\
Modulus $=10$ \\
\\
Target: \\
Johnson-Cook Fracture \\
D1 $=0.05$, Tmelt $=0.16 \mathrm{eV}$, \\
JFPF0 $=-80 \mathrm{MPa}$, Weibull \\
Modulus $=10$ \\
\end{tabular} & none & $\begin{array}{c}2 \mathrm{D}: 12,3 \mathrm{D}: \\
2,5\end{array}$ & $2 \mathrm{D}, 3 \mathrm{D}$ \\
\hline Spheral & Pyrex & Basalt & \begin{tabular}{|c} 
Mie-Gruneisen \\
(Stickle and \\
Schultz, 2012)
\end{tabular} & Tillotson (see Table 3) & & $\begin{array}{c}\text { von Mises } \\
\mathrm{y} 0=600 \mathrm{Mpa}, \mathrm{G}=29 \\
\mathrm{Gpa}\end{array}$ & $\begin{array}{c}\text { Tensor generalization of the } \\
\text { Benz-Asphaug implentation } \\
\text { of Grady-Kipp damage } \\
\text { (Benz and Asphaug, 1994) } \\
\begin{array}{c}\text { Weibull constants: } \mathrm{k}=5 \mathrm{e} 24 \\
\mathrm{~cm}-3, \mathrm{~m}=9.0\end{array}\end{array}$ & $7 \%$ porosity & 5 & 3D \\
\hline
\end{tabular}




\section{Appendix B. Summary of values as a function of time}

Table B.1. Summary of crater depth, diameter, and calculated momentum transfer efficiency for Case 1a. When a given result was not supplied by specific modelers, it is marked as "not provided" in the table.

\begin{tabular}{|c|c|c|c|c|c|c|c|}
\hline Model & Resolution & Case & Strength & Time [us] & $\begin{array}{c}\text { Crater } \\
\text { Depth } \\
{[\mathrm{cm}]}\end{array}$ & $\begin{array}{c}\text { Crater } \\
\text { Diameter } \\
{[\mathrm{cm}]}\end{array}$ & $\beta$ \\
\hline iSALE & $40 \mathrm{cppr}$ & $1 \mathrm{a}$ & none & 100 & 3.05 & 5.37 & 4.02 \\
\hline iSALE & $40 \mathrm{cppr}$ & $1 a$ & none & 400 & 4.87 & 8.87 & 8.68 \\
\hline CTH (2D) & $20 \mathrm{cppr}$ & $1 \mathrm{a}$ & none & 100 & 3.20 & 5.54 & 4.54 \\
\hline CTH (2D) & $20 \mathrm{cppr}$ & $1 \mathrm{a}$ & none & 400 & 5.18 & 9.19 & 10.22 \\
\hline CTH (2D) & $20 \mathrm{cppr}$ & $1 a$ & none & 800 & 6.71 & 11.83 & 12.57 \\
\hline CTH (3D) & $6 \mathrm{cppr}$ & $1 a$ & none & 100 & 3.19 & 5.45 & 3.68 \\
\hline CTH (3D) & $6 \mathrm{cppr}$ & $1 a$ & none & 400 & 5.19 & 9.02 & 5.19 \\
\hline CTH (3D) & $6 \mathrm{cppr}$ & $1 a$ & none & 800 & 6.53 & 11.60 & 5.82 \\
\hline RAGE & $2.5 \mathrm{cppr}$ & $1 a$ & none & 100 & $\begin{array}{c}\text { not } \\
\text { provided }\end{array}$ & $\begin{array}{c}\text { not } \\
\text { provided }\end{array}$ & 2.49 \\
\hline RAGE & $5 \mathrm{cppr}$ & $1 a$ & none & 100 & $\begin{array}{c}\text { not } \\
\text { provided }\end{array}$ & $\begin{array}{c}\text { not } \\
\text { provided }\end{array}$ & 4.63 \\
\hline RAGE & $10 \mathrm{cppr}$ & $1 a$ & none & 100 & $\begin{array}{c}\text { not } \\
\text { provided }\end{array}$ & $\begin{array}{c}\text { not } \\
\text { provided }\end{array}$ & 5.15 \\
\hline RAGE & $20 \mathrm{cppr}$ & $1 a$ & none & 100 & $\begin{array}{c}\text { not } \\
\text { provided }\end{array}$ & $\begin{array}{c}\text { not } \\
\text { provided }\end{array}$ & 5.40 \\
\hline RAGE & $2.5 \mathrm{cppr}$ & $1 a$ & none & 400 & $\begin{array}{c}\text { not } \\
\text { provided }\end{array}$ & $\begin{array}{c}\text { not } \\
\text { provided }\end{array}$ & 5.20 \\
\hline RAGE & $5 \mathrm{cppr}$ & $1 \mathrm{a}$ & none & 400 & $\begin{array}{c}\text { not } \\
\text { provided }\end{array}$ & $\begin{array}{c}\text { not } \\
\text { provided }\end{array}$ & 7.42 \\
\hline RAGE & $10 \mathrm{cppr}$ & $1 a$ & none & 400 & $\begin{array}{c}\text { not } \\
\text { provided }\end{array}$ & $\begin{array}{c}\text { not } \\
\text { provided }\end{array}$ & 8.26 \\
\hline RAGE & $20 \mathrm{cppr}$ & $1 \mathrm{a}$ & none & 400 & $\begin{array}{c}\text { not } \\
\text { provided }\end{array}$ & $\begin{array}{c}\text { not } \\
\text { provided }\end{array}$ & 9.14 \\
\hline $\begin{array}{c}\text { Spheral } \\
\text { (2D) }\end{array}$ & $\mathrm{nrl}=5$ & $1 a$ & none & 100 & 1.17 & 2.36 & 3.68 \\
\hline
\end{tabular}




\begin{tabular}{|c|c|c|c|c|c|c|c|}
\hline $\begin{array}{c}\text { Spheral } \\
\text { (2D) }\end{array}$ & $\mathrm{nrl}=10$ & $1 a$ & none & 100 & 1.2 & 2.36 & 5.17 \\
\hline $\begin{array}{l}\text { Spheral } \\
\text { (2D) }\end{array}$ & $\mathrm{nrl}=20$ & $1 a$ & none & 100 & $\begin{array}{c}\text { not } \\
\text { provided }\end{array}$ & $\begin{array}{c}\text { not } \\
\text { provided }\end{array}$ & 5.92 \\
\hline $\begin{array}{c}\text { Spheral } \\
\text { (2D) }\end{array}$ & $\mathrm{nrl}=40$ & $1 a$ & none & 100 & $\begin{array}{c}\text { not } \\
\text { provided }\end{array}$ & $\begin{array}{c}\text { not } \\
\text { provided }\end{array}$ & 6.90 \\
\hline $\begin{array}{c}\text { Spheral } \\
\text { (3D) }\end{array}$ & $\mathrm{nrl}=3$ & $1 a$ & none & 100 & $\begin{array}{c}\text { not } \\
\text { provided }\end{array}$ & $\begin{array}{c}\text { not } \\
\text { provided }\end{array}$ & 1.95 \\
\hline $\begin{array}{c}\text { Spheral } \\
\text { (3D) }\end{array}$ & $\mathrm{nrl}=5$ & $1 a$ & none & 100 & 2.69 & 4.24 & 3.12 \\
\hline $\begin{array}{c}\text { Spheral } \\
\text { (3D) }\end{array}$ & $\mathrm{nrl}=7$ & $1 a$ & none & 100 & 2.8 & 4.42 & 3.87 \\
\hline PAGOSA & $2.5 \mathrm{cppr}$ & $1 a$ & none & 100 & 3.27 & 6.13 & 9.41 \\
\hline PAGOSA & $5 \mathrm{cppr}$ & $1 a$ & none & 100 & 3.26 & 5.65 & 6.99 \\
\hline PAGOSA & 10 срpr & $1 a$ & none & 100 & 3.17 & 5.51 & 6.63 \\
\hline PAGOSA & 20 сppr & $1 a$ & none & 100 & 3.17 & 5.47 & 6.45 \\
\hline PAGOSA & $2.5 \mathrm{cppr}$ & $1 a$ & none & 400 & 5.71 & 10.08 & 13.69 \\
\hline PAGOSA & $5 \mathrm{cppr}$ & $1 a$ & none & 400 & 5.08 & 9.30 & 11.05 \\
\hline PAGOSA & 10 сppr & $1 a$ & none & 400 & 5.13 & 9.17 & 10.54 \\
\hline PAGOSA & 20 сppr & $1 a$ & none & 400 & 5.10 & 9.12 & 10.16 \\
\hline PAGOSA & $2.5 \mathrm{cppr}$ & $1 a$ & none & 800 & 6.76 & 12.85 & 19.75 \\
\hline PAGOSA & $5 \mathrm{cppr}$ & $1 a$ & none & 800 & 6.49 & 11.91 & 12.52 \\
\hline PAGOSA & $10 \mathrm{cppr}$ & $1 a$ & none & 800 & 6.61 & 11.75 & 11.50 \\
\hline PAGOSA & $20 \mathrm{cppr}$ & $1 a$ & none & 800 & 6.73 & 11.72 & 10.94 \\
\hline
\end{tabular}

Table B.2. Summary of crater depth, diameter, and calculated momentum transfer efficiency for modified Case 1a. When a given result was not supplied by specific modelers, it is marked as "not provided" in the table.

\begin{tabular}{|c|c|c|c|c|c|c|c|}
\hline Model & Resolution & Case & Strength & Time [us] & $\begin{array}{c}\text { Crater } \\
\text { Depth } \\
{[\mathbf{c m}]}\end{array}$ & $\begin{array}{c}\text { Crater } \\
\text { Diameter } \\
{[\mathbf{c m}]}\end{array}$ & $\boldsymbol{\beta}$ \\
\hline PAGOSA & $2.5 \mathrm{cppr}$ & $1 \mathrm{a}$ & $\begin{array}{c}\text { Steinburg- } \\
\text { Guinan }\end{array}$ & 100 & 2.58 & 1.15 & 1.03 \\
\hline PAGOSA & $5 \mathrm{cppr}$ & $1 \mathrm{a}$ & $\begin{array}{c}\text { Steinburg- } \\
\text { Guinan }\end{array}$ & 100 & 2.20 & 1.08 & 1.03 \\
\hline
\end{tabular}




\begin{tabular}{|c|c|c|c|c|c|c|c|}
\hline PAGOSA & $10 \mathrm{cppr}$ & $1 a$ & $\begin{array}{l}\text { Steinburg- } \\
\text { Guinan }\end{array}$ & 100 & 2.08 & 1.09 & 1.09 \\
\hline PAGOSA & $20 \mathrm{cppr}$ & $1 a$ & $\begin{array}{c}\text { Steinburg- } \\
\text { Guinan }\end{array}$ & 100 & 2.06 & 1.09 & 1.03 \\
\hline PAGOSA & $2.5 \mathrm{cppr}$ & $1 a$ & $\begin{array}{c}\text { Steinburg- } \\
\text { Guinan }\end{array}$ & 400 & 2.56 & 1.18 & 1.00 \\
\hline PAGOSA & $5 \mathrm{cppr}$ & $1 a$ & $\begin{array}{c}\text { Steinburg- } \\
\text { Guinan }\end{array}$ & 400 & 2.19 & 1.08 & 1.20 \\
\hline PAGOSA & $10 \mathrm{cppr}$ & $1 a$ & $\begin{array}{l}\text { Steinburg- } \\
\text { Guinan }\end{array}$ & 400 & 2.08 & 1.08 & 1.02 \\
\hline PAGOSA & $20 \mathrm{cppr}$ & $1 a$ & $\begin{array}{l}\text { Steinburg- } \\
\text { Guinan }\end{array}$ & 400 & 1.06 & 0.98 & 1.01 \\
\hline RAGE & $2.5 \mathrm{cppr}$ & $1 a$ & $\begin{array}{l}\text { Steinburg- } \\
\text { Guinan }\end{array}$ & 100 & $\begin{array}{c}\text { not } \\
\text { provided }\end{array}$ & $\begin{array}{c}\text { not } \\
\text { provided }\end{array}$ & 2.75 \\
\hline RAGE & $5 \mathrm{cppr}$ & $1 a$ & $\begin{array}{c}\text { Steinburg- } \\
\text { Guinan }\end{array}$ & 100 & $\begin{array}{c}\text { not } \\
\text { provided }\end{array}$ & $\begin{array}{c}\text { not } \\
\text { provided }\end{array}$ & 2.78 \\
\hline RAGE & 10 cppr & $1 a$ & $\begin{array}{c}\text { Steinburg- } \\
\text { Guinan }\end{array}$ & 100 & $\begin{array}{c}\text { not } \\
\text { provided }\end{array}$ & $\begin{array}{c}\text { not } \\
\text { provided }\end{array}$ & 2.85 \\
\hline RAGE & $20 \mathrm{cppr}$ & $1 a$ & $\begin{array}{c}\text { Steinburg- } \\
\text { Guinan }\end{array}$ & 100 & $\begin{array}{c}\text { not } \\
\text { provided }\end{array}$ & $\begin{array}{c}\text { not } \\
\text { provided }\end{array}$ & 2.90 \\
\hline RAGE & $2.5 \mathrm{cppr}$ & $1 a$ & $\begin{array}{c}\text { Steinburg- } \\
\text { Guinan }\end{array}$ & 400 & $\begin{array}{c}\text { not } \\
\text { provided }\end{array}$ & $\begin{array}{c}\text { not } \\
\text { provided }\end{array}$ & 3.81 \\
\hline RAGE & $5 \mathrm{cppr}$ & $1 a$ & $\begin{array}{c}\text { Steinburg- } \\
\text { Guinan }\end{array}$ & 400 & $\begin{array}{c}\text { not } \\
\text { provided }\end{array}$ & $\begin{array}{c}\text { not } \\
\text { provided }\end{array}$ & 3.54 \\
\hline RAGE & $10 \mathrm{cppr}$ & $1 a$ & $\begin{array}{c}\text { Steinburg- } \\
\text { Guinan }\end{array}$ & 400 & $\begin{array}{c}\text { not } \\
\text { provided }\end{array}$ & $\begin{array}{c}\text { not } \\
\text { provided }\end{array}$ & 3.40 \\
\hline RAGE & 20 сppr & $1 a$ & $\begin{array}{c}\text { Steinburg- } \\
\text { Guinan }\end{array}$ & 400 & $\begin{array}{c}\text { not } \\
\text { provided }\end{array}$ & $\begin{array}{c}\text { not } \\
\text { provided }\end{array}$ & 3.31 \\
\hline RAGE & $2.5 \mathrm{cppr}$ & $1 a$ & $\begin{array}{c}\text { Steinburg- } \\
\text { Guinan }\end{array}$ & 800 & $\begin{array}{c}\text { not } \\
\text { provided }\end{array}$ & $\begin{array}{c}\text { not } \\
\text { provided }\end{array}$ & 4.93 \\
\hline RAGE & $5 \mathrm{cppr}$ & $1 a$ & $\begin{array}{c}\text { Steinburg- } \\
\text { Guinan }\end{array}$ & 800 & $\begin{array}{c}\text { not } \\
\text { provided }\end{array}$ & $\begin{array}{c}\text { not } \\
\text { provided }\end{array}$ & 4.24 \\
\hline RAGE & $10 \mathrm{cppr}$ & $1 a$ & $\begin{array}{c}\text { Steinburg- } \\
\text { Guinan }\end{array}$ & 800 & $\begin{array}{c}\text { not } \\
\text { provided }\end{array}$ & $\begin{array}{c}\text { not } \\
\text { provided }\end{array}$ & 3.76 \\
\hline RAGE & $20 \mathrm{cppr}$ & $1 a$ & $\begin{array}{l}\text { Steinburg- } \\
\text { Guinan }\end{array}$ & 800 & $\begin{array}{c}\text { not } \\
\text { provided }\end{array}$ & $\begin{array}{c}\text { not } \\
\text { provided }\end{array}$ & -- \\
\hline
\end{tabular}




\begin{tabular}{|c|c|c|c|c|c|c|c|}
\hline iSALE & $40 \mathrm{cppr}$ & $1 a$ & $\begin{array}{c}\text { Johnson- } \\
\text { Cook }\end{array}$ & 100 & 1.37 & 2.56 & $\begin{array}{c}\text { not } \\
\text { provided }\end{array}$ \\
\hline iSALE & $40 \mathrm{cppr}$ & $1 a$ & $\begin{array}{l}\text { Johnson- } \\
\text { Cook }\end{array}$ & 370 & 1.18 & 2.59 & $\begin{array}{c}\text { not } \\
\text { provided }\end{array}$ \\
\hline $\begin{array}{l}\text { iSALE } \\
\text { (grid) }\end{array}$ & $60 \mathrm{cppr}$ & $1 a^{\prime}$ & von Mises & 80 & 1.19 & 2.36 & 1.00 \\
\hline iSALE (cell) & $60 \mathrm{cppr}$ & $1 a^{\prime}$ & von Mises & 80 & 1.19 & 2.36 & 1.41 \\
\hline CTH (2D) & $5 \mathrm{cppr}$ & $1 a^{\prime}$ & von Mises & 80 & 1.24 & 2.22 & 1.23 \\
\hline CTH (2D) & $10 \mathrm{cppr}$ & $1 a^{\prime}$ & von Mises & 80 & 1.25 & 2.32 & 1.28 \\
\hline CTH (2D) & $20 \mathrm{cppr}$ & $1 a^{\prime}$ & von Mises & 80 & 1.25 & 2.37 & 1.57 \\
\hline CTH (2D) & $5 \mathrm{cppr}$ & $1 a^{\prime}$ & von Mises & 100 & 1.24 & 2.22 & 1.22 \\
\hline CTH (2D) & $10 \mathrm{cppr}$ & $1 a^{\prime}$ & von Mises & 100 & 1.25 & 2.32 & 1.28 \\
\hline CTH (2D) & $20 \mathrm{cppr}$ & $1 a^{\prime}$ & von Mises & 100 & 1.25 & 2.37 & 1.49 \\
\hline CTH (3D) & $5 \mathrm{cppr}$ & $1 a^{\prime}$ & von Mises & 40 & 1.26 & 2.29 & 1.36 \\
\hline $\begin{array}{c}\text { Spheral } \\
\text { (3D) }\end{array}$ & $\mathrm{nrl}=3$ & $1 a^{\prime}$ & von Mises & 30 & $\begin{array}{c}\text { not } \\
\text { provided }\end{array}$ & $\begin{array}{c}\text { not } \\
\text { provided }\end{array}$ & 1.00 \\
\hline $\begin{array}{c}\text { Spheral } \\
\text { (3D) }\end{array}$ & $\mathrm{nrl}=5$ & $1 a^{\prime}$ & von Mises & 30 & 1.26 & 2.10 & 1.05 \\
\hline $\begin{array}{c}\text { Spheral } \\
\text { (3D) }\end{array}$ & $\mathrm{nrl}=6$ & $1 a^{\prime}$ & von Mises & 100 & 1.26 & 2.10 & -- \\
\hline $\begin{array}{l}\text { Spheral } \\
\text { (3D) }\end{array}$ & $\mathrm{nrl}=7$ & $1 a^{\prime}$ & von Mises & 30 & 1.20 & 2.12 & 1.11 \\
\hline $\begin{array}{c}\text { Spheral } \\
\text { (3D) }\end{array}$ & $\mathrm{nrl}=7$ & $1 a^{\prime}$ & von Mises & 100 & 1.20 & 2.12 & -- \\
\hline $\begin{array}{c}\text { Spheral } \\
\text { (2D) }\end{array}$ & $\mathrm{nrl}=5$ & $1 a^{\prime}$ & von Mises & 24 & 1.17 & 2.36 & 1.15 \\
\hline $\begin{array}{c}\text { Spheral } \\
\text { (2D) }\end{array}$ & $\mathrm{nrl}=6$ & $1 a^{\prime}$ & von Mises & 100 & 1.18 & 2.36 & -- \\
\hline $\begin{array}{c}\text { Spheral } \\
\text { (2D) }\end{array}$ & $\mathrm{nrl}=10$ & $1 a^{\prime}$ & von Mises & 35 & $\begin{array}{c}\text { not } \\
\text { provided }\end{array}$ & $\begin{array}{c}\text { not } \\
\text { provided }\end{array}$ & 1.15 \\
\hline $\begin{array}{c}\text { Spheral } \\
\text { (2D) }\end{array}$ & $\mathrm{nrl}=20$ & $1 a^{\prime}$ & von Mises & 35 & $\begin{array}{c}\text { not } \\
\text { provided }\end{array}$ & $\begin{array}{c}\text { not } \\
\text { provided }\end{array}$ & 1.25 \\
\hline $\begin{array}{c}\text { Spheral } \\
\text { (2D) }\end{array}$ & $\mathrm{nrl}=40$ & $1 a^{\prime}$ & von Mises & 35 & $\begin{array}{c}\text { not } \\
\text { provided }\end{array}$ & $\begin{array}{c}\text { not } \\
\text { provided }\end{array}$ & 1.23 \\
\hline
\end{tabular}


Table B.3. Summary of crater depth, diameter, and calculated momentum transfer efficiency for Case 2. When a given result was not supplied by specific modelers, it is marked as "not provided" in the table.

\begin{tabular}{|c|c|c|c|c|c|c|c|}
\hline Model & Resolution & Case & Strength & $\begin{array}{l}\text { Time } \\
\text { [us] }\end{array}$ & $\begin{array}{c}\text { Crater } \\
\text { Depth } \\
{[\mathrm{cm}]}\end{array}$ & $\begin{array}{c}\text { Crater } \\
\text { Diameter } \\
{[\mathrm{cm}]}\end{array}$ & $\boldsymbol{\beta}$ \\
\hline \multirow[t]{3}{*}{ CTH (2D) } & $5 \mathrm{cppr}$ & 2 & geo & 100 & 2.19 & 4.51 & 3.54 \\
\hline & $10 \mathrm{cppr}$ & 2 & geo & 100 & 2.17 & 4.67 & 3.68 \\
\hline & $20 \mathrm{cppr}$ & 2 & geo & 100 & 2.06 & 5.03 & 3.48 \\
\hline \multirow[t]{3}{*}{ CTH (2D) } & $5 \mathrm{cppr}$ & 2 & geo & 400 & 2.38 & 6.03 & 5.37 \\
\hline & $10 \mathrm{cppr}$ & 2 & geo & 400 & 2.37 & 6.57 & 5.28 \\
\hline & $20 \mathrm{cppr}$ & 2 & geo & 400 & 1.90 & 7.41 & 6.54 \\
\hline \multirow[t]{3}{*}{ CTH (2D) } & $5 \mathrm{cppr}$ & 2 & geo & 800 & 2.19 & 6.67 & 6.32 \\
\hline & 10 cppr & 2 & geo & 800 & 2.21 & 7.14 & 6.88 \\
\hline & 20 сppr & 2 & geo & 800 & 1.42 & 8.43 & 7.33 \\
\hline \multirow[t]{3}{*}{ CTH (2D) } & $5 \mathrm{cppr}$ & 2 & BDL & 100 & 0.90 & 1.81 & 1.71 \\
\hline & $10 \mathrm{cppr}$ & 2 & $\mathrm{BDL}$ & 100 & 0.90 & 1.81 & 1.71 \\
\hline & $20 \mathrm{cppr}$ & 2 & $\mathrm{BDL}$ & 100 & 0.85 & 1.86 & 1.67 \\
\hline \multirow[t]{3}{*}{ CTH (2D) } & $5 \mathrm{cppr}$ & 2 & $\mathrm{BDL}$ & 300 & 1.10 & 2.51 & 1.61 \\
\hline & $10 \mathrm{cppr}$ & 2 & $\mathrm{BDL}$ & 300 & 1.10 & 2.51 & 1.61 \\
\hline & $20 \mathrm{cppr}$ & 2 & BDL & 300 & 1.04 & 2.56 & 1.56 \\
\hline \multirow[t]{3}{*}{ CTH (2D) } & $5 \mathrm{cppr}$ & 2 & $\mathrm{BDL}$ & 500 & 1.09 & 2.76 & 1.62 \\
\hline & $10 \mathrm{cppr}$ & 2 & BDL & 500 & 1.09 & 2.76 & 1.62 \\
\hline & $20 \mathrm{cppr}$ & 2 & $\mathrm{BDL}$ & 500 & 1.02 & 2.81 & 1.55 \\
\hline \multirow[t]{5}{*}{ iSALE } & $5 \mathrm{cppr}$ & 2 & ROCK & 100 & 1.27 & 3.43 & $\begin{array}{c}\text { not } \\
\text { provided }\end{array}$ \\
\hline & $10 \mathrm{cppr}$ & 2 & ROCK & 100 & 1.28 & 3.49 & $\begin{array}{c}\text { not } \\
\text { provided }\end{array}$ \\
\hline & $20 \mathrm{cppr}$ & 2 & ROCK & 100 & 1.28 & 3.56 & $\begin{array}{c}\text { not } \\
\text { provided }\end{array}$ \\
\hline & $30 \mathrm{cppr}$ & 2 & ROCK & 100 & 1.30 & 3.60 & $\begin{array}{c}\text { not } \\
\text { provided }\end{array}$ \\
\hline & $40 \mathrm{cppr}$ & 2 & ROCK & 100 & 1.30 & 3.62 & 1.18 \\
\hline
\end{tabular}




\begin{tabular}{|c|c|c|c|c|c|c|c|}
\hline \multirow[t]{5}{*}{ iSALE } & $5 \mathrm{cppr}$ & 2 & ROCK & 315 & 1.27 & 4.45 & $\begin{array}{c}\text { not } \\
\text { provided }\end{array}$ \\
\hline & $10 \mathrm{cppr}$ & 2 & ROCK & 307 & 1.27 & 4.51 & $\begin{array}{c}\text { not } \\
\text { provided }\end{array}$ \\
\hline & $20 \mathrm{cppr}$ & 2 & ROCK & 308 & 1.21 & 4.61 & $\begin{array}{c}\text { not } \\
\text { provided }\end{array}$ \\
\hline & $30 \mathrm{cppr}$ & 2 & ROCK & 299 & 1.30 & 4.61 & $\begin{array}{c}\text { not } \\
\text { provided }\end{array}$ \\
\hline & $40 \mathrm{cppr}$ & 2 & ROCK & 315 & 1.18 & 4.78 & 2.25 \\
\hline \multirow[t]{3}{*}{ CTH (3D) } & $6 \mathrm{cppr}$ & 2 & geo & 100 & 2.19 & 4.36 & 3.83 \\
\hline & $6 \mathrm{cppr}$ & 2 & geo & 300 & 2.19 & 5.63 & 5.20 \\
\hline & $6 \mathrm{cppr}$ & 2 & geo & 500 & 2.06 & 6.00 & 5.49 \\
\hline \multirow[t]{3}{*}{ CTH (3D) } & $6 \mathrm{cppr}$ & 2 & $\mathrm{BDL}$ & 100 & 0.86 & 1.78 & 1.60 \\
\hline & $6 \mathrm{cppr}$ & 2 & $\mathrm{BDL}$ & 300 & 0.92 & 2.25 & 1.53 \\
\hline & $6 \mathrm{cppr}$ & 2 & $\mathrm{BDL}$ & 500 & 0.92 & 2.19 & 1.44 \\
\hline \multirow[t]{6}{*}{$\begin{array}{c}\text { Spheral } \\
\text { (3D) }\end{array}$} & $\mathrm{nrl}=3$ & 2 & $\begin{array}{c}\text { von } \\
\text { Mises }\end{array}$ & 100 & $\begin{array}{c}\text { not } \\
\text { provided }\end{array}$ & $\begin{array}{c}\text { not } \\
\text { provided }\end{array}$ & 5.33 \\
\hline & $\mathrm{nrl}=3$ & 2 & $\begin{array}{c}\text { von } \\
\text { Mises }\end{array}$ & 400 & $\begin{array}{c}\text { not } \\
\text { provided }\end{array}$ & $\begin{array}{c}\text { not } \\
\text { provided }\end{array}$ & 9.92 \\
\hline & $\mathrm{nrl}=5$ & 2 & $\begin{array}{l}\text { von } \\
\text { Mises }\end{array}$ & 100 & 3.20 & 6.62 & 5.72 \\
\hline & $\mathrm{nrl}=5$ & 2 & $\begin{array}{c}\text { von } \\
\text { Mises }\end{array}$ & 400 & 3.20 & 6.62 & 11.42 \\
\hline & $\mathrm{nrl}=7$ & 2 & $\begin{array}{c}\text { von } \\
\text { Mises }\end{array}$ & 100 & 3.24 & 7.03 & 5.87 \\
\hline & $\mathrm{nrl}=7$ & 2 & $\begin{array}{c}\text { von } \\
\text { Mises }\end{array}$ & 400 & 3.24 & 7.03 & 11.06 \\
\hline \multirow[t]{2}{*}{$\begin{array}{c}\text { Spheral } \\
\text { (3D) }\end{array}$} & $2 \mathrm{cppr}$ & 2 & $\begin{array}{c}\text { von } \\
\text { Mises }\end{array}$ & 100 & $\begin{array}{c}\text { not } \\
\text { provided }\end{array}$ & $\begin{array}{c}\text { not } \\
\text { provided }\end{array}$ & 6.05 \\
\hline & $2 \mathrm{cppr}$ & 2 & $\begin{array}{l}\text { von } \\
\text { Mises }\end{array}$ & 400 & $\begin{array}{c}\text { not } \\
\text { provided }\end{array}$ & $\begin{array}{c}\text { not } \\
\text { provided }\end{array}$ & 11.94 \\
\hline \multirow[t]{2}{*}{$\begin{array}{c}\text { Spheral } \\
\text { (3D) }\end{array}$} & $4 \mathrm{cppr}$ & 2 & $\begin{array}{l}\text { von } \\
\text { Mises }\end{array}$ & 100 & $\begin{array}{c}\text { not } \\
\text { provided }\end{array}$ & $\begin{array}{c}\text { not } \\
\text { provided }\end{array}$ & 5.55 \\
\hline & $4 \mathrm{cppr}$ & 2 & $\begin{array}{c}\text { von } \\
\text { Mises }\end{array}$ & 400 & $\begin{array}{c}\text { not } \\
\text { provided }\end{array}$ & $\begin{array}{c}\text { not } \\
\text { provided }\end{array}$ & 10.13 \\
\hline
\end{tabular}




\begin{tabular}{|c|c|c|c|c|c|c|c|}
\hline $\begin{array}{c}\text { Spheral } \\
\text { (3D) }\end{array}$ & $8 \mathrm{cppr}$ & 2 & $\begin{array}{c}\text { von } \\
\text { Mises }\end{array}$ & 100 & $\begin{array}{c}\text { not } \\
\text { provided }\end{array}$ & $\begin{array}{c}\text { not } \\
\text { provided }\end{array}$ & 4.80 \\
\hline
\end{tabular}

Table B.4. Summary of crater depth, diameter, and calculated momentum transfer efficiency for Case 3. When a given result was not supplied by specific modelers, it is marked as "not provided" in the table.

\begin{tabular}{|c|c|c|c|c|c|c|c|c|}
\hline Model & Resolution & Case & Strength & Porosity & $\begin{array}{l}\text { Time } \\
\text { [us] }\end{array}$ & $\begin{array}{c}\text { Crater } \\
\text { Depth } \\
{[\mathrm{cm}]}\end{array}$ & $\begin{array}{c}\text { Crater } \\
\text { Diameter } \\
{[\mathrm{cm}]}\end{array}$ & $\beta$ \\
\hline $\begin{array}{c}\text { Spheral } \\
\text { (3D) }\end{array}$ & $\mathrm{nrl}=5$ & 3 & von Mises & 20 & 100 & $\begin{array}{c}\text { not } \\
\text { provided }\end{array}$ & $\begin{array}{c}\text { not } \\
\text { provided }\end{array}$ & 1.31 \\
\hline $\begin{array}{c}\text { Spheral } \\
\text { (3D) }\end{array}$ & $\mathrm{nrl}=5 \mathrm{v} 2$ & 3 & von Mises & 20 & 100 & $\begin{array}{c}\text { not } \\
\text { provided }\end{array}$ & $\begin{array}{c}\text { not } \\
\text { provided }\end{array}$ & 1.19 \\
\hline $\begin{array}{c}\text { Spheral } \\
\text { (3D) }\end{array}$ & $\mathrm{nrl}=5$ & 3 & von Mises & 20 & 200 & $\begin{array}{c}\text { not } \\
\text { provided }\end{array}$ & $\begin{array}{c}\text { not } \\
\text { provided }\end{array}$ & 1.46 \\
\hline $\begin{array}{c}\text { Spheral } \\
\text { (3D) }\end{array}$ & $\mathrm{nrl}=5 \mathrm{v} 2$ & 3 & von Mises & 20 & 200 & $\begin{array}{c}\text { not } \\
\text { provided }\end{array}$ & $\begin{array}{c}\text { not } \\
\text { provided }\end{array}$ & 1.25 \\
\hline iSALE & $40 \mathrm{cppr}$ & 3 & ROCK & 20 & 100 & 1.23 & 3.35 & 1.38 \\
\hline iSALE & $40 \mathrm{cppr}$ & 3 & ROCK & 45 & 100 & 2.34 & 3.14 & 1.11 \\
\hline iSALE & $40 \mathrm{cppr}$ & 3 & ROCK & 60 & 100 & 2.89 & 2.87 & 1.05 \\
\hline iSALE & $40 \mathrm{cppr}$ & 3 & ROCK & 20 & 200 & 0.71 & 3.87 & 1.51 \\
\hline iSALE & $40 \mathrm{cppr}$ & 3 & ROCK & 45 & 200 & 2.24 & 3.54 & 1.17 \\
\hline iSALE & $40 \mathrm{cppr}$ & 3 & ROCK & 60 & 200 & 2.80 & 3.32 & 1.08 \\
\hline CTH (2D) & $11 \mathrm{cppr}$ & 3 & geo & 20 & 100 & 3.29 & 4.66 & 2.68 \\
\hline CTH (2D) & $11 \mathrm{cppr}$ & 3 & geo & 45 & 100 & 3.18 & 3.21 & 1.20 \\
\hline CTH (2D) & $11 \mathrm{cppr}$ & 3 & geo & 60 & 100 & 3.46 & 2.74 & 1.10 \\
\hline CTH (2D) & $11 \mathrm{cppr}$ & 3 & geo & 20 & 200 & 3.67 & 5.55 & 3.51 \\
\hline CTH (2D) & $11 \mathrm{cppr}$ & 3 & geo & 45 & 200 & 3.27 & 3.35 & 1.37 \\
\hline CTH (2D) & $11 \mathrm{cppr}$ & 3 & geo & 60 & 200 & 3.76 & 2.84 & 1.19 \\
\hline
\end{tabular}




\begin{tabular}{|c|c|c|c|c|c|c|c|c|}
\hline CTH (2D) & $11 \mathrm{cppr}$ & 3 & geo & 20 & 500 & 3.36 & 6.49 & 4.01 \\
\hline CTH (2D) & 11 срpr & 3 & geo & 45 & 500 & 3.48 & 3.16 & 1.54 \\
\hline CTH (2D) & $11 \mathrm{cppr}$ & 3 & geo & 60 & 500 & 4.44 & 2.65 & 1.31 \\
\hline CTH (3D) & $5 \mathrm{cppr}$ & 3 & geo & 20 & 100 & 2.84 & 4.51 & 3.05 \\
\hline CTH (3D) & $5 \mathrm{cppr}$ & 3 & geo & 45 & 100 & 3.31 & 3.34 & 1.24 \\
\hline CTH (3D) & $5 \mathrm{cppr}$ & 3 & geo & 60 & 100 & 3.42 & 3.19 & 1.15 \\
\hline CTH (3D) & $5 \mathrm{cppr}$ & 3 & geo & 20 & 200 & 2.84 & 5.21 & 3.39 \\
\hline CTH (3D) & $5 \mathrm{cppr}$ & 3 & geo & 45 & 200 & 3.66 & 3.52 & 1.34 \\
\hline CTH (3D) & $5 \mathrm{cppr}$ & 3 & geo & 60 & 200 & 3.80 & 3.33 & 1.19 \\
\hline CTH (3D) & $5 \mathrm{cppr}$ & 3 & geo & 20 & 500 & 2.78 & 5.92 & 4.58 \\
\hline CTH (3D) & $5 \mathrm{cppr}$ & 3 & geo & 45 & 500 & 4.01 & 3.49 & 1.41 \\
\hline CTH (3D) & $5 \mathrm{cppr}$ & 3 & geo & 60 & 500 & 3.98 & 3.05 & 1.24 \\
\hline
\end{tabular}

Table B.5. Summary of crater depth, diameter, and calculated momentum transfer efficiency for Case 4. When a given result was not supplied by specific modelers, it is marked as "not provided" in the table.

\begin{tabular}{|c|c|c|c|c|c|c|c|c|}
\hline Model & Resolution & Case & Strength & Porosity & $\begin{array}{c}\text { Time } \\
\text { [us] }\end{array}$ & $\begin{array}{c}\text { Crater } \\
\text { Crater } \\
\text { Depth [cm] }\end{array}$ & $\begin{array}{c}\text { Diameter } \\
\text { [cm] }\end{array}$ & $\boldsymbol{\beta}$ \\
\hline CTH (2D) & $12 \mathrm{cppr}$ & 4 & geo & 0 & 100 & 2.64 & 5.575 & 3.90 \\
\hline CTH (2D) & $12 \mathrm{cppr}$ & 4 & geo & 0 & 200 & 3.09 & 7.475 & 4.43 \\
\hline CTH (2D) & $12 \mathrm{cppr}$ & 4 & geo & 0 & 500 & 3.64 & 11.275 & 5.15 \\
\hline & & & & & & & & \\
\hline CTH (2D) & $12 \mathrm{cppr}$ & 4 & geo & 20 & 100 & 2.76 & 4.525 & 2.40 \\
\hline CTH (2D) & $12 \mathrm{cppr}$ & 4 & geo & 20 & 200 & 2.74 & 5.225 & 2.44 \\
\hline CTH (2D) & $12 \mathrm{cppr}$ & 4 & geo & 20 & 500 & 2.64 & 5.575 & 3.11 \\
\hline & & & & & & & & \\
\hline CTH (2D) & $25 \mathrm{cppr}$ & 4 & BDL & 10 & 100 & 1.44 & 2.8625 & 1.64 \\
\hline CTH (2D) & $25 \mathrm{cppr}$ & 4 & BDL & 10 & 200 & 1.46 & 2.8625 & 1.12 \\
\hline CTH (2D) & $25 \mathrm{cppr}$ & 4 & BDL & 10 & 500 & 1.46 & 2.8625 & 1.04 \\
\hline & & & & & & & & \\
\hline CTH (2D) & $25 \mathrm{cppr}$ & 4 & BDL & 20 & 100 & 1.63 & 2.7385 & 1.07 \\
\hline
\end{tabular}




\begin{tabular}{|c|c|c|c|c|c|c|c|c|}
\hline CTH (2D) & $25 \mathrm{cppr}$ & 4 & $\mathrm{BDL}$ & 20 & 200 & 1.63 & 2.7385 & 1.06 \\
\hline CTH (2D) & $25 \mathrm{cppr}$ & 4 & $\mathrm{BDL}$ & 20 & 460 & 1.62 & 2.7385 & 1.02 \\
\hline CTH (3D) & $3 \mathrm{cppr}$ & 4 & geo & 0 & 100 & 2.31 & 4.8756 & 3.91 \\
\hline CTH (3D) & $3 \mathrm{cppr}$ & 4 & geo & 0 & 200 & 2.44 & 5.625 & 4.92 \\
\hline CTH (3D) & $3 \mathrm{cppr}$ & 4 & geo & 0 & 500 & 2.56 & 6.75 & 5.16 \\
\hline CTH (3D) & $3 \mathrm{cppr}$ & 4 & geo & 20 & 100 & 1.44 & 2.125 & 1.12 \\
\hline CTH (3D) & $3 \mathrm{cppr}$ & 4 & geo & 20 & 200 & 1.31 & 2.125 & 1.13 \\
\hline CTH (3D) & $3 \mathrm{cppr}$ & 4 & geo & 20 & 300 & 1.19 & 2 & 1.13 \\
\hline iSALE & $15 \mathrm{cppr}$ & 4 & ROCK & 20 & 100 & 1.27 & 3.56 & $\begin{array}{c}\text { not } \\
\text { provided }\end{array}$ \\
\hline iSALE & $15 \mathrm{cppr}$ & 4 & ROCK & 20 & 200 & 1.15 & 4.19 & $\begin{array}{c}\text { not } \\
\text { provided }\end{array}$ \\
\hline iSALE & $15 \mathrm{cppr}$ & 4 & ROCK & 20 & 339 & 0.99 & 4.66 & $\begin{array}{c}\text { not } \\
\text { provided }\end{array}$ \\
\hline $\begin{array}{c}\text { Spheral } \\
\text { (3D) }\end{array}$ & $5 \mathrm{cppr}$ & 4 & $\begin{array}{c}\text { von } \\
\text { Mises }\end{array}$ & 20 & 100 & $\begin{array}{c}\text { not } \\
\text { provided }\end{array}$ & $\begin{array}{c}\text { not } \\
\text { provided }\end{array}$ & 1.36 \\
\hline $\begin{array}{c}\text { Spheral } \\
\text { (3D) }\end{array}$ & $5 \mathrm{cppr}$ & 4 & $\begin{array}{c}\text { von } \\
\text { Mises }\end{array}$ & 20 & 200 & $\begin{array}{c}\text { not } \\
\text { provided }\end{array}$ & $\begin{array}{c}\text { not } \\
\text { provided }\end{array}$ & 1.51 \\
\hline $\begin{array}{c}\text { Spheral } \\
\text { (3D) }\end{array}$ & $5 \mathrm{cppr}$ & 4 & $\begin{array}{c}\text { von } \\
\text { Mises }\end{array}$ & 20 & 216 & $\begin{array}{c}\text { not } \\
\text { provided }\end{array}$ & $\begin{array}{c}\text { not } \\
\text { provided }\end{array}$ & 1.53 \\
\hline
\end{tabular}

